\title{
Effective strategies for changing public opinion: A
}

\section{literature review}

Jamie Harris: Sentience Institute, jamie@sentienceinstitute.org

\section{Abstract}

Social movements often try to affect public opinion as a lever for legislation and other social change. This report provides a broad overview of research relating to (1) whether advocates can successfully influence public opinion and how they can do so most effectively, and (2) what the other causes of public opinion change are and how advocates can harness them. Key findings include that direct persuasion attempts to change attitudes (rather than behavior) tend to have "small" or "very small" short-term effects, but advocates may be able to have lasting indirect effects on public opinion via policy change or reframing the issues. We list factors that affect how persuasive messages are and make tentative suggestions for how advocates can cost-effectively leverage external influences on public opinion such as the media, celebrities, politicians, and policy.

Keywords: public opinion; attitudes; social change; social movements; persuasion 


\section{Introduction}

Public opinion — "the preferences of the adult population on matters of relevance to government"1 — is important for social change: While historical causation is always difficult to assess, our previous research projects indicate a significant effect of public opinion on legislative outcomes. $^{2}$ Political scientist Alan Monroe (1998) found that in $70 \%$ of policy decisions between 1980 and 1993 in which the public favored the status quo, the US government maintained it. ${ }^{3}$ Sentience Institute's “Summary of Evidence for Foundational Questions in Effective Animal Advocacy" lists a number of other instances where public opinion could be important (citations omitted):

- "Public opinion could play an important role in affecting whether legislation is preserved or subsequently overturned...

- The decision-making of the Supreme Court of the United States seems to be substantially influenced by public opinion.

\footnotetext{
${ }^{1}$ Robert S. Erikson and Kent L. Tedin, American Public Opinion: Its Origins, Content and Impact (Abingdon, UK: Routledge, 2015), 8.

${ }^{2}$ See the section on "External constraints on the impact of social movements" in Jamie Harris and Jacy Reese Anthis, "How Tractable Is Changing the Course of History?," Sentience Institute (blog), April 12, 2019, http://www.sentienceinstitute.org/blog/how-tractable-is-changing-the-course-of-history, the strategic implication beginning "For securing desired legislative outcomes..." in Jamie Harris, Jacy Reese Anthis, and Kelly McNamara, "Social Movement Lessons From the US Anti-Abortion Movement," November 26, 2019, https://sentienceinstitute.org/anti-abortion, and the paragraph beginning "Public opinion can influence..." in Jamie Harris, Jacy Reese Anthis, and Kelly McNamara, "Social Movement Lessons from the US Anti-Death Penalty Movement," May 22, 2020, https://sentienceinstitute.org/death-penalty.

${ }^{3}$ Alan D. Monroe, "Public Opinion and Public Policy, 1980-1993," The Public Opinion Quarterly 62, no. 1 (1998): 13. This compares to $82 \%$ in 1960-79 and policy change being implemented when the US public favored change in 45\% of cases in 1980-93. Benjamin I. Page and Robert Y. Shapiro, "Effects of Public Opinion on Policy," The American Political Science Review 77, no. 1 (1983): 175-90, https://doi.org/10.2307/1956018 found "congruent change in opinion and policy" in $66 \%$ of cases with policy change. For a review of other evidence of the link between public opinion and policy outcomes, see Robert S. Erikson and Kent L. Tedin, American Public Opinion: Its Origins, Content and Impact (Abingdon, UK: Routledge, 2015), 307-17.
} 
- When pre-decision public opinion is more closely aligned with a Supreme Court decision, the risk of legislative backlash is lower and the effects of the ruling on public opinion seem likely to be more positive...

- Corporate welfare campaigns have been partly dependent upon mobilizing the public to express dissatisfaction with a particular practice in animal farming, such as the caging of layer hens. It may be crucial that the public is already opposed to a practice for such campaigns to be successful.",4

Hence, although much animal advocacy research has treated behavior change, especially individual diet change, as the main outcome of interest, ${ }^{5}$ understanding the causes of public opinion change also seems useful for cost-effectively encouraging social change.

The research reviewed here is relevant for evaluating the usefulness of moral circle expansion (i.e., advocacy to increase the number of beings given moral consideration, such as legal protection) and other forms of values spreading as strategies for influencing the long-term future. The impact of these strategies rests on fundamental questions, such as ${ }^{6}$ :

- Does advocating for a value system increase or reduce the number of people with these values?

\footnotetext{
${ }^{4}$ Sentience Institute, "A Summary of Evidence for Foundational Questions in Effective Animal Advocacy," accessed April 12, 2021, http://www.sentienceinstitute.org/foundational-questions-summaries.

${ }^{5}$ E.g. Animal Charity Evaluators, "Leafleting," Animal Charity Evaluators (blog), November 2017, https://animalcharityevaluators.org/advocacy-interventions/interventions/leafleting/, Jamie Harris, Jacy Reese Anthis, and Kelly Anthis, "Health Behavior Interventions Literature Review," July 24, 2020, https://sentienceinstitute.org/health-behavior, and Maya B. Mathur et al., "Interventions to Reduce Meat Consumption by Appealing to Animal Welfare: Meta-Analysis and Evidence-Based Recommendations," Appetite 164 (September 1, 2021): 105277, https://doi.org/10.1016/j.appet.2021.105277.

${ }^{6}$ Adapted from Tobias Baumann, "Arguments for and against Moral Advocacy," Cause Prioritization Research (blog), July 5, 2017, https://prioritizationresearch.com/arguments-for-and-against-moral-advocacy/.
} 
- Do persuaded individuals take action in support of their new values, such as further advocacy?

- Do the actions of persuaded individuals tend to align with the intentions of the original advocates?

- Will the values that are spread be durable or will they revert to an equilibrium?

\section{Summary of strategic implications}

Below are a number of strategic claims supported by the evidence in this review:

- Direct advocacy and persuasive messages focused on attitudes seem likely to have effect sizes conventionally interpreted as "small" or "very small." Though not the norm, persuasive messages can sometimes cause attitudes to change in the opposite direction to intended ("boomerang" attitude change), e.g. when the difference between the message's position and the receiver's position is very large.

- There are a number of communicator, message, and receiver factors that have small or moderate effects on how persuasive messages are. For example:

- More communicator credibility (expertise, trustworthiness, and caring), likeability, attractiveness, communicator-receiver similarity, and authority usually enhance persuasiveness. These factors tend to be more influential when the receiver is not thinking carefully about the issue, e.g. if it is of low relevance to them. 
- Advocates can increase their effectiveness if they make emotional appeals to fear, guilt, anger, or disgust. However, these tactics can reduce message effectiveness or lead to boomerang effects if they are used incorrectly or excessively.

Describing but refuting opposing arguments can increase the effectiveness of persuasive messages and make audiences more resistant to opposing persuasion attempts.

- Persuasive messages tend to be more effective if the audience is less familiar with or opinionated about an issue. This suggests that advocates can influence public opinion towards less salient attributes or sub-topics (e.g. a specific farming practice) if they are able to shape the initial media coverage or share persuasive messages widely. It also suggests that tactics that are aimed at increasing salience may be counterproductive (by making subsequent attitude change more difficult) on issues where public opinion is currently unfavorable.

- Framing variations can influence attitudes through different mechanisms to direct persuasion attempts by encouraging audiences to place more weight on some considerations than others.

- Protests and social movement events can influence public opinion as well as the public's perceptions of the importance of certain issues.

- The media can cause public opinion change through persuasive messaging or one-sided coverage. Additionally, if it highlights certain attributes of an issue over others, the media can influence overall public opinion without persuasion, similarly to how advocates can influence attitudes through framing manipulations. If advocates can focus media attention 
on more favorable attributes of an issue, they may be able to indirectly influence public opinion.

- High media coverage tends to make the public think that an issue is more important.

- Politicians and celebrities can act as advocates, influencing the attitudes of their audience, though they are not always more persuasive than alternative spokespeople. They can also influence media coverage and public perceptions of the importance of certain topics or attributes. This suggests that if advocates can encourage supportive public comments from these individuals, this could be worthwhile, but efforts would be counterproductive if they encouraged hostile comments.

- If advocates can secure policy change, public opinion will tend to move towards support for those policies.

- Intergroup contact and several other prejudice reduction strategies can encourage moral consideration of outgroups, though it may be difficult for advocates to cost-effectively utilize these strategies on a large scale.

- The effects on attitudes from exposure to single messages — whether from persuasive messaging, framing manipulations, or media coverage — are most pronounced immediately after exposure to the message. The effects diminish with time, though at least some effects have been found weeks afterwards. For advocates to cost-effectively cause lasting public opinion change, they therefore probably need to encourage some sort of self-perpetuating mechanism such as new legislation, social norms, or framings used by the media. 
- A number of indirect or long-term factors can influence public opinion, such as demographic changes and major events beyond the control of advocates.

\section{Methodology}

Search terms were inputted into Google Scholar, seeking to identify meta-analyses, textbooks, and summary articles relevant to the causes of public opinion change, especially those that might be relevant for advocacy strategy. The citations of and by some of the most important and relevant items were also searched. There were no strict inclusion or exclusion criteria. For example, although the focus was usually on meta-analyses and textbooks, if these were not available for topics of interest, individual studies were sometimes sought. Items were included if they seemed useful and relevant in some way to the topic, even if they did not meet a certain definition of the term "public opinion" (of which there are several ${ }^{7}$ ). For example, this review does not usually distinguish between attitudes and public opinion, so includes research on both. ${ }^{8}$ Research on the causes of changes in less relevant outcomes (e.g. behavior or knowledge) was usually excluded, but sometimes discussed briefly for comparison to research on public opinion.

This topic is too broad to be suited to a single systematic review and the outcomes used are too diverse for an overview of reviews to be appropriate either. ${ }^{9}$ This report does not attempt to

\footnotetext{
${ }^{7}$ See, e.g. Robert S. Erikson and Kent L. Tedin, American Public Opinion: Its Origins, Content and Impact (Abingdon, UK: Routledge, 2015), 8.

${ }^{8}$ Public opinion is essentially the aggregation of many people's attitudes, so evidence about the causes of attitude change also provides evidence about the causes of public opinion change. Some specific attitudes might be irrelevant to matters of government, but studies about changes to such attitudes may still be informative.

${ }^{9}$ For example, some studies and reviews looked at attitude change, some looked at framing effects (i.e. the weights placed on different arguments), and others looked at agenda-setting effects (i.e. evaluations of the importance of different issues or attributes). Something analogous to Jamie Harris, Jacy Reese Anthis, and Kelly Anthis, "Health
} 
comprehensively review the literature on any specific topic, but rather to identify and summarize a variety of research findings of interest to advocates and researchers of social change. The reviewed research comes from a number of disciplines, including communication studies, political science, psychology, and sociology.

When reporting on the effect sizes from included meta-analyses, the metrics provided by the original reviewers are used, most commonly standardized mean difference (SMD) / Cohen's $d$ and Pearson's $r$ correlation coefficients. Guidelines exist for interpreting some of these different forms of outcome measures, most notably Jacob Cohen's definitions of $r=0.1$ or $d=0.2$ as a "small effect size," $r=0.3$ or $d=0.5$ as a "medium effect size," and $r=0.5$ or $d=0.8$ as a "large effect size." 10

Behavior Interventions Literature Review," July 24, 2020, https://sentienceinstitute.org/health-behavior could have been attempted, but that research was extremely time-consuming. Another difficulty is that the primary studies had only been systematically reviewed or meta-analysed for some of the relevant research areas, so a formal overview would have left many important gaps.

${ }^{10}$ Jacob Cohen, Statistical Power Analysis for the Behavioral Sciences (New York, NY: Academic Press, 2013). This implies that effect sizes under $r=0.1$ or $d=0.2$ are very small (sometimes referred to as "negligible") and that effect sizes well above $r=0.5$ or $d=0.8$ are very large. 


\section{Findings}

\section{Can advocates successfully influence public opinion and if so, how}

\section{can they do so most effectively?}

This section focuses on tactics that advocates can use to influence public opinion fairly directly, e.g. via direct advocacy and persuasion; opportunities for more indirect influence are reviewed in the following section.

\section{Direct advocacy and persuasion}

Although findings are mixed, a number of studies suggest that social movements can influence public opinion in the direction that they intend through public campaigns and persuasive messaging. ${ }^{11}$ For example, several studies on anti-abortion and anti-death penalty attitudes

\footnotetext{
${ }^{11}$ Andreas Dür, "How Interest Groups Influence Public Opinion: Arguments Matter More than the Sources," European Journal of Political Research 58, no. 2 (2019): 514-35, https://doi.org/10.1111/1475-6765.12298 summarizes that, "[i]n an early publication, Page et al. (1987) concluded that when interest groups push in one direction, public opinion more often than not moves in the other. A study of the effect of interest group campaigning on five ballot initiatives in California also came to the conclusion that interest groups can find it difficult to positively shape public opinion (Lupia 1994). In an experimental study, Nicholson (2011) found that support for a fictitious ballot proposal was the same when it was sponsored by the tobacco industry and when it was sponsored by a public health advocacy group. McEntire et al. (2015), finally, show how different types of frames that human rights organisations use matter for citizens' attitudes towards human rights abuses. Several case studies also assessed the impact of specific interest group campaigns on public opinion (Burstein 1985; Wlezien \& Goggin 1993; Andsager 2000; McKnight \& Hobbs 2013; Dür \& Mateo 2014). While some of them find little evidence of an impact of these campaigns (e.g., Andsager 2000), others offer evidence of interest groups' ability to push public opinion in the desired direction (McKnight \& Hobbs 2013; Dür \& Mateo 2014). A few studies also look at the impact of interest group endorsements on support for specific political candidates (Arceneaux \& Kolodny 2009; Weber et al. 2012; Neddenriep \& Nownes 2014). Most of them find that interest groups can influence vote choices." Dür conducts two experiments, providing a persuasive argument attributed to either interest groups or some other entity, and finds that these arguments can significantly affect opinion but that the source cue makes little difference.
} 
suggest that educational interventions can have positive effects, but the effects may be small and short-term. $^{12}$

Rains et al. (2018) review and summarize "149 meta-analyses exploring human communication phenomena" (not all focusing on attitude change) which have a mean effect size of $r=.21$, a small effect size. ${ }^{13}$ Marketing scholar Jacob Hornik and colleagues (2016) combined 2,276 different effect sizes from advertising studies in meta-analysis and found a mean weighted effect size on persuasion outcomes (including "attitude toward the product, attitude toward the brand, purchase intention, and product choice") of $r=.19 .{ }^{14}$ Although neither of these reviews focused

Andreas Jungherr et al., "A Source Like Any Other? Field and Survey Experiment Evidence on How Interest Groups Shape Public Opinion," Journal of Communication 71, no. 2 (April 1, 2021): 276-304, https://doi.org/10.1093/joc/jgab005 found from "a parallel survey and field experiment with three survey waves $(\mathrm{N}=$ $4,659)$ " that "a communicative intervention by a German business group with a low public profile... increased the salience of the policy addressed, persuaded recipients of the interest group's position, and increased the number of accessible supporting considerations. These effects were modest in size and decayed over the course of a week."

The authors of both papers argue that there has been little exploration of the effects of social movement actions on public opinion. I have not encountered any systematic reviews of this empirical research, though Edwin Amenta and Francesca Polletta, "The Cultural Impacts of Social Movements," Annual Review of Sociology 45, no. 1 (2019): 279-99, https://doi.org/10.1146/annurev-soc-073018-022342 provides a brief qualitative review.

${ }^{12}$ See the strategic implication beginning "As people become more aware of a topic..." in Jamie Harris, Jacy Reese Anthis, and Kelly McNamara, "Social Movement Lessons from the US Anti-Death Penalty Movement," May 22, 2020, https://sentienceinstitute.org/death-penalty and the strategic implication beginning "Overall, efforts to modify public opinion..." in Jamie Harris, Jacy Reese Anthis, and Kelly McNamara, "Social Movement Lessons From the US Anti-Abortion Movement," November 26, 2019, https://sentienceinstitute.org/anti-abortion.

${ }^{13}$ Stephen A. Rains, Timothy R. Levine, and Rene Weber, "Sixty Years of Quantitative Communication Research Summarized: Lessons from 149 Meta-Analyses," Annals of the International Communication Association 42, no. 2 (April 3, 2018): 105-24, https://doi.org/10.1080/23808985.2018.1446350. Averaging across the 12 included meta-analyses that seem, according to Rains et al.' wording, to focus specifically on attitudinal outcomes and comparing a certain intervention type to no intervention also yields an average effect size of $r=.21$.

${ }^{14}$ Jacob Hornik, Chezy Ofir, and Matti Rachamim, "Quantitative Evaluation of Persuasive Appeals Using Comparative Meta-Analysis," The Communication Review 19, no. 3 (July 2, 2016): 192-222, https://doi.org/10.1080/10714421.2016.1195204. 
exclusively on attitude outcomes, meta-analyses with a narrower focus on attitude change tend to find small or very small effects. ${ }^{15}$ For example:

- A meta-analysis of 36 experiments found that "communicating evidence of a policy's effectiveness increased support for the policy $(\mathrm{SMD}=0.11,95 \% \mathrm{CI}[0.07,0.15], \mathrm{p}<$ 0.0001)" and "[c]ommunicating evidence of ineffectiveness decreased policy support $(\mathrm{SMD}=-0.14,95 \% \mathrm{CI}[-0.22,-0.06], \mathrm{p}<0.001) .{ }^{\prime 16}$

- A meta-analysis found significant effects on attitudes from 10 experiments and quasi-experiments of descriptive social norms manipulations, which focus on "the perceived prevalence of a behavior" $(d=0.17,95 \%$ CI $[0.06,0.27])$ and 4 studies of injunctive norms manipulations, which focus on "the social (dis)approval of one's actions" $(d=0.34,95 \%$ CI $[0.17,0.50]){ }^{17}$

- A meta-analysis of 30 studies found that "[f]act-checking has a significantly positive overall influence on political beliefs $(d=0.29) .{ }^{.18}$

\footnotetext{
${ }^{15}$ Dolores Albarracin and Sharon Shavitt, "Attitudes and Attitude Change," Annual Review of Psychology 69, no. 1 (2018): 302-3, https://doi.org/10.1146/annurev-psych-122216-011911 share a similar impression and list several examples.

${ }^{16}$ J. P. Reynolds et al., "Communicating the Effectiveness and Ineffectiveness of Government Policies and Their Impact on Public Support: A Systematic Review with Meta-Analysis," Royal Society Open Science 7, no. 1 (January 2020): 190522, https://doi.org/10.1098/rsos.190522. These effect sizes were equivalent to support increasing from $50 \%$ to $54 \%$ or decreasing from $50 \%$ to $44 \%$.

${ }^{17}$ Nancy Rhodes, Hillary C. Shulman, and Nikki McClaran, "Changing Norms: A Meta-Analytic Integration of Research on Social Norms Appeals," Human Communication Research 46, no. 2-3 (July 1, 2020): 161-91, https://doi.org/10.1093/hor/hqz023. The effects of 6 studies of mixed manipulations were also significant $(\mathrm{d}=0.28$, 95\% CI [0.23-0.33]).

${ }^{18}$ Nathan Walter et al., "Fact-Checking: A Meta-Analysis of What Works and for Whom," Political Communication 37, no. 3 (May 3, 2020): 350-75, https://doi.org/10.1080/10584609.2019.1668894.
}

Man-pui Sally Chan et al., "Debunking: A Meta-Analysis of the Psychological Efficacy of Messages Countering Misinformation," Psychological Science 28, no. 11 (November 1, 2017): 1531-46, https://doi.org/10.1177/0956797617714579 "revealed large effects for presenting misinformation (ds = 2.41-3.08), debunking ( $\mathrm{ds}=1.14-1.33)$, and the persistence of misinformation in the face of debunking $(\mathrm{ds}=0.75-1.06)$," though the effect size does not focus on attitudes. Concerningly, they cite evidence that, "[c]orrections that merely encourage people to consider the opposite of initial information often inadvertently strengthen the misinformation" and their own moderator analyses suggest that "using a more detailed debunking message was effective to discredit the misinformation but was associated with greater misinformation persistence." 
- A meta-analysis of 49 field experiments of political campaign advertising and outreach actually found an average effect of zero on US voting choices. ${ }^{19}$

Many of these effects come from studies using only short messages in artificial contexts, so they may not be very informative about the effects we should expect from real-world advocacy contexts. More extensive interactions (e.g. a lengthy conversation, a documentary, a book) or repeated exposure to similar arguments (e.g. via shifts in media coverage, discussed below) may have larger effects. ${ }^{20}$

However, there is evidence from a number of meta-analyses on health behavior (e.g. persuading people to eat more healthily, exercise more, or smoke less) that education or information only

\footnotetext{
${ }^{19}$ Joshua L. Kalla and David E. Broockman, "The Minimal Persuasive Effects of Campaign Contact in General Elections: Evidence from 49 Field Experiments," American Political Science Review 112, no. 1 (February 2018): 148-66, https://doi.org/10.1017/S0003055417000363. They note that this includes contact through "the mail, phone calls, canvassing, TV, online ads, or literature drops on voters' candidate choices and evaluations." They note that a recent meta-analysis had found significant effects of such contact on voter turnout and that "campaigns increasingly focus on rousing the enthusiasm of existing supporters instead of reaching across party lines to win over new supporters," so this doesn't seem like strong evidence that persuasive interventions cannot be effective, especially given contrary evidence from other reviews of similar interventions (e.g. Richard R. Lau, Lee Sigelman, and Ivy Brown Rovner, "The Effects of Negative Political Campaigns: A Meta-Analytic Reassessment," The Journal of Politics 69, no. 4 (November 1, 2007): 1176-1209, https://doi.org/10.1111/j.1468-2508.2007.00618.x and Alexander Coppock, Seth J. Hill, and Lynn Vavreck, "The Small Effects of Political Advertising Are Small Regardless of Context, Message, Sender, or Receiver: Evidence from 59 Real-Time Randomized Experiments," Science Advances 6, no. 36 (September 1, 2020): eabc4046, https://doi.org/10.1126/sciadv.abc4046).

${ }^{20}$ This point has been made by others. For example, Alexander Coppock, Seth J. Hill, and Lynn Vavreck, "The Small Effects of Political Advertising Are Small Regardless of Context, Message, Sender, or Receiver: Evidence from 59 Real-Time Randomized Experiments," Science Advances 6, no. 36 (September 1, 2020): eabc4046, https://doi.org/10.1126/sciadv.abc4046 argue that persuasive interventions tend to have small effects when a single message is tested, but note that, "[d] espite these small effects, campaign advertising may still play a large role in election outcomes. Our intervention delivers one additional ad in the heart of a marked presidential campaign that aired hundreds of thousands of such advertisements. This promotes external validity, but we are measuring the marginal effect of one additional advertisement. We do not measure the impact of an entire advertising campaign. If effectiveness were to increase linearly in advertisements viewed (or if the marginal returns diminished slowly enough), then these small effects could be highly consequential, consistent with the observed level of spending by candidates on advertising. Our data cannot speak to this question of scale, although the result in Table 1 that effects do not vary by battleground status (where people see many more advertisements than those who live in non-battleground states) suggests that marginal effectiveness may not depend on ambient levels of advertising."
} 
interventions, social norms interventions, mass media campaigns, social marketing, and

advertising also tend to have small or very small effect sizes. These studies tend to focus on more

realistic interventions, such as lessons conducted over a number of weeks in schools or

large-scale mass media campaigns visible to the general public. ${ }^{21}$ Attitude and behavior change

are correlated, ${ }^{22}$ so this provides a rough guide for expected effect sizes of changes in attitudes

from targeted individuals in comparable interventions focused on public opinion. Some reviews

of mass media campaigns find changes in attitudes that are larger than the changes in behaviors,

though they are still sometimes very small. ${ }^{23}$ Even if advocates are able to provide repeated

persuasive messages to their audience, encouraging attitude change is difficult.

${ }^{21}$ Jamie Harris, Jacy Reese Anthis, and Kelly Anthis, “Health Behavior Interventions Literature Review,” July 24, 2020, https://sentienceinstitute.org/health-behavior. The 17 effect sizes reported as standardized mean difference or other outcome measures interpreted in a similar way (e.g. Hedges' $g$ ) have an average of .23, which would conventionally be interpreted as very small.

${ }^{22}$ Min-Sun Kim and John E. Hunter, "Relationships Among Attitudes, Behavioral Intentions, and Behavior: A Meta-Analysis of Past Research, Part 2," Communication Research 20, no. 3 (June 1, 1993): 331-64, https://doi.org/10.1177/00936509302000300 and Stephen J. Kraus, "Attitudes and the Prediction of Behavior: A Meta-Analysis of the Empirical Literature," Personality and Social Psychology Bulletin 21, no. 1 (January 1, 1995): 58-75, https://doi.org/10.1177/0146167295211007 provide substantially different estimates of the strength of this correlation ( $\mathrm{r}=.38$ and $\mathrm{r}=.79$, respectively). For further discussion of the relationship between attitudes and behavior and how to minimize the gap, see Richard M. Perloff, The Dynamics of Persuasion: Communication and Attitudes in the Twenty-First Century, 6th ed. (New York, NY: Routledge, 2017), 155-82 https://doi.org/10.4324/9781315657714.

${ }^{23}$ James H. Derzon and Mark W. Lipsey, "A Meta-Analysis of the Effectiveness of Mass-Communication for Changing Substance-Use Knowledge, Attitudes, and Behavior," in Mass Media and Drug Prevention, ed. William D. Crano, Michael Burgoon, and Stuart Oskamp (Mahwah, NJ: Lawrence ErIbaum, 2002), 245 note that, "[i]n striking contrast to the relative effects of media interventions on substance-use behavior, the pre-to-post changes in substance-use attitudes were almost universally positive, irrespective of the specific characteristics of the intervention or even of whether participants were exposed to one of the interventions studied," but the difference between pre-to-post differences in the " 39 samples exposed to media intervention" and the " 12 control samples" was only $d=.02$.

Ben Young et al., "Effectiveness of Mass Media Campaigns to Reduce Alcohol Consumption and Harm: A Systematic Review," Alcohol and Alcoholism 53, no. 3 (May 1, 2018): 302-16, https://doi.org/10.1093/alcalc/agx094 find "little evidence of reductions in alcohol consumption associated with exposure to campaigns based on 13 studies which measured consumption," compared to "mixed evidence of changes in intentions, motivation, beliefs and attitudes about alcohol," but do not report effect sizes.

Richard M. Perloff, The Dynamics of Persuasion: Communication and Attitudes in the Twenty-First Century, 6th ed. (New York, NY: Routledge, 2017), 566-8 https://doi.org/10.4324/9781315657714 provides evidence-based recommendations on how to maximize the effectiveness of mass media campaigns. 


\section{Moderators}

If advocates design and deliver messages in the most effective manner possible, the effects on attitudes may still be small. ${ }^{24}$ Nevertheless, there are a number of factors that make small or moderate differences to the effectiveness of persuasive messages.

\section{Theories of persuasion moderators}

In chapters 2 to 8 of Persuasion: Theory and Research (2015), communication scholar Daniel J.

O'Keefe outlines various theories that help to explain outcomes from persuasive messages and the factors that moderate how effective they are. ${ }^{25}$ For example:

- Chapter 2 describes "social judgement theory," where, "the effect of a persuasive communication depends upon the way in which the receiver evaluates the position it advocates. ${ }^{26}$ A key prediction of this theory, supported by numerous studies, is that the relationship between message discrepancy ("the difference between the message's position and the receiver's position") and attitude change "is suggested to be something

\footnotetext{
${ }^{24}$ For example, Alexander Coppock, Seth J. Hill, and Lynn Vavreck, "The Small Effects of Political Advertising Are Small Regardless of Context, Message, Sender, or Receiver: Evidence from 59 Real-Time Randomized Experiments," Science Advances 6, no. 36 (September 1, 2020): eabc4046, https://doi.org/10.1126/sciadv.abc4046, a study using 49 different political advertisements, found that the effects were consistently small, despite variations in communicator, message, and recipient factors. They summarize that they "investigate heterogeneous effects by sender (candidates or groups), receiver (subject partisanship), content (attack or promotional), and context (battleground versus non-battleground, primary versus general election, and early versus late). We find small average effects on candidate favorability and vote. These small effects, however, do not mask substantial heterogeneity even where theory from political science suggests that we should find it." They did find "partial support for the 'partisan match' theory: Democratic subjects respond more strongly to pro-Democratic advertisements than to pro-Republican advertisements. However, we do not observe a corresponding pattern among Republican respondents: Both pro-Democratic and pro-Republican advertisements have approximately the same small, positive, nonsignificant effect."

${ }^{25}$ Daniel J. O'Keefe, Persuasion: Theory and Research (Los Angeles, CA: SAGE Publications, 2015).

${ }^{26}$ Daniel J. O'Keefe, Persuasion: Theory and Research (Los Angeles, CA: SAGE Publications, 2015), 48-70.
} 
like an inverted-U-shaped curve." ${ }^{27}$ In other words, advocates need to carefully evaluate

how radical to make their messages in order to achieve maximum effect — too

conservative and the attitude change produced will be in the intended direction but small,

too radical and the attitude change produced could be small, non-existent, or even in the

opposite direction to intended ("boomerang" attitude change). ${ }^{28}$ The ideal message will

vary depending on the audience and their current view.

- Social judgement theory also predicts that when someone has less extreme views on a

topic, e.g. because it has little personal relevance to them, a persuader might be able to

successfully advocate for a more discrepant position. ${ }^{29}$ This suggests that persuasion

attempts relating to less salient topics will be more tractable, as will those relating to

public policy and other institutional changes rather than, say, a recipient's dietary choices.

However, a number of strategies may facilitate effective persuasion for audiences with

strong attitudes. ${ }^{30}$

\footnotetext{
${ }^{27}$ Daniel J. O'Keefe, Persuasion: Theory and Research (Los Angeles, CA: SAGE Publications, 2015), 56-8. On pages 62-6, O'Keefe provides various criticisms of social judgement theory and concludes that it "must be judged something of an historical relic at present," but the provided criticisms seem to all focus on the concept of ego-involvement and its implications. More ambiguously, Stuart Oskamp and P. Wesley Schultz, Attitudes and Opinions (New York, NY: Psychology Press, 2005), 227-30 summarize various studies providing support for social judgement theory but remark on page 232 that, "enough of [the research on "message discrepancy and ego-involvement"] has been nonsupportive that the theory's prominence in the field of attitude change has declined." ${ }^{28}$ Daniel J. O'Keefe, Persuasion: Theory and Research (Los Angeles, CA: SAGE Publications, 2015), 56-7.

${ }^{29}$ Daniel J. O'Keefe, Persuasion: Theory and Research (Los Angeles, CA: SAGE Publications, 2015), 57-8, though on pages 62-5 O'Keefe notes the evidence is relatively weak for the idea that personal involvement is an important factor. Relatedly, Dennis Chong and James N. Druckman, "Framing Theory," Annual Review of Political Science 10, no. 1 (2007): 103-26, https://doi.org/10.1146/annurev.polisci.10.072805.103054 cite evidence that efforts to change attitudes by reframing a topic tend to be less successful if the recipient has more extreme prior views. The evidence specifically for the importance of personal relevance seems quite weak, however.

${ }^{30}$ Richard M. Perloff, The Dynamics of Persuasion: Communication and Attitudes in the Twenty-First Century, 6th ed. (New York, NY: Routledge, 2017), 130-1 https://doi.org/10.4324/9781315657714 suggests the following theoryor evidence-based strategies: "[point] out that the person whose prejudiced attitude you want to modify has friends who embrace a more tolerant view... Find a persuasive role model to showcase the attitude you want to change... Induce the individual to contemplate the other side of the issue... Remind the person whose attitude you want to change that he or she values fairness and consideration of different points of view... Frame the position in terms that are consistent with the individual's own perspectives on the issue... . Don't say things that will fall into the
} 
- Chapter 3 describes "functional approaches to attitude," where, "[t]he basic idea is that attitudes may serve various functions." ${ }^{\text {31 }}$ This is relevant because "substantial evidence suggests that persuasive appeals that are matched to the receiver's attitude function will be more persuasive than mismatched appeals. ${ }^{{ }^{32}}$ This implies that it is useful to understand why your audience holds certain attitudes and tailor messages towards their attitude function where possible.

- Chapter 5 summarizes and evaluates cognitive dissonance theory which entails that attitudes can change because "persons seek to maximize the internal psychological consistency of their cognitions (beliefs, attitudes, etc.). ${ }^{\prime 33}$ The theory has many implications for persuasion. One key point is that people may resolve cognitive dissonance - discomfort from conflicting thoughts — in a number of ways, e.g. by changing their attitudes to justify their new behavior (if you manage to change behavior without changing attitudes first), or changing their behavior to bring it in line with their new attitudes (if you manage to persuade them of something). ${ }^{34}$ This provides an explanation for why attitude change relating to personal behaviors is so hard - people

\footnotetext{
individual's latitude of rejection. Point to instances where both sides agree. Expect that persuasion will occur slowly, in stages."

${ }^{31}$ Daniel J. O'Keefe, Persuasion: Theory and Research (Los Angeles, CA: SAGE Publications, 2015), 71-101.

${ }^{32}$ Daniel J. O'Keefe, Persuasion: Theory and Research (Los Angeles, CA: SAGE Publications, 2015), 80-2.

${ }^{33}$ Daniel J. O'Keefe, Persuasion: Theory and Research (Los Angeles, CA: SAGE Publications, 2015), 76-97. The basic principles underlying this seem to be well-supported in a number of contexts. For example, Stuart Oskamp and P. Wesley Schultz, Attitudes and Opinions (New York, NY: Psychology Press, 2005), 233-54 evaluate "consistency theories" more broadly and on page 241 summarize that, "[d]espite the disagreements among consistency theorists and researchers, there remains considerable agreement on the underlying importance of consistency as a construct, and on the general tendency for individuals to prefer consistency... reduced attention to consistency theories may be due to their having been so thoroughly woven into the fabric of social psychology as to have acquired the character of unquestioned wisdom."

${ }^{34}$ For a concise list of possible responses to cognitive dissonance, see Richard M. Perloff, The Dynamics of Persuasion: Communication and Attitudes in the Twenty-First Century, 6th ed. (New York, NY: Routledge, 2017), 421-2 https://doi.org/10.4324/9781315657714. For an example of specific relevance to the farmed animal movement, see Hank Rothgerber, "Efforts to Overcome Vegetarian-Induced Dissonance among Meat Eaters," Appetite 79 (August 1, 2014): 32-41, https://doi.org/10.1016/j.appet.2014.04.003.
} 
will want their attitudes to match their behaviors, so may reject arguments that you present to them.

- Chapter 8 analyzes the Elaboration Likelihood Model (ELM), which "suggests that important variations in the nature of persuasion are a function of the likelihood that receivers will engage in elaboration of (that is, thinking about) information relevant to the persuasive issue." ${ }^{35}$ There is evidence that, "attitudes shaped under conditions of high elaboration will (compared with attitudes shaped under conditions of low elaboration) display greater temporal persistence, be more predictive of intentions and subsequent behavior, and be more resistant to counterpersuasion." ${ }^{, 36}$ All else being equal, it is clearly preferable to encourage attitude change under conditions of high elaboration, though this may be more difficult. There is also evidence supporting ELM's implication that, under conditions of low elaboration, such as when a topic has little personal relevance to the receiver, heuristics such as the communicator's perceived credibility (discussed below) become especially important as determinants of attitude change, relative to argument quality. ${ }^{37}$

\section{Communicator factors}

There are a number of "communicator factors" that make persuasive efforts more or less effective. These have been identified in numerous studies and summarized in chapter 10 in

\footnotetext{
${ }^{35}$ Daniel J. O'Keefe, Persuasion: Theory and Research (Los Angeles, CA: SAGE Publications, 2015), 148-75.

${ }^{36}$ Daniel J. O'Keefe, Persuasion: Theory and Research (Los Angeles, CA: SAGE Publications, 2015), 238. Relatedly, Man-pui Sally Chan et al., "Debunking: A Meta-Analysis of the Psychological Efficacy of Messages Countering Misinformation," Psychological Science 28, no. 11 (November 1, 2017): 1531-46, https://doi.org/10.1177/0956797617714579 found that greater elaboration around misinformation makes later debunking efforts less effective and that debunking efforts are more effective with greater elaboration on counterarguments to misinformation.

${ }^{37}$ Daniel J. O'Keefe, Persuasion: Theory and Research (Los Angeles, CA: SAGE Publications, 2015), 247-9.
} 
O'Keefe's Persuasion (2015) and chapter 8 in The Dynamics of Persuasion (2017), another

textbook on persuasion by communications scholar Richard Perloff ${ }^{38}$ :

- Although high credibility communicators tend to be more persuasive, surprisingly, "at least sometimes low-credibility communicators are significantly more effective than high-credibility communicators." 39 One notable finding is that, "[w]ith a counterattitudinal message [i.e. one which opposes the receiver's current view], the high-credibility communicator will tend to have a persuasive advantage over the low-credibility source; with a proattitudinal message, however, the low-credibility communicator appears to enjoy greater persuasive success than the high-credibility source." 40 The perceived "credibility" of the communicator is influenced by their perceived "expertise," e.g. education, occupation, and experience; citation of evidence sources (rather than providing vague claims); and "nonfluencies in delivery" (like saying "uh" a lot). ${ }^{41}$ Credibility is also influenced by perceived trustworthiness ${ }^{42}$ and perceived

\footnotetext{
${ }^{38}$ Richard M. Perloff, The Dynamics of Persuasion: Communication and Attitudes in the Twenty-First Century, 6th ed. (New York, NY: Routledge, 2017), https://doi.org/10.4324/9781315657714 and Daniel J. O'Keefe, Persuasion: Theory and Research (Los Angeles, CA: SAGE Publications, 2015).

${ }^{39}$ Daniel J. O'Keefe, Persuasion: Theory and Research (Los Angeles, CA: SAGE Publications, 2015), 303.

${ }^{40}$ Daniel J. O'Keefe, Persuasion: Theory and Research (Los Angeles, CA: SAGE Publications, 2015), 303. See also Stuart Oskamp and P. Wesley Schultz, Attitudes and Opinions (New York, NY: Psychology Press, 2005), 228-9 who note that high credibility is especially important in conditions of high message discrepancy, i.e. more counterattitudinal messages. Interestingly, Andreas Jungherr et al., "A Source Like Any Other? Field and Survey Experiment Evidence on How Interest Groups Shape Public Opinion," Journal of Communication 71, no. 2 (April 1, 2021): 276-304, https://doi.org/10.1093/joc/jqab005 find evidence from several related studies that assessments of the credibility of interest groups have little effect on their persuasive appeals.

${ }^{41}$ Daniel J. O'Keefe, Persuasion: Theory and Research (Los Angeles, CA: SAGE Publications, 2015), 291-9. Richard M. Perloff, The Dynamics of Persuasion: Communication and Attitudes in the Twenty-First Century, 6th ed. (New York, NY: Routledge, 2017), 299-300 https://doi.org/10.4324/9781315657714 notes that the communicator's confidence also affects their perceived credibility.

${ }^{42}$ Daniel J. O'Keefe, Persuasion: Theory and Research (Los Angeles, CA: SAGE Publications, 2015), 293. Richard M. Perloff, The Dynamics of Persuasion: Communication and Attitudes in the Twenty-First Century, 6th ed. (New York, NY: Routledge, 2017), 305-10 https://doi.org/10.4324/9781315657714 discusses "knowledge bias" and "reporting bias," two aspects of perceived trustworthiness.
} 
caring (goodwill), though the latter is less consistently identified as important. ${ }^{43}$

Credibility is especially important under conditions of low elaboration and if the communicator's identity is clear before a message is delivered. ${ }^{44}$

- As with credibility, communicators who are more liked by their audience are usually more persuasive, especially under conditions that prompt low elaboration. Again, however, sometimes disliked communicators are more effective, typically when the audience has "freely chosen to listen to the message." 45 There is also evidence that, "[t]he effects of liking can apparently be overridden by credibility." 46

- Physical attractiveness and communicator-receiver similarity can both affect persuasiveness, but operate indirectly such as through effects on liking and credibility. ${ }^{47}$ - Authority can induce compliance (i.e. outward conformity), but not necessarily private acceptance. ${ }^{48}$ It is unclear whether compliance will be sufficient for advocacy purposes.

\footnotetext{
${ }^{43}$ Richard M. Perloff, The Dynamics of Persuasion: Communication and Attitudes in the Twenty-First Century, 6th ed. (New York, NY: Routledge, 2017), 301-2 https://doi.org/10.4324/9781315657714. Robert H. Gass and John S. Seiter, Persuasion: Social Influence and Compliance Gaining, 6th ed. (New York: Routledge, 2018), 160 https://doi.org/10.4324/9781315209302 provide a table summarizing the various dimensions of credibility. ${ }^{44}$ Daniel J. O'Keefe, Persuasion: Theory and Research (Los Angeles, CA: SAGE Publications, 2015), 301-2. Relatedly, Maxwell McCombs and Sebastian Valenzuela, Setting the Agenda: Mass Media and Public Opinion (Cambridge, UK: Polity Press, 2021), 87 and 100 summarize studies finding that, when people have low personal experience with a topic or make less cognitive effort (operationalized by reading fewer stories), "incidental media cues" like news format or the story's prominence on a website had larger agenda-setting effects. Stuart Oskamp and P. Wesley Schultz, Attitudes and Opinions (New York, NY: Psychology Press, 2005), 190-1 note that there are theoretical reasons (with some supporting experimental evidence) to expect that a credible source is more likely to produce "internalization" rather than merely "compliance... without private acceptance."

${ }^{45}$ Daniel J. O'Keefe, Persuasion: Theory and Research (Los Angeles, CA: SAGE Publications, 2015), 304-6.

${ }^{46}$ Daniel J. O'Keefe, Persuasion: Theory and Research (Los Angeles, CA: SAGE Publications, 2015), 305.

${ }^{47}$ Daniel J. O'Keefe, Persuasion: Theory and Research (Los Angeles, CA: SAGE Publications, 2015), 307-10. Richard M. Perloff, The Dynamics of Persuasion: Communication and Attitudes in the Twenty-First Century, 6th ed. (New York, NY: Routledge, 2017), 313-4 https://doi.org/10.4324/9781315657714 notes that perceived similarity can sometimes trade off against perceived expertise.

${ }^{48}$ Richard M. Perloff, The Dynamics of Persuasion: Communication and Attitudes in the Twenty-First Century, 6th ed. (New York, NY: Routledge, 2017), 284-295 https://doi.org/10.4324/9781315657714 and Stuart Oskamp and P. Wesley Schultz, Attitudes and Opinions (New York, NY: Psychology Press, 2005), 190-1 and 219.
} 
There are many complexities affecting when being evaluated positively on each of these factors is more or less useful. As a general rule, however, more credibility (expertise, trustworthiness, and caring), likeability, attractiveness, communicator-receiver similarity, and authority usually enhance persuasiveness. ${ }^{49}$

Message factors

Scholars have also identified a number of "message factors" that affect persuasiveness:

- Narratives can sometimes be more persuasive than nonnarrative messages, especially if the audience identifies with the characters or is "transported by" ("caught up in, or carried away by") the story. ${ }^{50}$

- The use of evidence also enhances persuasion, either by improving the strength of the arguments or by acting as a cue of the communicator's credibility. ${ }^{51}$ Meta-analyses examining whether statistical evidence or narratives are more effective have come to

\footnotetext{
${ }^{49}$ Richard M. Perloff, The Dynamics of Persuasion: Communication and Attitudes in the Twenty-First Century, 6th ed. (New York, NY: Routledge, 2017) https://doi.org/10.4324/9781315657714 emphasizes the downsides far less than Daniel J. O'Keefe, Persuasion: Theory and Research (Los Angeles, CA: SAGE Publications, 2015), tending to present these factors as usually enhancing persuasiveness, albeit sometimes only by small amounts. Robert H. Gass and John S. Seiter, Persuasion: Social Influence and Compliance Gaining, 6th ed. (New York: Routledge, 2018), https://doi.org/10.4324/9781315209302 summarize their chapter on credibility with the comment that, "[a]s long as we keep in mind that credibility is a perceptual phenomenon, the generalization that high-credibility sources are more influential than low-credibility sources is as close as one can come to a universal 'law' of persuasion. In advancing this generalization, however, we believe it is important to underscore the point that credibility is a complex, multidimensional, situational communication phenomenon."

${ }^{50}$ Daniel J. O'Keefe, Persuasion: Theory and Research (Los Angeles, CA: SAGE Publications, 2015), 331-3 and Richard M. Perloff, The Dynamics of Persuasion: Communication and Attitudes in the Twenty-First Century, 6th ed. (New York, NY: Routledge, 2017), 341-6 https://doi.org/10.4324/9781315657714.

${ }^{51}$ Richard M. Perloff, The Dynamics of Persuasion: Communication and Attitudes in the Twenty-First Century, 6th ed. (New York, NY: Routledge, 2017), 338-40 https://doi.org/10.4324/9781315657714.
} 
conflicting conclusions. ${ }^{52}$ Statistical evidence may be most effective in specific contexts, e.g. under conditions of high elaboration. ${ }^{53}$

- More broadly, one meta-analysis has found that "vividness" of persuasive appeals has small positive effects on attitudes ${ }^{54}$ and another has found that emotional appeals tend to be more persuasive than rational appeals in advertising. ${ }^{55}$

- A meta-analysis of 38 studies found that, overall, metaphors have a very small persuasive advantage over literal messages $(r=.07)$, which rose to a moderate effect size $(r=.42)$ "under optimal conditions, when a single, nonextended metaphor was novel, had a familiar target, and was used early in a message."

- Intense language may be effective at enhancing enthusiasm among supporters, but ineffective at persuading those with contrasting views. ${ }^{57}$

\footnotetext{
${ }^{52}$ Simon Zebregs et al., "The Differential Impact of Statistical and Narrative Evidence on Beliefs, Attitude, and Intention: A Meta-Analysis," Health Communication 30, no. 3 (March 4, 2015): 282-89, https://doi.org/10.1080/10410236.2013.842528 and Mike Allen and Raymond W. Preiss, "Comparing the Persuasiveness of Narrative and Statistical Evidence Using Meta-analysis," Communication Research Reports 14, no. 2 (March 1, 1997): 125-31, https://doi.org/10.1080/08824099709388654 find that statistical evidence is more effective for changing attitudes, whereas Fuyuan Shen, Vivian Sheer, and Ruobing Li, "Impact of Narratives on Persuasion in Health Communication: A Meta-Analysis," Journal of Advertising 44 (April 3, 2015): 105-13, https://doi.org/10.1080/00913367.2015.1018467 and Corinna Oschatz and Caroline Marker, "Long-Term Persuasive Effects in Narrative Communication Research: A Meta-Analysis," Journal of Communication 70, no. 4 (August 1, 2020): 473-96, https://doi.org/10.1093/joc/jqaa017 come to the opposite conclusion.

${ }^{53}$ See Richard M. Perloff, The Dynamics of Persuasion: Communication and Attitudes in the Twenty-First Century, 6th ed. (New York, NY: Routledge, 2017), 346-8 https://doi.org/10.4324/9781315657714 for discussion.

${ }^{54}$ Jérôme Blondé and Fabien Girandola, "Revealing the Elusive Effects of Vividness: A Meta-Analysis of Empirical Evidences Assessing the Effect of Vividness on Persuasion," Social Influence 11, no. 2 (April 2, 2016): 111-29, https://doi.org/10.1080/15534510.2016.1157096.

${ }^{55}$ Jacob Hornik, Chezy Ofir, and Matti Rachamim, "Quantitative Evaluation of Persuasive Appeals Using Comparative Meta-Analysis," The Communication Review 19, no. 3 (July 2, 2016): 192-222, https://doi.org/10.1080/10714421.2016.1195204.

${ }^{56}$ Pradeep Sopory and James Dillard, "The Persuasive Effects of Metaphor: A Meta-Analysis," Human Communication Research 28 (January 10, 2006): 382-419, https://doi.org/10.1111/j.1468-2958.2002.tb00813.x.

${ }^{57}$ Richard M. Perloff, The Dynamics of Persuasion: Communication and Attitudes in the Twenty-First Century, 6th ed. (New York, NY: Routledge, 2017), 362-6 https://doi.org/10.4324/9781315657714 notes that this follows social judgement theory: "Intense rhetoric accentuates contrast effects, pushing the message further into the latitude of rejection, producing more negative attitudes among opponents."
} 
- There are usually stronger effects for messages that explicitly state their recommendation, rather than omitting it. ${ }^{58}$ Relatedly, "messages with more specific descriptions of the recommended action are more persuasive than those providing general, nonspecific recommendations." 59

- Fear appeals can be effective - they tend to have small positive effects on attitudes, intentions, and behaviors. ${ }^{60}$ However, to have the intended effects, they need to first successfully "convince message recipients that they are susceptible to negative outcomes," that "the recommended response will alleviate the threat," and that the recipients are capable of achieving the recommended response. ${ }^{61}$ They also must not induce so much fear that recipient becomes incapacitated. ${ }^{62}$

- Guilt appeals may be even more effective — one meta-analysis found "a strong positive overall effect of guilt $(\mathrm{r}=.49,95 \%$ CI $0.31-0.64)$ " on "health-related attitudes and intentions." ${ }^{63}$ Like fear appeals, they may be effective "only if certain conditions are met.

\footnotetext{
${ }^{58}$ Daniel J. O'Keefe, Persuasion: Theory and Research (Los Angeles, CA: SAGE Publications, 2015), 327-9. Additionally, O'Keefe notes on pages 55-6 that social judgement theory highlights that a lack of clarity about an advocated position can lead to minimal change due to "assimilation effects," where the audience perceives the message as advocating a position that is close to or the same as their current position. Ronald D. Smith, Strategic Planning for Public Relations (New York, NY: Routledge, 2017), 287 https://doi.org/10.4324/9781315270876 caveats that, "some evidence suggests that when audience members - especially educated ones - draw their own conclusion, both the conclusion and the attitude on which it rests are more resistant to change than if the conclusion is presented by the source. Some studies have indicated that when the purpose of a message is to reduce criticism or opposition it may be better not to draw conclusions for the audience."

${ }^{59}$ Daniel J. O'Keefe, Persuasion: Theory and Research (Los Angeles, CA: SAGE Publications, 2015), 329-30.

${ }^{60}$ Richard M. Perloff, The Dynamics of Persuasion: Communication and Attitudes in the Twenty-First Century, 6th ed. (New York, NY: Routledge, 2017), 400 https://doi.org/10.4324/9781315657714 and "Fear Appeals" in Appendix A of Jamie Harris, Jacy Reese Anthis, and Kelly Anthis, "Health Behavior Interventions Literature Review," (July 24, 2020), https://sentienceinstitute.org/health-behavior.

${ }^{61}$ Richard M. Perloff, The Dynamics of Persuasion: Communication and Attitudes in the Twenty-First Century, 6th ed. (New York, NY: Routledge, 2017), 394-7 https://doi.org/10.4324/9781315657714.

${ }^{62}$ Richard M. Perloff, The Dynamics of Persuasion: Communication and Attitudes in the Twenty-First Century, 6th ed. (New York, NY: Routledge, 2017), 394-7 https://doi.org/10.4324/9781315657714. Perloff provides a number of recommendations for the design of effective fear appeals on pages 400-4.

${ }^{63} \mathrm{Zhan} \mathrm{Xu}$ and Hao Guo, "A Meta-Analysis of the Effectiveness of Guilt on Health-Related Attitudes and Intentions," Health Communication 33, no. 5 (May 4, 2018): 519-25, https://doi.org/10.1080/10410236.2017.1278633.
} 
Research suggests that guilt appeals can work if: (a) the message induces empathy, (b) instills a sense of social, normative responsibility to help, and (c) convinces individuals that the recommended behavior will reduce guilt or repair the problem. However, if the message goes too far, eliciting reactance [a perception of threat] and making people angry, it can backfire." ${ }^{\circ 4}$ There is evidence that encouraging shame may also be persuasive, though perhaps more likely to backfire than encouraging guilt. ${ }^{65}$

- A meta-analysis of 36 studies found no significant overall effects of using intentional evocations of anger in persuasive messaging focused on attitudes. However, there were small positive effects when the anger evoked was relevant to the message and when the message was combined with strong arguments or an appeal that reassures the individuals that the recommended behavior will address the problem. ${ }^{66}$

\footnotetext{
${ }^{64}$ Richard M. Perloff, The Dynamics of Persuasion: Communication and Attitudes in the Twenty-First Century, 6th ed. (New York, NY: Routledge, 2017), 407 https://doi.org/10.4324/9781315657714. Internal citations omitted.

${ }^{65}$ Vanessa Boudewyns, Monique M. Turner, and Ryan S. Paquin, "Shame-Free Guilt Appeals: Testing the Emotional and Cognitive Effects of Shame and Guilt Appeals," Psychology \& Marketing 30, no. 9 (2013): 811-25, https://doi.org/10.1002/mar.20647, Imène Becheur and Pierre Valette-Florence, "The Use of Negative Emotions in Health Communication Messages: Study of the Effects of Fear, Guilt, and Shame," Recherche et Applications En Marketing (English Edition) 29, no. 4 (December 1, 2014): 89-109, https://doi.org/10.1177/2051570714552620, Tae Hyun Baek and Sukki Yoon, "Guilt and Shame: Environmental Message Framing Effects," Journal of Advertising 46, no. 3 (July 3, 2017): 440-53, https://doi.org/10.1080/00913367.2017.1321069, and Adam Duhachek, Nidhi Agrawal, and Dahee Han, "Guilt versus Shame: Coping, Fluency, and Framing in the Effectiveness of Responsible Drinking Messages,” Journal of Marketing Research 49, no. 6 (December 1, 2012): 928-41, https://doi.org/10.1509/jmr.10.0244.

${ }^{66}$ Nathan Walter et al., "Meta-Analysis of Anger and Persuasion: An Empirical Integration of Four Models," Journal of Communication 69, no. 1 (February 1, 2019): 73-93, https://doi.org/10.1093/joc/jqv054.
} 
- Some studies (including two focused on opposition to animal exploitation) suggest that disgust may enhance persuasion. ${ }^{67}$ However, as with guilt and fear appeals, other studies suggest negligible or counterproductive effects. ${ }^{68}$

- Although persuasive messages that explicitly encourage positive emotions such as pride and joy are less well studied than those that encourage negative emotions like fear and guilt, such messages may also be effective. ${ }^{69}$

- Hornik et al.'s (2016) meta-analysis of advertising studies found that humor had the second largest persuasive effect size of the seven tested appeal types $(r=.35)$, above fear appeals and various more rational persuasion types. ${ }^{70}$ A more recent meta-analysis focusing on a broader range of persuasion studies (not limited to advertising) found that the use of humor in persuasion has significant effects on knowledge $(r=.23, \mathrm{k}=29)$,

\footnotetext{
${ }^{67}$ Robin L. Nabi, "The Effect of Disgust-eliciting Visuals on Attitudes toward Animal Experimentation," Communication Quarterly 46, no. 4 (September 1, 1998): 472-84, https://doi.org/10.1080/01463379809370116, Chelsea Fristoe, "The Persuasive Impact of Disgust-Provoking Images in Animal-Rights Campaigns" (Michigan State University, 2010), https://www.proquest.com/openview/ba84b8acea8b2cf2a95cc85d8fdd9fdb/1?pq-origsite=gscholar\&cbl=18750\&dis $\underline{\mathrm{s}=\mathrm{y}}$, Renata Porzig-Drummond et al., "Can the Emotion of Disgust Be Harnessed to Promote Hand Hygiene? Experimental and Field-Based Tests," Social Science \& Medicine (1982) 68 (February 1, 2009): 1006-12, https://doi.org/10.1016/j.socscimed.2009.01.013, Glenn Leshner, Paul Bolls, and Erika Thomas, "Scare' Em or Disgust 'Em: The Effects of Graphic Health Promotion Messages," Health Communication 24, no. 5 (July 31, 2009): 447-58, https://doi.org/10.1080/10410230903023493, and Andrea C. Morales, Eugenia C. Wu, and Gavan J. Fitzsimons, "How Disgust Enhances the Effectiveness of Fear Appeals," Journal of Marketing Research 49, no. 3 (June 1, 2012): 383-93, https://doi.org/10.1509/jmr.07.0364.

${ }^{68}$ Torleif Halkjelsvik and Jostein Rise, "Disgust in Fear Appeal Anti-Smoking Advertisements: The Effects on Attitudes and Abstinence Motivation," Drugs: Education, Prevention and Policy 22, no. 4 (July 4, 2015): 362-69, https://doi.org/10.3109/09687637.2015.1015491 found "no or potentially very small benefits of using disgust elements when level of fear was held constant" and Chun Yang, "The Impact of Disgust on Threat Appeals: Enhancement or Attenuation of Persuasion?," August 17, 2017, https://etda.libraries.psu.edu/catalog/14716cuy129 found some evidence that disgust reduced persuasiveness.

${ }^{69}$ See e.g. Noam Karsh and Tal Eyal, "How the Consideration of Positive Emotions Influences Persuasion: The Differential Effect of Pride Versus Joy," Journal of Behavioral Decision Making 28, no. 1 (2015): 27-35, https://doi.org/10.1002/bdm.1826 and Alexander Ort, Perina Siegenthaler, and Andreas Fahr, "How Positively Valenced Health Messages Can Foster Information Selection: Evidence from Two Experiments," Frontiers in Communication 6 (2021): 16, https://doi.org/10.3389/fcomm.2021.534496.

${ }^{70}$ Jacob Hornik, Chezy Ofir, and Matti Rachamim, "Quantitative Evaluation of Persuasive Appeals Using Comparative Meta-Analysis," The Communication Review 19, no. 3 (July 2, 2016): 192-222, https://doi.org/10.1080/10714421.2016.1195204.
} 
attitudes $(r=.12, \mathrm{k}=58)$, and behavioral intent $(r=.09, \mathrm{k}=29)$. However, the effects were insignificant and close to zero for each of these outcomes for both "political topics $(\mathrm{k}=21)$, such as gun control and social security" and "health topics $(\mathrm{k}=27)$, such as cervical cancer and mouth hygiene," suggesting that humor is not likely to make messages relating to serious ethical issues either consistently more or less persuasive. ${ }^{71}$ That said, if humor helps to increase public attention to a persuasive message (even if it does not increase its persuasiveness per se), then it could sometimes still be useful as long as it does not trivialize the movement or have other indirect negative effects. ${ }^{72}$

- Similarly, Hornik et al. (2016) found sex appeals to have the largest persuasive effect size of all tested advertising appeal types $(r=.46),{ }^{73}$ but communications scholar Ronald D. Smith (2017) notes that a "consistent finding from persuasion research is that sex appeal should not be used simply for shock value. It is far more effective when the sexual theme has a legitimate association with the product (such as lingerie, perfume, or condoms) or

\footnotetext{
${ }^{71}$ Nathan Walter et al., "A Priest, a Rabbi, and a Minister Walk into a Bar: A Meta-Analysis of Humor Effects on Persuasion," Human Communication Research 44, no. 4 (October 1, 2018): 343-73, https://doi.org/10.1093/hcr/hqy005. Health and political topics were compared to "marketing topics (k=24), such as soft drinks and hair products; (d) education topics $(\mathrm{k}=12)$, such as safety instructions." The effects of humor were not significant for behavioral outcomes $(\mathrm{r}=.04, \mathrm{k}=5)$. They also note that humor has stronger effects when the topic has higher personal relevance to the receiver and there is "an inverted U-shaped effect of humor intensity on persuasion." Ronald D. Smith, Strategic Planning for Public Relations (New York, NY: Routledge, 2017), https://doi.org/10.4324/9781315270876 277-8 also makes the case that, if used inappropriately, humor can be counterproductive.

${ }^{72}$ For some additional discussion of related strategic considerations, see section "2. Stop using gimmicks..." in Jacy Reese Anthis, "3 Big Changes We Need in the Farmed Animal Movement," Sentience Institute (blog), June 25, 2018, http://www.sentienceinstitute.org/blog/three-big-changes and "Focus less on increasing issue salience" in Jamie Harris, Jacy Reese Anthis, and Ali Ladak, "Key Lessons From Social Movement History," Sentience Institute (blog), June 30, 2021, http://www.sentienceinstitute.org/blog/key-lessons-from-social-movement-history.

${ }^{73}$ Jacob Hornik, Chezy Ofir, and Matti Rachamim, "Quantitative Evaluation of Persuasive Appeals Using Comparative Meta-Analysis," The Communication Review 19, no. 3 (July 2, 2016): 192-222, https://doi.org/10.1080/10714421.2016.1195204. Using some different outcome measures, John G. Wirtz, Johnny V. Sparks, and Thais M. Zimbres, "The Effect of Exposure to Sexual Appeals in Advertisements on Memory, Attitude, and Purchase Intention: A Meta-Analytic Review," International Journal of Advertising 37, no. 2 (March 4, 2018): 168-98, https://doi.org/10.1080/02650487.2017.1334996 found less promising results.
} 
with the cause (such as birth control or responsible sexual behavior)." ${ }^{, 74}$ A similar effect

may occur in social advocacy. Indeed, a study testing the effects of PETA advertisements

suggests that sexual ads will backfire for animal advocates. ${ }^{75}$

- Fast speech rate may enhance persuasion by acting as a cue of credibility under

conditions of low elaboration and may capture attention. But it may reduce the

communicator's apparent goodwill (so could be counterproductive for sensitive issues) ${ }^{76}$

and comprehension by the audience. ${ }^{77}$

- There are a number of factors that can make imagery persuasive, ${ }^{78}$ though a meta-analysis

of 12 studies found that, overall, adding "visual images to verbal texts had no significant

effect on persuasion." 79

- "Refutational two-sided messages" (those which describe but refute opposing arguments)

“are dependably more persuasive than one-sided messages; nonrefutational two-sided

messages, on the other hand, are slightly less persuasive than their one-sided

\footnotetext{
${ }^{74}$ Ronald D. Smith, Strategic Planning for Public Relations (New York, NY: Routledge, 2017), https://doi.org/10.4324/9781315270876, 277. Additional caveats include that "audience demographics affect how that attention is received," "audiences often remember the sexual content of an advertisement but fail to associate it with the brand being promoted or the sponsor presenting the message," and "for all their high ability to gain attention, they are notoriously weak in leading receivers toward desired action." Citations are not provided for the individual claims.

${ }^{75}$ Renata Bongiorno, Paul G. Bain, and Nick Haslam, “When Sex Doesn't Sell: Using Sexualized Images of Women Reduces Support for Ethical Campaigns," PLOS ONE 8, no. 12 (December 18, 2013): e83311, https://doi.org/10.1371/journal.pone.0083311.

${ }^{76}$ Richard M. Perloff, The Dynamics of Persuasion: Communication and Attitudes in the Twenty-First Century, 6th ed. (New York, NY: Routledge, 2017), 352-4 https://doi.org/10.4324/9781315657714.

${ }^{77}$ Barbara Mae Gayle and Raymond W. Preiss, "Exploring the Relationship Between Listening Comprehension and Rate of Speech," in Classroom Communication and Instructional Processes: Advances Through Meta-Analysis, ed. Barbara Mae Gayle et al. (Mahwah, NJ: Routledge, 2009), 315-28.

${ }^{78}$ See Chapter 14 in Robert H. Gass and John S. Seiter, Persuasion: Social Influence and Compliance Gaining, 6th ed. (New York: Routledge, 2018), https://doi.org/10.4324/9781315209302 and Kiwon Seo, "Meta-Analysis on Visual Persuasion- Does Adding Images to Texts Influence Persuasion?," Athens Journal of Mass Media and Communications 6, no. 3 (June 30, 2020): 177-90, https://doi.org/10.30958/ajmmc.6-3-3.

${ }^{79}$ Kiwon Seo, "Meta-Analysis on Visual Persuasion- Does Adding Images to Texts Influence Persuasion?," Athens Journal of Mass Media and Communications 6, no. 3 (June 30, 2020): 177-90, https://doi.org/10.30958/aimmc.6-3-3.
} 
counterparts. ${ }^{" 80}$ There are a number of caveats and exceptions where one-sided messages

can be more effective. ${ }^{81}$

Relatedly, "showing receivers refutations of weak opposing arguments makes receivers more

resistant to persuasion (by subsequent attack messages) than they otherwise would have been."${ }^{92}$

This "inoculation" strategy is one of several possible strategies for preventing unwanted attitude

change. A meta-analysis suggests that, "providing people with arguments and information

supporting their current views" can confer resistance to persuasion, but that these "supportive"

\begin{abstract}
${ }^{80}$ Daniel J. O'Keefe, Persuasion: Theory and Research (Los Angeles, CA: SAGE Publications, 2015), 340.
${ }^{81}$ Daniel J. O'Keefe, Persuasion: Theory and Research (Los Angeles, CA: SAGE Publications, 2015), 341 notes two important caveats. Firstly, "[e]xamination of the messages in these studies suggests that the refuted counterarguments were ones that might well have been entertained by the audience as potentially significant objections. One ought not necessarily expect the same results if implausible or trivial objections were to be refuted." Secondly, "in consumer advertisements, nonrefutational two-sided messages are neither more nor less persuasive than one-sided advertisements."

Stephen A. Rains, Timothy R. Levine, and Rene Weber, "Sixty Years of Quantitative Communication Research Summarized: Lessons from 149 Meta-Analyses," Annals of the International Communication Association 42, no. 2 (April 3, 2018): 105-24, https://doi.org/10.1080/23808985.2018.1446350 note that, "O'Keefe(1999), for example, examined differences in the persuasiveness of one and two-sided messages and reported a weighted mean effect of $r$ $=-.001$. This estimate varied based on the nature of two-sidedmessages. Refutational two-sided messages were more persuasive than one-sided messages, $\mathrm{r}=.08$, whereas non-refutational two-sided messages were less persuasive, $r=-.05$." These differences are very small, suggesting that the difference between these three strategies is, as a general rule, negligible, and likely more dependent upon specifics.
\end{abstract}

Ronald D. Smith, Strategic Planning for Public Relations (New York, NY: Routledge, 2017), https://doi.org/10.4324/9781315270876 claims that, "[f]our conditions warrant the use of one-sided arguments: (1) the audience is friendly and already agrees with your position, (2) its members have low educational or knowledge levels, (3) your position will be the only one presented, or (4) the objective is immediate opinion change. Presenting only one side of an argument can cause a temporary attitudinal change, but this probably will be eliminated if the audience later hears a convincing argument from the other side."

${ }^{82}$ Daniel J. O'Keefe, Persuasion: Theory and Research (Los Angeles, CA: SAGE Publications, 2015), 393. O'Keefe notes that "the resistance conferred by inoculation generalizes beyond the refuted arguments; receivers who have been inoculated are also more resistant (than they would have been) to novel opposing arguments." 
treatments are less effective than "inoculation." ${ }^{93}$ Warning a receiver that they are about to hear a message intended to persuade them also stimulates resistance to persuasion. ${ }^{84}$

Although not easily employed to alter public opinion, there are a number of techniques that have been found to increase the effectiveness of interpersonal persuasion efforts aimed at changing behaviors, such as the "foot-in-the-door," "door-in-the-face," "that's-not-all," "low-balling," "fear-then-relief," "but-you-are-free," and "disrupt-then-reframe" techniques. ${ }^{85}$ Techniques focused on persuasion within groups could potentially be applied at the level of whole organizations or even social movements, such as the finding that a member of a group with a minority view can sometimes persuade the majority to change their view by either "conforming with the group and then deviating" or "consistently disagreeing with the group." 86 There is also evidence that certain advertising techniques — such as increased exposure to a product and association between the product and certain images or attributes — can positively influence attitudes toward the product. The success of these techniques is influenced by a variety of

\footnotetext{
${ }^{83}$ Daniel J. O'Keefe, Persuasion: Theory and Research (Los Angeles, CA: SAGE Publications, 2015), 393-4, citing John A. Banas and Stephen A. Rains, "A Meta-Analysis of Research on Inoculation Theory," Communication Monographs 77, no. 3 (September 1, 2010): 281-311, https://doi.org/10.1080/03637751003758193. Banas and Rains note that, "the point estimates from our meta-analysis revealed equivalent resistance between immediate and moderate delays between inoculation and attack, with a decay in resistance after two weeks."

${ }^{84}$ Daniel J. O'Keefe, Persuasion: Theory and Research (Los Angeles, CA: SAGE Publications, 2015), 394-5. More specific warnings, telling the receiver the topic and position of the incoming message, are more effective with a few minutes' between the warning and receipt of the message, but this doesn't seem to be the case for generic persuasive-intent warnings.

${ }^{85}$ Richard M. Perloff, The Dynamics of Persuasion: Communication and Attitudes in the Twenty-First Century, 6th ed. (New York, NY: Routledge, 2017), 451-88 https://doi.org/10.4324/9781315657714 and chapters 8, 10, and 11 in Robert H. Gass and John S. Seiter, Persuasion: Social Influence and Compliance Gaining, 6th ed. (New York: Routledge, 2018), https://doi.org/10.4324/9781315209302.

${ }^{86}$ Robert H. Gass and John S. Seiter, Persuasion: Social Influence and Compliance Gaining, 6th ed. (New York: Routledge, 2018), 235 https://doi.org/10.4324/9781315209302. Other examples are provided throughout chapter 6. On page 260, they summarize that, "several factors (i.e., group size, moral conviction, having an ally, the intensity of indoctrination, the degree to which we identify with a group, communicator characteristics, and culture) influence how likely we are to conform. We also saw that social proof can be a powerful persuasive tactic because it relies on people's tendency to conform."
} 
factors, but it seems plausible that they could sometimes be employed to influence public opinion towards policies or social issues. ${ }^{87}$

\section{Other factors}

Persuasion can also be affected by "receiver factors" such as demographic factors or the receiver's mood ${ }^{88}$ which will often be difficult for advocates to account for but suggest that optimal persuasive messages will be tailored to their audiences. Some of this research has more generalizable advocacy-relevant implications. For example:

- It may sometimes be possible to encourage receptivity to persuasive messages before sharing the message itself, such as by asking people to reflect on their values. ${ }^{89}$

- "Reactance" is a state created by a perception of threat to the receiver's freedom, which makes the receiver more likely to reject a view advocated to them. It can be reduced by avoiding forceful claims (e.g. "it is impossible to deny all the evidence") and emphasizing the receiver's freedom of choice..$^{90}$

\footnotetext{
${ }^{87}$ Richard M. Perloff, The Dynamics of Persuasion: Communication and Attitudes in the Twenty-First Century, 6th ed. (New York, NY: Routledge, 2017), 493-535 https://doi.org/10.4324/9781315657714.

${ }^{88}$ See, for example, chapter 5 in Robert H. Gass and John S. Seiter, Persuasion: Social Influence and Compliance Gaining, 6th ed. (New York: Routledge, 2018), https://doi.org/10.4324/9781315209302.

${ }^{89}$ Tracy Epton et al., "The Impact of Self-Affirmation on Health-Behavior Change: A Meta-Analysis," Health Psychology: Official Journal of the Division of Health Psychology, American Psychological Association 34, no. 3 (March 2015): 187-96, https://doi.org/10.1037/hea0000116.

${ }^{90}$ Daniel J. O'Keefe, Persuasion: Theory and Research (Los Angeles, CA: SAGE Publications, 2015), 391. On pp. 385-90, O'Keefe also notes that a number of individual difference variables, such as cultural beliefs, can affect persuasion. More transient receiver variables, such as mood, can also affect persuasion. Presumably, these variables will be difficult to account for in mass marketing campaigns, but could be relevant to face-to-face persuasion. See also Christopher J. Carpenter, "A Meta-Analysis of the Effectiveness of the 'But You Are Free' Compliance-Gaining Technique," Communication Studies 64, no. 1 (January 1, 2013): 6-17, https://doi.org/10.1080/10510974.2012.727941.
} 
- It is harder to persuade someone if they are already knowledgeable about the topic..$^{91}$ This suggests that persuasive interventions focusing on professionals with relevant expertise are less likely to result in attitude change than interventions focusing on the general population. It also suggests that first impressions matter; advocates should ensure that awareness-raising tactics are persuasive to their audience, since it will be harder to change attitudes once knowledge has increased.

Psychologists Stuart Oskamp and P. Wesley Schultz (2005) summarize research findings as demonstrating that, “[p]rint media (books, magazines, and newspapers)... produce better comprehension and retention of complex material [as well as higher attitude change] than other media, but that this advantage does not hold for simple material... [P] eople's knowledge of current affairs is more closely related to their use of print media." ${ }^{92}$ They also summarize that, "[t]here is general agreement that personal communication usually has a stronger influence on people's attitudes and behavior than does mass communication.. ${ }^{93}$ Of course, this does not

\footnotetext{
${ }^{91}$ See "EM3: Does higher pre-decision issue salience decrease the effects of a Supreme Court decision on public opinion?" in Jamie Harris and Jacy Reese Anthis, "Is the US Supreme Court a Driver of Social Change or Driven by It? A Literature Review," (November 27, 2019), https://sentienceinstitute.org/scotus. Stuart Oskamp and P. Wesley Schultz, Attitudes and Opinions (New York, NY: Psychology Press, 2005), 184 also summarize that, "high intelligence or a high level of knowledge about the topic may reduce yielding to the message." On pages 326-7 they summarize that political advertising tends to be most effective in situations where people have low exposure to the candidates or issues. Thomas E. Nelson, Zoe M. Oxley, and Rosalee A. Clawson, "Toward a Psychology of Framing Effects," Political Behavior 19, no. 3 (September 1, 1997): 227, https://doi.org/10.1023/A:1024834831093 provide additional citations for the claim that "greater knowledge or sophistication about an issue inhibits attitude change via belief change," and list three reasons for this. Relatedly, Daniel J. O'Keefe, Persuasion: Theory and Research (Los Angeles, CA: SAGE Publications, 2015), 48-70 describe "social judgement theory" - one key prediction of this theory (with some empirical support) is that "as one's level of ego-involvement increases, the size of the latitude of rejection will also increase," i.e. that if people are more involved with an issue, they are more likely to reject persuasive messages.

${ }^{92}$ Stuart Oskamp and P. Wesley Schultz, Attitudes and Opinions (New York, NY: Psychology Press, 2005), 184-5. Internal citations omitted. Supporting evidence is provided on the following pages, though many of the citations are several decades old.

${ }^{93}$ Stuart Oskamp and P. Wesley Schultz, Attitudes and Opinions (New York, NY: Psychology Press, 2005), 198.
} 
necessarily mean that efforts to alter public opinion through personal communication will be

more cost-effective, since they may also be more resource-intensive.

There is a substantial amount of research demonstrating a "third-person effect," where people believe that a persuasive message will have a stronger influence on others than on themselves. For example, Paul et al.'s (2000) meta-analysis found an effect size of $r=0.50$, i.e. substantially "greater perceived effects on others than on oneself," 94 though Sun et al. (2008) found a smaller effect size $(d=0.65) .{ }^{95}$ In some contexts, it may be sufficient for advocates to encourage the perception that an issue is important or an attitude is widely held; ${ }^{96}$ the third-person effect suggests that doing so is tractable.

\footnotetext{
${ }^{94}$ Bryant Paul, Michael B. Salwen, and Michel Dupagne, "The Third-Person Effect: A Meta-Analysis of the Perceptual Hypothesis," Mass Communication and Society 3, no. 1 (February 1, 2000): 57-85, https://doi.org/10.1207/S15327825MCS0301 04. Martin Eisend, "The Third-Person Effect in Advertising: A Meta-Analysis," Journal of Advertising 46, no. 3 (July 3, 2017): 377-94, https://doi.org/10.1080/00913367.2017.1292481 explores why the third-person effect is smaller in advertising. Jie $\mathrm{Xu}$ and William J. Gonzenbach, "Does a Perceptual Discrepancy Lead to Action? A Meta-Analysis of the Behavioral Component of the Third-Person Effect," International Journal of Public Opinion Research 20, no. 3 (October 1, 2008): 375-85, https://doi.org/10.1093/ijpor/edn031 and Guangchao Charles Feng and Steve Zhongshi Guo, "Support for Censorship: A Multilevel Meta-Analysis of the Third-Person Effect," Communication Reports 25, no. 1 (January 1, 2012): 40-50, https://doi.org/10.1080/08934215.2012.661019 demonstrate that the third-person effect only has small effects on behavioral intentions.

${ }^{95}$ Ye Sun, Zhongdang Pan, and Lijiang Shen, "Understanding the Third-Person Perception: Evidence From a Meta-Analysis," Journal of Communication 58, no. 2 (June 2008): 280-300, https://doi.org/10.1111/j.1460-2466.2008.00385.x. They note that, "[p]art of the 'shrinkage' may have come from including more studies testing the [first-person perception] in our sample. Another major reason is that Paul et al. used the formula based on between subjects designs, which is inappropriate, to compute all effect sizes." ${ }^{96}$ For example, Yossi David, "Public Opinion, Media and Activism: The Differentiating Role of Media Use and Perceptions of Public Opinion on Political Behaviour," Social Movement Studies 0, no. 0 (January 12, 2021): 1-21, https://doi.org/10.1080/14742837.2021.1875321 found that "increased perception of majority support for the movement ["the summer 2011 protests in Israel"] led to increased rates of participation."
}

Additionally, several meta-analyses have found a small or very small "spiral of silence" effect, where "opinions that are held by the perceived majority are more likely to be expressed publicly compared with opinions shared by a perceived minority" (see Jörg Matthes, Johannes Knoll, and Christian von Sikorski, "The 'Spiral of Silence' Revisited: A Meta-Analysis on the Relationship Between Perceptions of Opinion Support and Political Opinion Expression," Communication Research 45, no. 1 (February 1, 2018): 3-33, https://doi.org/10.1177/0093650217745429). So encouraging the perception that a majority of people hold a certain attitude may help to facilitate discussion (and, more speculatively, institutional change) around that topic. 


\section{Duration}

When advocates successfully encourage attitude change, a substantial proportion of the change may endure for at least several weeks, as Oskamp and Schultz (2005) summarize:

After 4 to 6 weeks, the amount of attitude change retained may be from one-third to two-thirds of the initial change, which of course may have been small to begin with. In a study of five different TV documentaries shown to college students, Fitzsimmons and Osburn (1968) found that only one retained a significant attitudinal effect after 4 weeks. However, many experiments have found attitude changes lasting as long as 6 months, and a very impressive classroom study by Rokeach (1971) showed significant attitude changes lasting well over one year. ${ }^{97}$

This is promising, given that, "all of these findings stem from studies in which the persuasive message was delivered only once" and that, "[r]esearch has shown that repeated re-exposures to a persuasive message will strengthen and prolong any prior opinion change. ${ }^{\prime 98}$ More recently, political scientist Seth J. Hill and colleagues have noted that, "[s]cholars do not usually test for the duration of the effects of mass communication." ${ }^{\prime 99}$ Nevertheless, a "handful of recent studies [have] found that persuasion effects can be quite shortlived, decaying in a few weeks or even a

\footnotetext{
${ }^{97}$ Stuart Oskamp and P. Wesley Schultz, Attitudes and Opinions (New York, NY: Psychology Press, 2005), 193. Citations in parentheses omitted.

${ }^{98}$ Stuart Oskamp and P. Wesley Schultz, Attitudes and Opinions (New York, NY: Psychology Press, 2005), 193.

${ }^{99}$ Seth J. Hill et al., "How Quickly We Forget: The Duration of Persuasion Effects From Mass Communication," Political Communication 30, no. 4 (October 2013): 521-47, https://doi.org/10.1080/10584609.2013.828143.
} 
few days. ${ }^{\prime 100}$ A review of nine brief interventions intended to reduce implicit racial preferences found that "all nine interventions immediately reduced implicit preferences" but "none were effective after a delay of several hours to several days." ${ }^{\text {101 }}$ Two experimental studies of a documentary "that presents the health, environmental, and animal welfare motivations for reducing consumption of meat and animal products" found that it "did not meaningfully affect any of the... exploratory attitude outcomes" at follow-up after two weeks. ${ }^{102}$ Hill et al.'s own study (which uses political advertising data rather than an experimental design) and a subsequent experiment suggest that over half of the attitude change observed from persuasive interventions decayed within weeks, but that non-negligible proportions of the effects lasted for longer periods. ${ }^{103}$ Regression across numerous studies of social norms manipulations found no significant

\footnotetext{
${ }^{100}$ Seth J. Hill et al., "How Quickly We Forget: The Duration of Persuasion Effects From Mass Communication," Political Communication 30, no. 4 (October 2013): 521-47, https://doi.org/10.1080/10584609.2013.828143. ${ }^{101}$ Calvin K. Lai et al., "Reducing Implicit Racial Preferences: II. Intervention Effectiveness across Time.," Journal of Experimental Psychology. General 145, no. 8 (August 1, 2016): 1001-16, https://doi.org/10.1037/xge0000179.

${ }^{102}$ Maya Mathur et al., "Effectiveness of a Theory-Informed Documentary to Reduce Meat and Animal-Product Consumption: Three Randomized Controlled Experiments" (OSF Preprints, September 21, 2021), https://doi.org/10.31219/osf.io/vgu6z. The outcome measures were "Importance of health," "Importance of environment," "Importance of animal welfare," "Interest in activism," "Speciesism," and "Social dominance orientation." The authors note that "most standardized mean differences were very close to zero and all were less than 0.20 in magnitude (Table 2 [and Table 5]). None of Bonferroni-corrected secondary outcome p-values was less than 0.05." In the first study, the outcome measure for "Interest in activism" was significant $(p=0.04, S M D=0.17)$ before Bonferroni correction.

${ }^{103}$ Seth J. Hill et al., "How Quickly We Forget: The Duration of Persuasion Effects From Mass Communication," Political Communication 30, no. 4 (October 2013): 521-47, https://doi.org/10.1080/10584609.2013.828143 and Larry M. Bartels, "Remembering to Forget: A Note on the Duration of Campaign Advertising Effects," Political Communication 31, no. 4 (October 2, 2014): 532-44, https://doi.org/10.1080/10584609.2014.956198. Hill et al. hypothesize that long-term effects may be dependent upon "the communication causing them [being] continuously present." Bartels' results suggest that effects may have longer duration among people with ambivalent views or who are predisposed towards the persuasive messaging. These two studies propose different reasons for why the decay happens.

Though focused on belief accuracy rather than persuasion, Dustin Carnahan, Daniel E. Bergan, and Sangwon Lee, "Do Corrective Effects Last? Results from a Longitudinal Experiment on Beliefs Toward Immigration in the U.S.," Political Behavior, January 9, 2020, https://doi.org/10.1007/s11109-020-09591-9 similarly found that the effects remained significant and positive at two and four weeks' follow-up, but had decreased in size.
} 
effects of " $[t]$ he time in days between message exposure and final assessment" on attitudes

outcomes. $^{104}$

A natural experiment from Germany suggests that one-sided persuasion campaigns may have effects on social norms, beliefs, and behaviors that last for years. ${ }^{105}$ An observational study found that viewers of an advertisement designed to increase opposition to Canadian seal hunts still had significantly higher opposition two months after exposure than beforehand, though it had levelled off relative to their opposition immediately after viewing. ${ }^{106}$ This provides some evidence that persuasive interventions may cause long-term attitude change, but it also seems clear that most of the attitude change they cause will be temporary. For advocates to cost-effectively cause long-term public opinion change, they therefore probably need to encourage some sort of self-perpetuating mechanism such as new legislation, social norms, or framings used by the media.

\footnotetext{
${ }^{104}$ Nancy Rhodes, Hillary C. Shulman, and Nikki McClaran, "Changing Norms: A Meta-Analytic Integration of Research on Social Norms Appeals," Human Communication Research 46, no. 2-3 (July 1, 2020): 161-91, https://doi.org/10.1093/hcr/hqz023. The number of studies included in the meta-regression is unclear, though it may have been 26 with attitudes outcomes (if we count the numbers in the relevant column in Table 1). The range in the number of days in included studies is also unclear. They note that "[s]tatistically significant but extremely small effects of study duration were found for behavior $(b=-.0009 ; \mathrm{z}=-2.85 ; \mathrm{p}=.004)$ and perceived descriptive norm $(\mathrm{b}=-.0023 ; \mathrm{z}=-3.24 ; \mathrm{p}=.001)$, indicating a slight tendency for the manipulation effect to wane over time. There were no significant effects of study duration for attitudes, intention, and perceived injunctive norm."

${ }^{105}$ Kai Jäger, "When Do Campaign Effects Persist for Years? Evidence from a Natural Experiment," American Journal of Political Science 64, no. 4 (2020): 836-51, https://doi.org/10.1111/ajps.12488. They summarize: “After a one-sided campaign focusing on law and order, the party's vote share increased more than sixfold. By comparing the precinct with its direct surroundings, the study shows that the revote campaign had long-lasting effects on vote choice and broader security-sensitive behavior. Residents in the revote precinct installed more warning signs on their property to deter burglars. They were not more supportive of right-wing attitudes but were more likely to believe that election fraud reoccurred."

${ }^{106}$ Karin Braunsberger, "The Impact of Animal Welfare Advertising on Opposition to the Canadian Seal Hunt and Willingness to Boycott the Canadian Seafood Industry," Anthrozoös 27, no. 1 (March 1, 2014): 111-25, https://doi.org/10.2752/175303714X13837396326530.
} 


\section{Prejudice reduction strategies}

Research on advocacy and persuasion efforts that focus specifically on reducing prejudice is especially relevant to social movements targeting moral circle expansion. Psychologist Levy Paluck and colleagues (2021) reviewed and meta-analyzed "418 experiments reported in 309 manuscripts from 2007 to 2019 to assess which approaches work best and why." ${ }^{107}$ Table 1 is a summary of their findings.

Table 1: Effects of prejudice reduction strategies, summarized from Paluck et al. (2021) $)^{108}$

\begin{tabular}{|c|c|c|c|c|c|}
\hline Intervention & Definition & $d$ & $\mathbf{L L}$ & $\mathbf{U L}$ & $\mathbf{n}$ \\
\hline Entertainment & $\begin{array}{l}\text { "[E]ntertainment interventions have tested interactive } \\
\text { narratives that allow individuals to participate in the } \\
\text { construction of stories about outgroups, films made by and for } \\
\text { Black audiences, pro-integration music lyrics, and } \\
\text { entertainment education that incorporates educational messages } \\
\text { about prejudice into an entertaining storyline of a soap opera or } \\
\text { film." }\end{array}$ & 0.43 & 0.27 & 0.59 & 12 \\
\hline $\begin{array}{l}\text { Value } \\
\text { consistency } \\
\text { and self-worth }\end{array}$ & $\begin{array}{l}\text { "These interventions include reminders of } \\
\text { individuals' or their group's egalitarian preferences or history } \\
\text { in order to inspire consistency with that history in the present } \\
\text { moment, remind people of moral exemplars, and provoke }\end{array}$ & 0.41 & 0.23 & 0.6 & 35 \\
\hline
\end{tabular}

${ }^{107}$ Elizabeth Levy Paluck et al., "Prejudice Reduction: Progress and Challenges," Annual Review of Psychology 72, no. 1 (January 4, 2021): 533-60, https://doi.org/10.1146/annurev-psych-071620-030619.

${ }^{108}$ Elizabeth Levy Paluck et al., "Prejudice Reduction: Progress and Challenges," Annual Review of Psychology 72, no. 1 (January 4, 2021): 533-60, https://doi.org/10.1146/annurev-psych-071620-030619. 


\begin{tabular}{|c|c|c|c|c|c|}
\hline & introspection about one's existing beliefs and prejudices." & & & & \\
\hline $\begin{array}{l}\text { Extended and } \\
\text { imaginary } \\
\text { contact }\end{array}$ & $\begin{array}{l}\text { "[T] he majority of studies testing the extended contact } \\
\text { hypothesis used fictional friends or characters in books or } \\
\text { movies that belong to the same ingroup as the audience } \\
\text { member to test whether the fictional character's contact with an } \\
\text { outgroup member would reduce prejudice." }\end{array}$ & 0.37 & 0.3 & 0.44 & 137 \\
\hline $\begin{array}{l}\text { Social } \\
\text { categorization }\end{array}$ & $\begin{array}{l}\text { These interventions "encourage participants to rethink group } \\
\text { boundaries or to prioritize common identities shared with } \\
\text { specific outgroups." }\end{array}$ & 0.37 & 0.27 & 0.46 & 59 \\
\hline Overall & & 0.36 & 0.31 & 0.4 & 416 \\
\hline $\begin{array}{l}\text { Cognitive and } \\
\text { emotional } \\
\text { training }\end{array}$ & $\begin{array}{l}\text { "Interventions categorized as cognitive and emotional training } \\
\text { share the idea that individuals can be trained to use thinking } \\
\text { and emotion regulation strategies to fight off their personal } \\
\text { implicit or explicit prejudices." }\end{array}$ & 0.34 & 0.25 & 0.43 & 104 \\
\hline $\begin{array}{l}\text { Multicultural, } \\
\text { antibias, moral } \\
\text { education }\end{array}$ & $\begin{array}{l}\text { "Antibias education and multicultural education draw variously } \\
\text { on theories addressing the socialization of prejudice, cognitive } \\
\text { and moral development, and learning. The form of these } \\
\text { interventions also ranges widely." }\end{array}$ & 0.30 & 0.18 & 0.42 & 20 \\
\hline $\begin{array}{l}\text { Diversity } \\
\text { trainings }\end{array}$ & $\begin{array}{l}\text { "The notion of diversity training encompasses a wide category } \\
\text { of interventions that are 'designed to attack bias' among } \\
\text { managers and workers." }\end{array}$ & 0.30 & -0.12 & 0.71 & 6 \\
\hline $\begin{array}{l}\text { Interpersonal } \\
\text { contact }\end{array}$ & $\begin{array}{l}\text { Contact between members of groups. E.g. included studies } \\
\text { "randomized criminology students to have contact with }\end{array}$ & 0.28 & 0.17 & 0.38 & 29 \\
\hline
\end{tabular}




\begin{tabular}{|c|c|c|c|c|c|}
\hline & $\begin{array}{l}\text { individuals incarcerated for serious crimes" or "randomly } \\
\text { assigned Jewish and Arab Israelis to meet one another on peace } \\
\text { encounters." }\end{array}$ & & & & \\
\hline $\begin{array}{l}\text { Peer influence, } \\
\text { discussion / } \\
\text { dialogue }\end{array}$ & $\begin{array}{l}\text { "This category of interventions is united by the idea that people } \\
\text { who share important identities, peers, or ingroup members have } \\
\text { a powerful influence over one another's impression of the } \\
\text { attitudes and behaviors that are typical, desirable, and correct. } \\
\text { The interventions in this category wield peer influence in } \\
\text { various ways to reduce prejudice." }\end{array}$ & 0.27 & 0.13 & 0.41 & 39 \\
\hline Other & & 0.24 & 0.01 & 0.47 & 24 \\
\hline
\end{tabular}

$L L=95 \%$ confidence interval lower limit; $U L=95 \%$ confidence interval upper limit; $n=$ number of outcomes.

They found similar sized effects for "explicit attitudes or beliefs" $(d=0.35,95 \%$ CI [0.3, 0.39$], n$ $=335)$, behavior $(d=0.42,95 \%$ CI $[0.29,0.55], n=50)$, and other outcome types, though Table 1 combines all the outcome types they measured. ${ }^{109}$

They find evidence of substantial publication bias, noting that, "the average effect size drops $48 \%$, to 0.187 , when we focus solely on the top quintile of sample sizes" and that their analysis

${ }^{109}$ Elizabeth Levy Paluck et al., "Prejudice Reduction: Progress and Challenges," Annual Review of Psychology 72, no. 1 (January 4, 2021): 533-60, https://doi.org/10.1146/annurev-psych-071620-030619. The other included outcome types were empathy, behavioral intentions, implicit attitudes, emotion, and perceived norms. The $95 \%$ CIs overlapped for all of these. The results specifically for attitudes are reported in the text of the article for some but not all of the intervention types. 
suggests that "a study large enough to generate a standard error of approximately zero would, on average, produce no change in prejudice at all." ${ }^{110}$

The outcome measures tend to focus on prejudice itself, which is arguably less useful for advocates than measures of support for policies that affect marginalized groups. ${ }^{111}$ However, we might expect many interventions to affect both types of outcomes. For example, there is evidence that intergroup contact affects both. ${ }^{12}$

Some of the reviewed intervention types, such as intergroup contact and various training types, seem likely to be very expensive. It therefore remains unclear whether these mechanisms could be employed to cost-effectively encourage widespread attitude change. ${ }^{113}$ Paluck et al. note that $76 \%$ of their included studies evaluate "treatments that are easy to implement, brief (under 10 minutes), inexpensive, and thought to have lasting effects," but highlight that there is little evidence about the long-term effects of these interventions. ${ }^{114}$

\footnotetext{
${ }^{110}$ Elizabeth Levy Paluck et al., "Prejudice Reduction: Progress and Challenges," Annual Review of Psychology 72, no. 1 (January 4, 2021): 533-60, https://doi.org/10.1146/annurev-psych-071620-030619. The other included outcome types were empathy, behavioral intentions, implicit attitudes, emotion, and perceived norms. The 95\% CIs overlapped for all of these.

${ }^{111}$ Elizabeth Levy Paluck et al., "Prejudice Reduction: Progress and Challenges," Annual Review of Psychology 72, no. 1 (January 4, 2021): 533-60, https://doi.org/10.1146/annurev-psych-071620-030619 uses "the measurement of prejudice as an outcome" as an inclusion criterion, so "studies whose outcomes focused solely on policy preferences" are excluded.

${ }^{112}$ Stuart Oskamp and P. Wesley Schultz, Attitudes and Opinions (New York, NY: Psychology Press, 2005), 372-3 and 404-6.

${ }^{113}$ For some brief discussion, see Jamie Harris, "Kristof Dhont of University of Kent on Intergroup Contact Research and Research Careers," accessed May 27, 2021, http://www.sentienceinstitute.org/podcast, 58:08 to $1: 14: 52$.

${ }^{114}$ Elizabeth Levy Paluck et al., "Prejudice Reduction: Progress and Challenges," Annual Review of Psychology 72, no. 1 (January 4, 2021): 533-60, https://doi.org/10.1146/annurev-psych-071620-030619. There is also indirect evidence that such interventions might affect attitudes towards animals; see Béatrice Auger and Catherine E. Amiot, "The Impact of Imagined Contact in the Realm of Human-Animal Relations: Investigating a Superordinate Generalization Effect Involving Both Valued and Devalued Animals," Journal of Experimental Social Psychology 85 (November 1, 2019): 103872, https://doi.org/10.1016/j.jesp.2019.103872.
} 


\section{Framing}

"Framing" variations might influence public opinion through different psychological mechanisms to direct persuasion efforts. Political scientist Thomas E. Nelson and colleagues (1997) explain that, by highlighting certain aspects of a topic over others, "[f]rames may supply no new information" and have no effect on the recipient's beliefs about the topic, "yet their influence on our opinions may be decisive through their effect on the perceived relevance

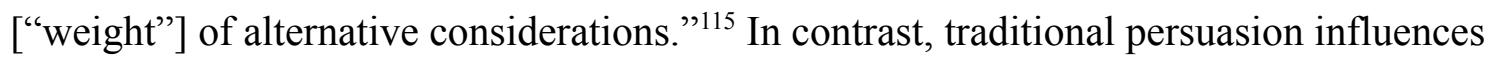
attitudes by providing new information and altering beliefs without influencing the weight of those beliefs.

For example, when presented with a choice of options that involve risk, the option that people are most likely to select varies substantially according to whether the positives (e.g. "lives saved") or negatives (e.g. "lives lost") are emphasised by the question, even when the options presented are logically identical. A meta-analysis of 136 empirical papers found a small effect ( $d$ $=0.31$ ) from such framing variations, with respondents more likely to avoid risk when the positives are emphasized. ${ }^{116}$

\footnotetext{
${ }^{115}$ Thomas E. Nelson, Zoe M. Oxley, and Rosalee A. Clawson, "Toward a Psychology of Framing Effects," Political Behavior 19, no. 3 (September 1, 1997): 221-46, https://doi.org/10.1023/A:1024834831093. This theoretical distinction seems to have been accepted by (at least some) other scholars, e.g. Dennis Chong and James N. Druckman, "Framing Theory," Annual Review of Political Science 10, no. 1 (2007): 103-26, https://doi.org/10.1146/annurev.polisci.10.072805.103054.

${ }^{116}$ Anton Kühberger, "The Influence of Framing on Risky Decisions: A Meta-Analysis," Organizational Behavior and Human Decision Processes 75, no. 1 (July 1, 1998): 23-55, https://doi.org/10.1006/obhd.1998.2781. A more recent re-analysis of the same data (Alexander Steiger and Anton Kühberger, "A Meta-Analytic Re-Appraisal of the Framing Effect," Zeitschrift Für Psychologie 226, no. 1 (2018): 45-55, https://doi.org/10.1027/2151-2604/a000321) used a different methodology to correct for publication bias and found a moderate effect size $(d=.52)$. Additionally, Kelsey McDonald et al., "Valence Framing Effects on Moral Judgments: A Meta-Analysis," Cognition 212 (July 1,
} 
Various other small differences in survey question wording (or perhaps ballot language ${ }^{117}$ ) that highlight certain aspects of a topic can elicit substantially different levels of support. A common survey question on the death penalty is Gallup's “Are you in favor of the death penalty for persons convicted of murder?" - this tends to receive majority approval in the US, but support for the death penalty can fall by $30 \%$ or more when the question instead asks whether the respondents support the death penalty or life without parole for convicted murderers. ${ }^{118}$ Political scientists Dennis Chong and James N. Druckman (2007) note that variations in framing have 2021): 104703, https://doi.org/10.1016/i.cognition.2021.104703 found a small effect $(d=.22)$ for these sorts of "Valence framing effects" on "moral judgements" specifically, using data from 146 experiments.

On the other hand, meta-analyses of comparisons between "gain-framed" and "loss-framed" messages have identified nonsignificant or very small differences for outcomes including "persuasiveness in charity advertising" (Jie Xu and Guanxiong Huang, "The Relative Effectiveness of Gain-Framed and Loss-Framed Messages in Charity Advertising: Meta-Analytic Evidence and Implications," International Journal of Nonprofit and Voluntary Sector Marketing 25, no. 4 (2020): e1675, https://doi.org/10.1002/nvsm.1675) and behavior, attitudes, or intentions relating to disease prevention (Daniel J. O'Keefe and Jakob D. Jensen, "The Relative Persuasiveness of Gain-Framed Loss-Framed Messages for Encouraging Disease Prevention Behaviors: A Meta-Analytic Review," Journal of Health Communication 12, no. 7 (October 11, 2007): 623-44, https://doi.org/10.1080/10810730701615198 and Kristel M. Gallagher and John A. Updegraff, "Health Message Framing Effects on Attitudes, Intentions, and Behavior: A Meta-Analytic Review," Annals of Behavioral Medicine 43, no. 1 (February 1, 2012): 101-16, https://doi.org/10.1007/s12160-011-9308-7). Some of these results, especially for certain subgroups of studies, indicate small or very small differences in favor of gain-framed messages being more effective (see also Xinyi Li et al., "Visualized Nutrition Education and Dietary Behavioral Change: A Systematic Review and Meta-Analysis," Critical Reviews in Food Science and Nutrition 59, no. 12 (July 4, 2019): 1976-85, https://doi.org/10.1080/10408398.2018.1469466), though another meta-analysis (Elie A. Akl et al., "Framing of Health Information Messages," Cochrane Database of Systematic Reviews, no. 12 (2011), https://doi.org/10.1002/14651858.CD006777.pub2) found loss-framed messages to be more persuasive for some outcome measures.

${ }^{117}$ Craig M. Burnett and Vladimir Kogan, "When Does Ballot Language Influence Voter Choices? Evidence from a Survey Experiment," Political Communication 32, no. 1 (January 2, 2015): 109-26, https://doi.org/10.1080/10584609.2014.894160.

${ }^{118}$ David Niven, "Bolstering an Illusory Majority: The Effects of the Media's Portrayal of Death Penalty Support," Social Science Quarterly 83, no. 3 (2002): 671-89, https://doi.org/10.1111/1540-6237.00108. For context, see the section "Changes to public opinion" and the strategic implication beginning "Publicizing opinion poll findings..." in Jamie Harris, Jacy Reese Anthis, and Kelly McNamara, "Social Movement Lessons from the US Anti-Death Penalty Movement," May 22, 2020, https://sentienceinstitute.org/death-penalty. 
been demonstrated to affect policy preferences in "experiments, surveys, and case studies across a range of issues." ${ }^{119}$

Such framing effects could occur at the level of societal discourse of a topic. As discussed in the section on "The media's agenda-setting effects" below, advocates could influence such discourse via the media. Encouraging widespread adoption of a particular frame could take a long time but have substantial effects on policy preferences. ${ }^{120}$ It therefore seems useful for advocates to identify the frames that are most persuasive to their audiences and then to apply these in their messages. ${ }^{121}$

\section{Moderators}

Chong and Druckman (2007) cite evidence that framing efforts are more effective if:

- The audience perceives the connection being made between the frame and the issue as valid,

- The audience does not have strong values that contradict the frame,

\footnotetext{
${ }^{119}$ Dennis Chong and James N. Druckman, "Framing Theory," Annual Review of Political Science 10, no. 1 (2007): 103-26, https://doi.org/10.1146/annurev.polisci.10.072805.103054. They note that these "framing effects" occur "when (often small) changes in the presentation of an issue or an event produce (sometimes large) changes of opinion. For example, when asked whether they would favor or oppose allowing a hate group to hold a political rally, $85 \%$ of respondents answered in favor if the question was prefaced with the suggestion, "Given the importance of free speech," whereas only $45 \%$ were in favor when the question was prefaced with the phrase, "Given the risk of violence'. Similarly, about $20 \%$ of the American public believes that too little is being spent on 'welfare,' but about $65 \%$ says that too little is being spent on 'assistance to the poor'." For other examples, see Richard M. Perloff, The Dynamics of Persuasion: Communication and Attitudes in the Twenty-First Century, 6th ed. (New York, NY: Routledge, 2017), 198-203 https://doi.org/10.4324/9781315657714.

${ }^{120}$ For examples of arguments along these lines, see George Lakoff, The All New Don't Think of an Elephant!: Know Your Values and Frame the Debate (White River Junction, VT: Chelsea Green Publishing, 2014) and Frank R. Baumgartner, Suzanna L. De Boef, and Amber E. Boydstun, The Decline of the Death Penalty and the Discovery of Innocence (Cambridge University Press, 2008).

${ }^{121}$ There seems to be a substantial qualitative and theoretical literature exploring how and why social movements create frames and seek to have them adopted more widely, which I have not summarized here. See, for example, Hank Johnston and John A. Noakes, Frames of Protest: Social Movements and the Framing Perspective (Rowman \& Littlefield Publishers, 2005).
} 
- The frame is "delivered by credible sources," or

- The frame "invoke[s] longstanding cultural values." 122

Given that framing can operate through different mechanisms to persuasion, it might have different moderators. For example, Nelson et al.'s (1997) experiment found evidence that framing variations have stronger effects for people with high "domain-specific knowledge about the arguments surrounding an issue, ${ }^{, 23}$ whereas other studies have found that the opposite tends to be the case for persuasion attempts. ${ }^{124}$ So even if persuasion attempts fail, reframing the issue might still successfully shift overall attitudes, and vice versa. ${ }^{125}$

\section{Duration}

As with research focused on the duration of the persuasive messages, some studies provide evidence that at least some attitude change caused by a single positively or negatively framed article can persist for several weeks, but that the size of the effect will diminish during that time.

${ }^{126}$ Presumably then, for a new frame to have substantial, long-lasting effects on attitudes,

${ }^{122}$ Dennis Chong and James N. Druckman, “Framing Theory," Annual Review of Political Science 10, no. 1 (2007): 103-26, https://doi.org/10.1146/annurev.polisci.10.072805.103054. Richard M. Perloff, The Dynamics of Persuasion: Communication and Attitudes in the Twenty-First Century, 6th ed. (New York, NY: Routledge, 2017), 350-1 https://doi.org/10.4324/9781315657714 also notes that, "persuaders are more likely to change attitudes when they emphasize the ways that the message reaffirms values their receivers hold near and dear."

${ }^{123}$ Thomas E. Nelson, Zoe M. Oxley, and Rosalee A. Clawson, "Toward a Psychology of Framing Effects," Political Behavior 19, no. 3 (September 1, 1997): 221-46, https://doi.org/10.1023/A:1024834831093.

${ }^{124}$ See footnote 91.

${ }^{125}$ Relatedly, reframing may enable change even when attitudes towards the intended beneficiaries are hostile, since there is evidence that framing issues "in ways that deflect attention away from the beneficiaries" decreases the importance of attitudes towards them (Thomas E. Nelson and Donald R. Kinder, "Issue Frames and Group-Centrism in American Public Opinion," The Journal of Politics 58, no. 4 (November 1996): 1055-78, https://doi.org/10.2307/2960149).

${ }^{126}$ Sophie Lecheler and Claes H. de Vreese, "Getting Real: The Duration of Framing Effects," Journal of Communication 61, no. 5 (October 1, 2011): 959-83, https://doi.org/10.1111/j.1460-2466.2011.01580.x cite two studies finding that at least some framing effects lasted until follow-up after one or two weeks, but a third study finding that framing effects had dissipated entirely by the time of follow-up ten days after the intervention. In their own study, they found significant differences at each follow-up point (immediate, one day, one week, and two 
advocates would need to engage in long-term campaigns with repeated messaging using the new frame (which could be very expensive), or successfully encourage the media, politicians, or other influencers to adopt the frame as well. Indeed, a review of 16 longitudinal, experimental studies testing how long news framing effects last found that "[s]tudies focusing on repetitive framing are [not] conclusive but suggest that repetitive news frame exposure strengthens the framing effect to some extent." ${ }^{127}$ They also found that:

- "Studies focusing on competitive framing often conclude that news framing effects persist beyond initial exposure, but are relatively easily altered, sometimes only one day later, by competitive exposure." 128

- "[S]tudies using non-salient issues are able to detect longer-lasting framing effects, probably because there is less exposure to issue-relevant news in the interim period between initial and delayed post-tests." ${ }^{129}$

weeks) in "support for the perceived economic benefits of the EU membership of Bulgaria and Romania" between groups exposed to positively framed, negatively framed, and neutral articles, though the effects of the positively framed article did diminish considerably.

A few years later, the same authors, Sophie Lecheler and Claes H. de Vreese, "How Long Do News Framing Effects Last? A Systematic Review of Longitudinal Studies," Annals of the International Communication Association 40, no. 1 (January 1, 2016): 3-30, https://doi.org/10.1080/23808985.2015.11735254 summarize that, "[t]here is conclusive evidence that news frames will have initial (strong) effects on opinions, and that these effects dissipate over time."

${ }^{127}$ Sophie Lecheler and Claes H. de Vreese, "How Long Do News Framing Effects Last? A Systematic Review of Longitudinal Studies," Annals of the International Communication Association 40, no. 1 (January 1, 2016): 3-30, https://doi.org/10.1080/23808985.2015.11735254.

${ }^{128}$ Sophie Lecheler and Claes H. de Vreese, "How Long Do News Framing Effects Last? A Systematic Review of Longitudinal Studies," Annals of the International Communication Association 40, no. 1 (January 1, 2016): 3-30, https://doi.org/10.1080/23808985.2015.11735254.

${ }^{129}$ Sophie Lecheler and Claes H. de Vreese, "How Long Do News Framing Effects Last? A Systematic Review of Longitudinal Studies," Annals of the International Communication Association 40, no. 1 (January 1, 2016): 3-30, https://doi.org/10.1080/23808985.2015.11735254. 
- " $[\mathrm{N}]$ egative news frames are likely to have stronger and therefore longer-lasting effects on opinions than positive news frames" 130

\section{Protest and social movement events}

Protest could presumably influence public opinion either by spreading persuasive arguments or affecting how social issues are framed and reported in the media. A recent observational study found that activism by the women's movement has had substantial cumulative effects on gender attitudes such as support for female presidents. ${ }^{131}$ However, other studies suggest that the cumulative effect of social movement protest and mobilization on public opinion is not always significant and positive, as sociologists Edwin Amenta and Francesca Polletta (2019) summarize:

Research indicates that protest may not budge public opinion, as was the case with the Occupy movement and anti-Vietnam War protests. A movement's impact may be canceled out by the impact of a counter movement, as was the case with

\footnotetext{
${ }^{130}$ Sophie Lecheler and Claes H. de Vreese, "How Long Do News Framing Effects Last? A Systematic Review of Longitudinal Studies," Annals of the International Communication Association 40, no. 1 (January 1, 2016): 3-30, https://doi.org/10.1080/23808985.2015.11735254. Relatedly, Richard R. Lau, Lee Sigelman, and Ivy Brown Rovner, "The Effects of Negative Political Campaigns: A Meta-Analytic Reassessment," The Journal of Politics 69, no. 4 (November 1, 2007): 1176-1209, https://doi.org/10.1111/j.1468-2508.2007.00618.x found that negative political ad campaigns "appear to be somewhat more memorable and to generate somewhat greater campaign-relevant knowledge" than positive campaigns although a recent study came to nearly the opposite conclusion (Stephen N. Goggin, "How Quickly We Selectively Forget: Experimental Tests of Information Order on Memory and Candidate Evaluation," Political Psychology 40, no. 1 (2019): 125-45, https://doi.org/10.1111/pops.12499).

${ }^{131}$ Lee Banaszak and Heather Ondercin, "Public Opinion as a Movement Outcome: The Case of the U.S. Women's Movement," Mobilization: An International Quarterly 21 (September 1, 2016): 361-78, https://doi.org/10.17813/1086-671X-21-3-361, an observational analysis of women's movement events between 1960 and 1992, which controls for several potential confounding factors, finds that "a single women's movement event [that was covered in the New York Times] causes aggregate opinion on gender attitudes to shift about two-fifths of a standard deviation." They explain the sort of real-world impact this has: "For example, the General Social Survey asked the question, "If your party nominated a woman for president, would you vote for her if she was qualified for the job?' thirteen times between 1972 and 1991. Over that time period public support for a female president increased from 73.68 percent to 90.62 percent, representing an increase of 16.96 percent. One quarter of this change, or 6.6 percent, can be attributed to the influence of the women's movement."
} 
environmentalists on climate change. Or movement action may backfire, leading to more negative views of the group or issue, as was the case for nuclear freeze proponents. Movements' influence on public opinion may depend on their being endorsed by more mainstream political elites. Anti-Vietnam War sentiment was limited until political leaders and reporters began to criticize the war, and public support for the Equal Rights Amendment in Oklahoma declined after legislators rejected it. At a cross-national level, public opinion on issues of importance to a movement's constituency may be driven more by political regime type, demographics, religion, and economic development than by the existence of a movement. ${ }^{132}$

${ }^{132}$ Edwin Amenta and Francesca Polletta, "The Cultural Impacts of Social Movements," Annual Review of Sociology 45, no. 1 (2019): 279-99, https://doi.org/10.1146/annurev-soc-073018-022342. Citations omitted. 
Some studies find that protests can improve attitudes towards movements' intended beneficiaries

${ }^{133}$ and attitudes towards the movements themselves, ${ }^{134}$ though violent protest can have negative

effects on such attitudes. ${ }^{135}$

Activism can be widely covered in the media, ${ }^{136}$ which can in turn influence the public's

assessment of how important affected issues are. ${ }^{137}$ Relatedly, a number of studies have found

\begin{abstract}
${ }^{133}$ Soumyajit Mazumder, “Black Lives Matter for Whites' Racial Prejudice: Assessing the Role of Social Movements in Shaping Racial Attitudes in the United States" (SocArXiv, May 6, 2019), https://doi.org/10.31235/osf.io/ap46d finds from US survey data that "that the BLM movement was successful in reducing whites' racial prejudice." See also Edwin Amenta and Francesca Polletta, "The Cultural Impacts of Social Movements," Annual Review of Sociology 45, no. 1 (2019): 279-99,

https://doi.org/10.1146/annurev-soc-073018-022342 on how social movements might encourage wider cultural changes.

${ }^{134}$ Kenneth T. Andrews, Kraig Beyerlein, and Tuneka Tucker Farnum, "The Legitimacy of Protest: Explaining White Southerners' Attitudes Toward the Civil Rights Movement," Social Forces 94, no. 3 (March 1, 2016): 1021-44, https://doi.org/10.1093/sf/sov097 analyze "a representative survey conducted in 1961 with nearly 700 white adults living in the South" in logistic regression, including "contextual data measuring local protest, political behavior, and civic organizations," and find evidence that civil rights protests "won sympathy from a small subset of white Southerners, thereby fracturing the dominant consensus in support of Jim Crow segregation."
\end{abstract}

Phillip M. Ayoub, Douglas Page, and Sam Whitt, "Pride amid Prejudice: The Influence of LGBT+ Rights Activism in a Socially Conservative Society," American Political Science Review 115, no. 2 (May 2021): 467-85, https://doi.org/10.1017/S0003055420001082 find, "using nationwide and local panel surveys... that support for LGBT+ activism increased locally after the Pride but did not diffuse nationwide."

Ruud Wouters, "The Persuasive Power of Protest. How Protest Wins Public Support," Social Forces 98, no. 1 (September 1, 2019): 403-26, https://doi.org/10.1093/sf/soy110 finds that "demonstrations that mobilized more diverse participants, who behaved worthy and acted in unison, elicited more supportive reactions."

${ }^{135}$ See, for example, Connor Huff and Dominika Kruszewska, "Banners, Barricades, and Bombs: The Tactical Choices of Social Movements and Public Opinion," Comparative Political Studies 49, no. 13 (November 2016): 1774-1808, https://doi.org/10.1177/0010414015621072, Jordi Muñoz and Eva Anduiza, “"If a Fight Starts, Watch the Crowd': The Effect of Violence on Popular Support for Social Movements," Journal of Peace Research 56, no. 4 (July 1, 2019): 485-98, https://doi.org/10.1177/0022343318820575, and Omar Wasow, "Agenda Seeding: How 1960s Black Protests Moved Elites, Public Opinion and Voting," American Political Science Review 114, no. 3 (August 2020): 638-59, https://doi.org/10.1017/S000305542000009X.

${ }^{136}$ See, for example, Omar Wasow, “Agenda Seeding: How 1960s Black Protests Moved Elites, Public Opinion and Voting," American Political Science Review 114, no. 3 (August 2020): 638-59, https://doi.org/10.1017/S000305542000009X.

${ }^{137}$ On the mechanisms that might explain such an effect, see the section "The media's agenda-setting effects" below. For an example of direct evidence of this process happening due to social movement action, see Tony E. Carey, Regina P. Branton, and Valerie Martinez-Ebers, "The Influence of Social Protests on Issue Salience among Latinos," Political Research Quarterly 67, no. 3 (September 1, 2014): 615-27, https://doi.org/10.1177/1065912914534074. Edwin Amenta and Francesca Polletta, "The Cultural Impacts of Social Movements," Annual Review of Sociology 45, no. 1 (2019): 279-99, https://doi.org/10.1146/annurev-soc-073018-022342 summarize that "movements may not 
that social movement activism can have significant effects on the political agenda, encouraging hearings and the introduction of legislation relevant to the targeted issues. ${ }^{138}$

\section{What are some other causes of public opinion change and how can}

\section{advocates harness them?}

This section does not attempt to review all possible causes of public opinion change; the focus is on factors that seem especially well-studied in the academic literature or especially relevant to social movements targeting moral circle expansion.

\section{The media's persuasive effects}

Psychologists Stuart Oskamp and P. Wesley Schultz (2005) summarize that the scholarly consensus on whether and when the media tends to affect public opinion or not has changed:

The first, a powerful effects model, was dominant from the 1920s through the 1940s, as illustrated in the deep fear of the possibly irresistible effects of propaganda on a defenseless public... It was followed by the minimal effects model, articulated by Klapper (1960), based on the many empirical studies which found no effects or very limited effects of the media in changing people's beliefs, attitudes, and behavior. More recently, a model of powerful effects under limiting conditions has gained more

\footnotetext{
change people's opinions about an issue but rather raise the issue's profile, importance, or salience. This was the case with civil rights (Burstein 1985), immigration (Cary et al. 2014), and lesbian and gay rights (Powell et al. 2010, Woodly 2015)."

${ }^{138}$ See Stefaan Walgrave and Rens Vliegenthart, "The Complex Agenda-Setting Power of Protest: Demonstrations, Media, Parliament, Government, and Legislation in Belgium, 1993-2000," Mobilization: An International Quarterly 17, no. 2 (July 10, 2012): 129-56, https://doi.org/10.17813/maiq.17.2.pw053m281356572h, especially Table 1.
} 
adherents. It denies the early all-powerful view of the media, but stresses that they have important effects in particular circumstances and with particular individuals. Thus current research is apt to focus on the interacting variables and contingent conditions under which media effects will emerge most clearly_for instance, under conditions of heavy viewing and weak prior predispositions. Furthermore, current conceptions include a wide range of media effects — not just changing attitudes, but also forming new attitudes, beliefs, or behaviors, reinforcing already existing ones, and crystallizing previously vague or unstated beliefs or attitudes. ${ }^{139}$

They summarize that there is evidence that, "mass communication usually serves to reinforce existing attitudes and opinions" and "[w]hen mass communication does produce attitude change, minor change in the extremity or intensity of the attitude is much more common than is 'conversion' from one side of an issue to the other side." 140

\footnotetext{
${ }^{139}$ Stuart Oskamp and P. Wesley Schultz, Attitudes and Opinions (New York, NY: Psychology Press, 2005), 191. ${ }^{140}$ Stuart Oskamp and P. Wesley Schultz, Attitudes and Opinions (New York, NY: Psychology Press, 2005), 192. They add that, "[e]xamples of minor change have been shown both with adolescents' traditional sex-role attitudes and with their racial attitudes, which can be shifted in either direction by appropriate television portrayals (e.g., Johnston, Ettema, \& Davidson, 1980; Christenson \& Roberts, 1983). Analogous findings of minor shifts in the area of political attitudes started with the pioneering study of Lazarsfeld et al. (1948). Similarly, a large-scale panel study of television's influence in British elections showed again that attitude changes of most voters were either small or absent altogether. Only about $10 \%$ of voters changed their intended vote from one party to another during the campaign (Blumler \& McQuail, 1969). Even such a major political upheaval as the Watergate scandal, with its massive media coverage, caused relatively small changes in political attitudes among the American public (Robinson, 1974)." On pages 324-5 they likewise summarize that, "[m]ost studies of electioneering propaganda have shown relatively little resulting attitude change — often no change at all. However... In many cases the most important effect of political persuasion may be reinforcement - that is, strengthening people's already existing attitudes," especially given that people often self-select which messages to listen to. Indeed, they note that the candidates who spend the most on political advertising tend to win elections, though this could plausibly be explained by many factors that Oskamp and Schultz do not discuss.
} 
This does not preclude the possibility that advocates could encourage substantial public opinion changes in usual circumstances, such as if they manage to encourage sustained shifts in the overall tone of media coverage. Indeed, there is evidence that where "coverage of a public issue is unbalanced in a pro or con direction, public opinion is likely to shift in that direction subsequently." ${ }^{141}$ This may be tractable if advocates can strategically raise the salience of certain attributes (see "Attribute salience and effects on public opinion" below) or create newsworthy persuasive materials such as documentaries or exposes that shift the balance of what news is being covered. ${ }^{142}$

\footnotetext{
${ }^{141}$ Stuart Oskamp and P. Wesley Schultz, Attitudes and Opinions (New York, NY: Psychology Press, 2005), 197, citing Benjamin I. Page, Robert Y. Shapiro, and Glenn R. Dempsey, "What Moves Public Opinion?," American Political Science Review 81, no. 1 (March 1987): 23-43, https://doi.org/10.2307/1960777, who find that a single positive TV news commentary "is associated with more than four percentage points of opinion change," and cite several studies with similar findings. Relatedly, Frank R. Baumgartner, Suzanna L. De Boef, and Amber E. Boydstun, The Decline of the Death Penalty and the Discovery of Innocence (Cambridge University Press, 2008), 188-215 find that the "net tone" of The New York Times' coverage of the death penalty had significant effects on the "[1]ong run (equilibrium) opinion," but not on public opinion in the short-run. On page 197, Oskamp and Schultz also cite two studies for the claim that, "[i]n almost every election, the great majority of newspapers support the Republican presidential candidate... when other factors are held constant, careful research has shown that these lopsided newspaper endorsements have led several million readers to follow their paper's editorial advice-far more than needed for the winning margin in a close election." On page 202, they even note that research into US presidential elections "has shown that some TV network news anchors displayed systematically different amounts of positive facial expressions when they were mentioning different candidates [and that] the smiles they bestowed on candidates had a favorable impact on viewers' voting on election day." George Lakoff, The All New Don't Think of an Elephant!: Know Your Values and Frame the Debate (White River Junction, VT: Chelsea Green Publishing, 2014), 46 comments that if an individual is repeatedly exposed to conservative language and arguments, this "will activate the conservative moral system, making it a bit stronger every time the language is heard. As the conservative circuitry in her brain becomes stronger (the synapses strengthen), the more likely it is that her views on issues will change from progressive to conservative."

142 Jun Yin, "Elite Opinion and Media Diffusion: Exploring Environmental Attitudes," Harvard International Journal of Press/Politics 4, no. 3 (June 1, 1999): 62-86, https://doi.org/10.1177/1081180X99004003006 found in time series analysis that, "New York Times mentions of [the film] An Inconvenient Truth significantly boosted the public's perception of the urgency of climate change $(\mathrm{P} \leq .001)$. The number of mentions in the New York Times is a proxy for the extent of overall media attention to this film. The release of this movie, and the subsequent Academy Award, generated an enormous level of public attention regarding the threat posed by climate change. This attention translated into an increase in the CCTI [Climate Change Threat Index, which includes measures of perceived threat from climate change from 74 surveys]. For every mention of this movie in the Times, the CCTI increased by .18 points."
} 
There are several theories about how the media influences public opinion. These could be relevant to advocates, but tend to make broad claims and have mixed results in empirical tests. ${ }^{143}$ For example, in the "two-step flow" theory, "a small minority of 'opinion leaders'... act as intermediaries between the mass media and the majority of society," ${ }^{, 44}$ suggesting that it may be most cost-effective to focus resources on changing the opinions of influential audience members. However, some research suggests that, at least in some circumstances, it could be more cost-effective to ignore supposed opinion leaders and focus on whoever can be persuaded most easily. ${ }^{145}$

\section{Moderators}

Oskamp and Schultz (2005) note that, "[m]ass communication can be quite effective in changing attitudes in areas where people's existing opinions are weak" and "can be quite effective in creating opinions on new issues where there are no existing predispositions to reinforce."146

Presumably then, advocates could influence public opinion towards less well-known attributes or

\footnotetext{
${ }^{143}$ See Hans Mathias Kepplinger, "Effects of the News Media on Public Opinion," in The SAGE Handbook of Public Opinion Research, ed. Wolfgang Donsbach and Michael W. Traugott (London, UK: SAGE, 2007), 192-204 for a review.

${ }^{144}$ The definition is from Duncan J. Watts and Peter Sheridan Dodds, "Influentials, Networks, and Public Opinion Formation," Journal of Consumer Research 34, no. 4 (December 1, 2007): 441-58, https://doi.org/10.1086/518527.

For an example of a paper assuming the validity of the two-step model, see Matthew C. Nisbet and John E. Kotcher, "A Two-Step Flow of Influence?: Opinion-Leader Campaigns on Climate Change," Science Communication 30, no. 3 (March 1, 2009): 328-54, https://doi.org/10.1177/1075547008328797

${ }^{145}$ See, for example, Duncan J. Watts and Peter Sheridan Dodds, "Influentials, Networks, and Public Opinion Formation," Journal of Consumer Research 34, no. 4 (December 1, 2007): 441-58, https://doi.org/10.1086/518527.

${ }^{146}$ Stuart Oskamp and P. Wesley Schultz, Attitudes and Opinions (New York, NY: Psychology Press, 2005), 191-3. See also pages 174-5. On page 194, they also note that, "[i]n summarizing research findings on retention [remembering], Petty and Wegener (1998) suggested that message retention may lead to greater attitude change if the message recipient does not already hold a strong, well-thought-out attitude, and if there are no major peripheral cues, such as an expert source, that would influence the attitude. In such situations, the extent to which the individual recalls the content of the persuasive message will lead to attitudes that are more consistent with it."
}

Indeed, other research suggests that persuasive messages tend to have stronger effects on recipients with lower relevant knowledge — see footnote 91 . 
sub-topics (e.g. a specific farming practice) if they are able to shape the initial media coverage. It also suggests that tactics that are aimed at increasing awareness without necessarily being persuasive may be counterproductive for issues where public opinion is currently unfavorable because they may make subsequent attitude change more difficult.

Many of the other moderators described in the section above on "Direct advocacy and persuasion" likely hold in the context of media messaging.

\section{Duration}

Many of the studies of the duration of persuasive effects described in the section above on "Direct advocacy and persuasion" were tested using media articles or data; the effects from a single exposure to persuasive media content will diminish with time, though there may be some lasting effects, and repeated exposure to similar content may encourage longer-term attitude change.

\section{The media's agenda-setting effects}

Agenda-setting research finds evidence that, when the news media covers certain issues, the public tends to increase its evaluation of how important those issues are, i.e. that the media "can have strong, direct effects in the short term by influencing not what people think, but what they think about." ${ }^{147}$ This effect has been identified using a wide variety of methodologies, issue foci, geographical foci, and media types, but the prototypical design is that the media's agenda is

\footnotetext{
${ }^{147}$ Maxwell McCombs and Sebastian Valenzuela, Setting the Agenda: Mass Media and Public Opinion (Cambridge, UK: Polity Press, 2021), 4.
} 
assessed through content analysis, the public's agenda is assessed through survey questions, and the correlation between the two is then estimated. ${ }^{148}$ Luo et al.'s (2019) meta-analysis found that the mean correlation from the 67 included studies was $0.49 .{ }^{149}$ Maxwell McCombs and Sebastian Valenzuela, prominent scholars of the media's agenda-setting effects, summarize in their book Setting the Agenda (2021) evidence that these correlations are usually mostly explained by the media's effect on the public, rather than by the public's effect on the media or some other factor:

- Experiments have also demonstrated the media's agenda-setting effects,

- Comparisons between the media and public agenda at different time points tend to suggest that the media changes focus first, with the public following afterwards, and

- Studies have found correlations between the media and public agendas even when controlling for plausible lurking variables. ${ }^{150}$

\footnotetext{
${ }^{148}$ Maxwell McCombs and Sebastian Valenzuela, Setting the Agenda: Mass Media and Public Opinion (Cambridge, UK: Polity Press, 2021), 8, 19-23, and 36-8. See Maxwell E. McCombs and Donald L. Shaw, "The Agenda-Setting Function of Mass Media," Public Opinion Quarterly 36, no. 2 (January 1, 1972): 176-87, https://doi.org/10.1086/267990 for the prototypical study.

For example, Yunjuan Luo et al., "A Meta-Analysis of News Media's Public Agenda-Setting Effects, 1972-2015," Journalism \& Mass Communication Quarterly 96, no. 1 (March 1, 2019): 150-72,

https://doi.org/10.1177/1077699018804500 found that year of publication and media type (newspaper or otherwise) were not significant factors in their regressions, implying that agenda-setting effects persist despite the introduction of social media and other new media types.

${ }^{149}$ Yunjuan Luo et al., "A Meta-Analysis of News Media's Public Agenda-Setting Effects, 1972-2015,” Journalism \& Mass Communication Quarterly 96, no. 1 (March 1, 2019): 150-72, https://doi.org/10.1177/1077699018804500. This includes both Pearson's product-moment correlations and Spearman's rank correlations.

${ }^{150}$ Maxwell McCombs and Sebastian Valenzuela, Setting the Agenda: Mass Media and Public Opinion (Cambridge, UK: Polity Press, 2021), 9-12, 16-9, 28-31, 50-1, and 122-5. Although there is evidence relating to the direction of causation, most of the reported effect sizes are still simply bivariate correlations, meaning that it is difficult to know the all-things-considered "true" effects of media coverage on the public's agenda.
} 
There is also evidence that the media has various other effects related to its public agenda-setting

function: it can influence the political agenda, ${ }^{151}$ the public's knowledge and perceptions of reality, ${ }^{152}$ and the public's views about which criteria should be used to evaluate politicians. ${ }^{153}$

The agenda-setting hypothesis suggests that advocates can probably influence the public agenda

if they are able to increase media attention to an issue. ${ }^{154}$ The logical next questions are therefore:

can social movements influence the media agenda, and if so, how? These questions are not the

focus of this review, though McCombs and Valenzuela summarize some evidence that public

\footnotetext{
${ }^{151}$ Peter Van Aelst and Stefaan Walgrave, "Political Agenda Setting by the Mass Media: Ten Years of Research, 2005-2015," Handbook of Public Policy Agenda Setting, October 28, 2016, https://www.elgaronline.com/view/edcoll/9781784715915/9781784715915.00018.xml (summarized in Maxwell McCombs and Sebastian Valenzuela, Setting the Agenda: Mass Media and Public Opinion (Cambridge, UK: Polity Press, 2021), 114-5). Frank R. Baumgartner and Bryan D. Jones, Agendas and Instability in American Politics, Second Edition (Chicago, IL: University of Chicago Press, 2010), 74-5, 94-5, 129-30, 153-4, and 161-71 also argue that media salience and tone both tend to affect Congressional attention to topics.

${ }^{152}$ Michael Morgan and James Shanahan, "Two Decades of Cultivation Research: An Appraisal and Meta-Analysis," Annals of the International Communication Association 20, no. 1 (January 1, 1997): 1-45, https://doi.org/10.1080/23808985.1997.11678937. This stream of research assesses the effects of heavier television viewing. Morgan and Shanahan's meta-analysis suggests very small effects and that cultivation effects explain only a very small proportion of variance in answers given to survey questions.

${ }^{153}$ Maxwell McCombs and Sebastian Valenzuela, Setting the Agenda: Mass Media and Public Opinion (Cambridge, UK: Polity Press, 2021), 138-40. For an example of social movement advocacy sparking this sort of priming effect, see Omar Wasow, “Agenda Seeding: How 1960s Black Protests Moved Elites, Public Opinion and Voting," American Political Science Review 114, no. 3 (August 2020): 638-59, https://doi.org/10.1017/S000305542000009X. For a critique of the "priming hypothesis" and proposition of an alternative explanation for the observed effects, see Gabriel S. Lenz, "Learning and Opinion Change, Not Priming: Reconsidering the Priming Hypothesis," American Journal of Political Science 53, no. 4 (2009): 821-37, https://doi.org/10.1111/j.1540-5907.2009.00403.x.

${ }^{154} \mathrm{~A}$ lot of the agenda-setting research focuses primarily on political elections and the surrounding public discussion. Maxwell McCombs and Sebastian Valenzuela, Setting the Agenda: Mass Media and Public Opinion (Cambridge, UK: Polity Press, 2021) do not explicitly address whether agenda-setting theory would apply in the context of social movements seeking an expansion of the moral circle, but do provide some examples relating to such movements - these examples are mixed, sometimes demonstrating agenda-setting effects and sometimes detecting no effect (see pages 15, 34-5, 55, 58, 104, and 127).
} 
relations professionals have a substantial influence on the media agenda ${ }^{155}$ and some studies have found that social movement protests have influenced media coverage and the public agenda. ${ }^{156}$

\section{Moderators}

McCombs and Valenzuela provide evidence that the media tends to have weaker effects if the public has high personal experience of an issue or is otherwise already relatively certain about an issue's importance. ${ }^{157}$ For example, studies have found lower correlations between media coverage and the public's perceived importance of issues like crime and the cost of living which affect the public very directly — than between media coverage and the public's perceived importance of issues like pollution, drug abuse, and energy. ${ }^{158}$ One implication of these findings for social movements is that successfully attracting media coverage of institutional campaigns may have a stronger agenda-setting effect than successfully attracting media coverage of individual diet change topics.

\footnotetext{
${ }^{155}$ Maxwell McCombs and Sebastian Valenzuela, Setting the Agenda: Mass Media and Public Opinion (Cambridge, UK: Polity Press, 2021), 115-21. They note, for example, that, "[a] seminal examination of the New York Times and Washington Post across a twenty-year period found that nearly half of their news stories were substantially based on press releases and other direct information subsidies. Some 17.5 per cent of the total number of news stories appearing in these newspapers was based, at least in part, on press releases. Press conferences and background briefings accounted for another 32 per cent." There are many resources providing advice on how to implement successful public relations campaigns, such as Ronald D. Smith, Strategic Planning for Public Relations (New York, NY: Routledge, 2017), https://doi.org/10.4324/9781315270876, especially pages 196-202.

${ }^{156}$ See footnotes 136 and 137.

${ }^{157}$ Maxwell McCombs and Sebastian Valenzuela, Setting the Agenda: Mass Media and Public Opinion (Cambridge, UK: Polity Press, 2021), 73-81.

${ }^{158}$ Maxwell McCombs and Sebastian Valenzuela, Setting the Agenda: Mass Media and Public Opinion (Cambridge, UK: Polity Press, 2021), 10 and 81-4. They also discuss the idea that the media has weaker effects when the public perceives an issue to be of low "relevance," but the usage seems tautological — the public doesn't consider something to be important if they don't consider it to be relevant. Little evidence is provided for the claim, and it seems to contrast directly with the explanation of how "personal experience" moderates agenda setting effects.
} 
Relatedly, McCombs and Valenzuela summarize one study which seems to suggest that media coverage may have lower agenda-setting effects if the public already has higher awareness about a topic. ${ }^{159}$ This suggests that if certain topics have been on the agenda for some time already, further efforts to raise their salience may be less effective.

Demographic variables tend to have little or no moderating effect on agenda setting. There is evidence from several studies that people with more years of education more closely mirror the media agenda, though the difference is very small. ${ }^{160}$

\section{Duration}

McCombs and Valenzuela summarize that, "the point of decay of agenda-setting effects, defined as the point in time where significant correlations between the media agenda and the public agenda disappear, ranges from eight to twenty-six weeks." ${ }^{, 161}$ This suggests that advocates should usually not attempt to increase the salience of certain topics via the media unless they suspect that they will be able to sustain high media attention, since, if they are only successful in temporarily raising media attention, the effects on the public's perceptions of its importance will also be short-lived.

\footnotetext{
${ }^{159}$ Maxwell McCombs and Sebastian Valenzuela, Setting the Agenda: Mass Media and Public Opinion (Cambridge, UK: Polity Press, 2021), 89-90. Although they don't discuss this, it seems plausible that prior knowledge might also help to explain why the media has lower agenda-setting effects on topics where the public has high personal experience.

${ }^{160}$ Maxwell McCombs and Sebastian Valenzuela, Setting the Agenda: Mass Media and Public Opinion (Cambridge, UK: Polity Press, 2021), 98-9. They note, for example, that in one study, "individual differences defined by education and family income accounted for only 2 per cent of the variance in salience, while the wide swings from year to year attributable to variations in the news coverage accounted for 37 per cent."

${ }^{161}$ Maxwell McCombs and Sebastian Valenzuela, Setting the Agenda: Mass Media and Public Opinion (Cambridge, UK: Polity Press, 2021), 105-6.
} 
Advocates might also seek to increase salience if they have specific, strategic goals in mind for why higher salience will be useful at a particular time, e.g. to support a legislative campaign on an issue with high public support. McCombs and Valenzuela note, however, that, "the span of time involved in the transfer of issue salience from the media to the public agenda is generally in the range of four to eight weeks," 162 so advocates need to account for this time lag in their planning.

\section{Attribute salience and effects on public opinion}

The "first level" of agenda setting research focuses on assessing whether and how media attention influences the salience and perceived importance of certain "objects" (i.e. topics) among the public, while the "second level" assesses whether and how media attention influences the salience and perceived importance of more specific attributes of those objects. ${ }^{163}$ Luo et al. (2019) found that the correlations tended to be larger in studies of first level agenda-setting than studies of second-level agenda-setting — this difference was significant at $p<.10(\beta=0.53) .{ }^{164}$ McCombs and Valenzuela also note that the media only seems to have much of a second level agenda-setting effect where "both the political system and the news media are reasonably open and free." 165

\footnotetext{
${ }^{162}$ Maxwell McCombs and Sebastian Valenzuela, Setting the Agenda: Mass Media and Public Opinion (Cambridge, UK: Polity Press, 2021), 103-5.

${ }^{163}$ Maxwell McCombs and Sebastian Valenzuela, Setting the Agenda: Mass Media and Public Opinion (Cambridge, UK: Polity Press, 2021), 44.

${ }^{164}$ Yunjuan Luo et al., "A Meta-Analysis of News Media's Public Agenda-Setting Effects, 1972-2015,” Journalism \& Mass Communication Quarterly 96, no. 1 (March 1, 2019): 150-72, https://doi.org/10.1177/1077699018804500. Note that this is a more relaxed threshold for detecting significant effects than is conventionally used in most research. Maxwell McCombs and Sebastian Valenzuela, Setting the Agenda: Mass Media and Public Opinion (Cambridge, UK: Polity Press, 2021), 117-26 also provide a few examples of where a greater proportion of the correlation between the attribute salience (as opposed to object salience) in the media and public is explainable due to lurking variables such as politicians' attention to them.

${ }^{165}$ Maxwell McCombs and Sebastian Valenzuela, Setting the Agenda: Mass Media and Public Opinion (Cambridge, UK: Polity Press, 2021), 47-9.
} 
There is some evidence that increases in the salience of certain attributes can have disproportionately large effects on the salience of the broader object. ${ }^{166}$ More importantly, there is also evidence that certain attributes tend to be covered in a more positive tone in the media than other attributes; if those attributes (and their corresponding more or less positive coverage ${ }^{167}$ ) become more salient, then this can affect public opinion on the topic as a whole. ${ }^{168}$ This suggests that advocates can potentially alter both the public's perceived importance of a topic and public opinion on that topic by identifying specific attributes that tend to be seen more or less positively, then strategically raising the salience of certain attributes while avoiding raising the salience of others.

\section{Politicians and celebrities}

Politicians and celebrities can advocate particular ideas — presumably their persuasion efforts may be successful and are subject to the same moderators as other communicators. ${ }^{169}$ A number of studies have directly evaluated the persuasive and agenda-setting effects of politicians and celebrities too.

\footnotetext{
${ }^{166}$ Maxwell McCombs and Sebastian Valenzuela, Setting the Agenda: Mass Media and Public Opinion (Cambridge, UK: Polity Press, 2021), 55-8. Frank R. Baumgartner, Suzanna L. De Boef, and Amber E. Boydstun, The Decline of the Death Penalty and the Discovery of Innocence (Cambridge University Press, 2008), 136-65 provides theoretical reasons to expect that the rise of the innocence frame caused a rise in the use of other anti-death penalty framing types, but the provided evidence is correlational, not causal.

${ }^{167}$ It also seems plausible that, even if the overall tone of the media coverage doesn't change notably, highlighting certain attributes over others could change the audience's attitudes - see the section on "Framing."

${ }^{168}$ Maxwell McCombs and Sebastian Valenzuela, Setting the Agenda: Mass Media and Public Opinion (Cambridge, UK: Polity Press, 2021), 140-2, citing Frank R. Baumgartner and Bryan D. Jones, Agendas and Instability in American Politics, Second Edition (Chicago, IL: University of Chicago Press, 2010) and several other studies. On the effects of positive versus negative tone in news coverage more generally, see footnote 141.

${ }^{169}$ See the subsection on "Moderators" in the section on "Direct advocacy and persuasion" above.
} 
Several studies suggest that politicians can increase approval for specific policies by framing them as directed towards broad goals that the public support, ${ }^{170}$ and numerous others suggest that presidents can intentionally shape public opinion through persuasive messaging. ${ }^{171}$ Benoit et al.'s (2003) meta-analysis found that viewing US presidential debates had an effect size of .14 (95\% CI .03-.32, $\mathrm{k}=4$ ) on "preference for one candidate's issue positions over another's." ${ }^{172}$ So presidents can influence public opinion, though the effects may be small.

There is also evidence that political parties' positions influence the attitudes of partisan supporters. ${ }^{173}$ This influence may be stronger when party positions are polarized ${ }^{174}$ and when the

\footnotetext{
${ }^{170}$ Stuart Oskamp and P. Wesley Schultz, Attitudes and Opinions (New York, NY: Psychology Press, 2005), 315-6 summarize three such studies providing significant positive evidence of this.

${ }^{171}$ See, for example, Joshua B. Hill, Willard M. Oliver, and Nancy E. Marion, "Presidential Politics and the Problem of Drugs in America: Assessing the Relationship Between the President, Media, and Public Opinion," Criminal Justice Policy Review 23, no. 1 (March 1, 2012): 90-107, https://doi.org/10.1177/0887403410396211, Jeffrey E. Cohen, "Presidential Leadership of Public Opinion: An Embedded Survey Experiment," Political Communication 32, no. 3 (July 3, 2015): 345-55, https://doi.org/10.1080/10584609.2014.944321, Brandon Rottinghaus, "Presidential (Non) Leadership of Public Opinion, 1953-2001," White House Studies 6, no. 3 (June 22, 2006): 309-27, Jeffery J. Mondak et al., "Presidential Source Cues and Policy Appraisals, 1981-2000:," American Politics Research, July 26, 2016, https://doi.org/10.1177/1532673X03259940, and Brandon Rottinghaus, "Strategic Leaders: Determining Successful Presidential Opinion Leadership Tactics Through Public Appeals," Political Communication 26, no. 3 (July 31, 2009): 296-316, https://doi.org/10.1080/10584600903053510.

Note, however, that the findings are not always significant and positive. I have not sought to aggregate all such relevant research or identified a more recent review than William L. Benoit, Glenn J. Hansen, and Rebecca M. Verser, "A Meta-Analysis of the Effects of Viewing U.S. Presidential Debates," Communication Monographs 70, no. 4 (December 1, 2003): 335-50, https://doi.org/10.1080/0363775032000179133, despite checking the titles of all 360 items citing that paper.

${ }^{172}$ William L. Benoit, Glenn J. Hansen, and Rebecca M. Verser, "A Meta-Analysis of the Effects of Viewing U.S. Presidential Debates," Communication Monographs 70, no. 4 (December 1, 2003): 335-50, https://doi.org/10.1080/0363775032000179133.

${ }^{173}$ Rune Slothuus and Martin Bisgaard, "How Political Parties Shape Public Opinion in the Real World," American Journal of Political Science, November 4, 2020, https://doi.org/10.1111/ajps.12550..

${ }^{174}$ James N. Druckman, Erik Peterson, and Rune Slothuus, "How Elite Partisan Polarization Affects Public Opinion Formation," American Political Science Review 107, no. 1 (February 2013): 57-79, https://doi.org/10.1017/S0003055412000500 and Alexandra Guisinger and Elizabeth N. Saunders, "Mapping the Boundaries of Elite Cues: How Elites Shape Mass Opinion across International Issues," International Studies Quarterly 61, no. 2 (June 1, 2017): 425-41, https://doi.org/10.1093/isq/sqx022.
} 
public is less informed about an issue. ${ }^{175}$ Cumulatively, repeated cues from political elites

pushing in a certain direction could have substantial effects on public opinion, whereas

competing partisan cues in polarized debates could roughly balance each other out and

potentially even drown out the effects of other persuasion efforts. ${ }^{176}$

In addition to altering attitudes through persuasion or reframing, politicians can affect the

public's perceptions of the importance of issues via comments, actions, and press releases that

are reported in the media. ${ }^{177}$ Benoit et al.'s (2003) meta-analysis found that US presidential

debates had a mean weighted agenda-setting effect size of $.29(95 \% \mathrm{CI} .22-.44, \mathrm{k}=3) .{ }^{178}$

There is evidence that celebrities can have substantial effects on attitudes, though they are not always more effective than alternative spokespeople. ${ }^{179}$ Some advertising studies have found

\footnotetext{
${ }^{175}$ John G. Bullock, "Elite Influence on Public Opinion in an Informed Electorate," American Political Science Review 105, no. 3 (August 2011): 496-515, https://doi.org/10.1017/S0003055411000165.

${ }^{176}$ Jun Yin, "Elite Opinion and Media Diffusion: Exploring Environmental Attitudes," Harvard International Journal of Press/Politics 4, no. 3 (June 1, 1999): 62-86, https://doi.org/10.1177/1081180X99004003006 found in time series analysis that, " $[\mathrm{w}]$ hen Democrats released public statements promoting action to address climate change, the CCTI [Climate Change Threat Index, which includes measures of perceived threat from climate change from 74 surveys] increased significantly ( $\mathrm{P} \leq .001)$. For each statement, the CCTI increased .25 points. Similarly, when Congressional Republicans released public statements opposing climate change action, the CCTI index declined significantly $(\mathrm{P} \leq .05)$. Each Republican statement drove the index down .17 points." The author concludes that this affirms the claim of other researchers that, "[w]hen elites have consensus, the public follows suit and the issue becomes mainstreamed. When elites disagree, polarization occurs, and citizens rely on other indicators, such as political party or source credibility, to make up their minds." They comment that, "[g]iven the vested economic interests reflected in this polarization, it seems doubtful that any communication process focused on persuading individuals will have much impact." I have not searched thoroughly for other studies using similar methods to see if they support this claim, though it does seem consistent with what we might expect from the research on persuasion and the media's persuasion effects (see the relevant sections above).

${ }^{177}$ Maxwell McCombs and Sebastian Valenzuela, Setting the Agenda: Mass Media and Public Opinion (Cambridge, UK: Polity Press, 2021), 117-26.

${ }^{178}$ William L. Benoit, Glenn J. Hansen, and Rebecca M. Verser, "A Meta-Analysis of the Effects of Viewing U.S. Presidential Debates," Communication Monographs 70, no. 4 (December 1, 2003): 335-50, https://doi.org/10.1080/0363775032000179133.

179 Johannes Knoll and Jörg Matthes, “The Effectiveness of Celebrity Endorsements: A Meta-Analysis,” Journal of the Academy of Marketing Science 45, no. 1 (January 2017): 55-75, https://doi.org/10.1007/s11747-016-0503-8 "observed no significant overall effect of the celebrity endorsements on participants' responses $(\mathrm{d}=.04,95 \% \mathrm{CI}$
} 
support for the "matchup hypothesis," where "[c]elebrities or other endorsers are particularly apt

to enhance consumer attitudes when their characteristics 'match up with' or are relevant to the product being promoted," ${ }^{180}$ and we might expect a similar effect to hold for promotion of policies.

Even if celebrities or politicians are not seen as credible to speak on a particular issue, their involvement could be beneficial if it helps to bring attention to certain issues and arguments, either through a second-level agenda-setting effect ${ }^{181}$ or because it increases the prevalence of persuasive arguments pushing in a certain direction. ${ }^{182}$ But their involvement could backfire for the same reasons, so it seems more important to focus on getting these public figures promoting the right messages than on maximizing their general discussion of an issue.

$(-.09, .17), \mathrm{ns})$. However, highly significant heterogeneity was found among effect sizes." They find evidence that "celebrity endorsements perform worse compared to quality seals, award endorsements, or endorser brands, but they perform better when compared to no endorsement." Additionally, "[t]he most positive attitudinal effect appeared for male actors who match well with an implicitly endorsed object $(\mathrm{d}=.90)$. The most negative effect was found for female models not matching well with an explicitly endorsed object $(\mathrm{d}=-.96) . "$

Craig Garthwaite and Timothy J. Moore, "Can Celebrity Endorsements Affect Political Outcomes? Evidence from the 2008 US Democratic Presidential Primary," The Journal of Law, Economics, and Organization 29, no. 2 (April 1, 2013): 355-84, https://doi.org/10.1093/jleo/ewr031 estimate that Oprah Winfrey's endorsement of Barack Obama before the 2008 Democratic presidential primary increased Obama's votes by over one million. However, they note that Winfrey "is regarded as one of the most influential public figures in the United States. If a celebrity endorsement is ever going to have an empirically identifiable influence, then it is likely to be hers."

${ }^{180}$ Richard M. Perloff, The Dynamics of Persuasion: Communication and Attitudes in the Twenty-First Century, 6th ed. (New York, NY: Routledge, 2017), https://doi.org/10.4324/9781315657714.

${ }^{181}$ See the subsection on "Attribute salience and effects on public opinion" in the section on "The media's agenda-setting effects" above. For an example of celebrities influencing media coverage of political issues, see Matthew D Atkinson and Darin DeWitt, "Does Celebrity Issue Advocacy Mobilize Issue Publics?," Political Studies 67, no. 1 (February 1, 2019): 83-99, https://doi.org/10.1177/0032321717751294.

${ }^{182}$ See footnote 141 . There is also empirical support for a "sleeper effect" where "a message initially discounted by message receivers comes to be accepted over time," such as when "messages disseminated by low-credibility communicators can come to be viewed as true over time, particularly if they are memorable" (see Richard M. Perloff, The Dynamics of Persuasion: Communication and Attitudes in the Twenty-First Century, 6th ed. (New York, NY: Routledge, 2017), 374-7 https://doi.org/10.4324/9781315657714. This has been found in the context of celebrity endorsements of brands (Johannes Knoll et al., "How Long Does Celebrity Meaning Transfer Last? Delayed Effects and the Moderating Roles of Brand Experience, Celebrity Liking, and Age," International Journal of Advertising 36, no. 4 (July 4, 2017): 588-612, https://doi.org/10.1080/02650487.2016.1213062). 


\title{
Policy change
}

Oskamp and Schultz (2005) summarize several studies showing that public opinion often follows

US foreign policy quite closely. ${ }^{183}$ There is evidence from observational analyses and social

movement case studies that public opinion changes can occur from policies affecting social

issues and the breadth of the moral circle, too. For example, numerous countries have seen public

support for the death penalty decline since it was abolished. ${ }^{184}$ Some studies suggest that

international policies and policies in neighboring jurisdictions can also affect public opinion. ${ }^{185}$

\begin{abstract}
${ }^{183}$ Stuart Oskamp and P. Wesley Schultz, Attitudes and Opinions (New York, NY: Psychology Press, 2005), 289-90.
${ }^{184}$ See the strategic implication beginning "Abolition of a practice seems likely..." in Jamie Harris, Jacy Reese Anthis, and Kelly McNamara, "Social Movement Lessons from the US Anti-Death Penalty Movement," May 22, 2020, https://sentienceinstitute.org/death-penalty. For other examples, see the paragraph beginning "An important question for the farmed..." in Jamie Harris, Jacy Reese Anthis, and Kelly McNamara, "Social Movement Lessons From the US Anti-Abortion Movement," November 26, 2019, https://sentienceinstitute.org/anti-abortion, the section on "The effect of the law on public opinion" in Animal Charity Evaluators, "Children's Rights Report," February 2018, https://animalcharityevaluators.org/research/social-movement-analysis/childrens-rights/, and Stuart Oskamp and P. Wesley Schultz, Attitudes and Opinions (New York, NY: Psychology Press, 2005), 403.
\end{abstract}

Lee Banaszak and Heather Ondercin, "Public Opinion as a Movement Outcome: The Case of the U.S. Women's Movement," Mobilization: An International Quarterly 21 (September 1, 2016): 361-78, https://doi.org/10.17813/1086-671X-21-3-361 find that their "feminist-laws measure [which] is a count of the number of feminist bills signed into law each quarter" is the strongest predictor of their measure of gender attitudes — the coefficient is around three times the strength of their measure of women's workforce participation or the number of feminist events. Anne N. Costain and Steven Majstorovic, "Congress, Social Movements and Public Opinion: Multiple Origins of Women's Rights Legislation," Political Research Quarterly 47, no. 1 (March 1, 1994): 111-35, https://doi.org/10.1177/106591299404700106 find evidence that "Congress both led opinion and followed it."

However, Oskamp and Schultz summarize on pp. 289-90 that "[i]t is in the field of foreign affairs that public opinion most often follows rather than leads official policy. This is probably because public ignorance of and indifference to policy issues tend to be proportional to the issues' geographic distance from home, so most foreign affairs engage little citizen attention and develop public attitudes that are weakly held and rather easily changed." On pages 315-6, they make a similar point about presidents' ability to lead public opinion.

${ }^{185}$ Adam Chilton, "Experimentally Testing the Effectiveness of Human Rights Treaties," SSRN Scholarly Paper (Rochester, NY: Social Science Research Network, April 14, 2017), https://doi.org/10.2139/ssrn.2615143, section V summarizes a number of experiments that have demonstrated that highlighting international human rights agreements has significant effects on expressed support for a number of related policies — including when compared to very similarly worded conditions that do not mention international agreements explicitly.

Julianna Pacheco, "The Social Contagion Model: Exploring the Role of Public Opinion on the Diffusion of Antismoking Legislation across the American States," The Journal of Politics 74, no. 1 (January 1, 2012): 187-202, https://doi.org/10.1017/S0022381611001241 finds that both the proportion of neighboring states with smoking bans 
When the Supreme Court makes a decision, this tends to cause public opinion to move towards

the opinion implied by that decision, though this does not always happen. ${ }^{186}$ This all suggests that

if advocates can encourage policy change, public opinion will tend to move towards support for

those policies. Nevertheless, political scientist James Stimson (2015) presents evidence that

public preferences regarding the general direction of further government action sometimes shift

in the opposite direction to trends in government policy itself. ${ }^{187}$

\section{Indirect or long-term factors}

Reliably changing public opinion is less tractable if the main causes of fluctuations are

slow-moving and long-term, or only have an indirect relationship to change and are therefore

difficult to predict and control. ${ }^{188}$

in restaurants and whether or not the respondent's home state has adopted a smoking ban in restaurants were significant predictors of individual support for smoking bans in restaurants after controlling for a number of other factors. They conduct an additional test which suggests that the effect of bans in neighboring states is due to knowledge of those policies rather than advocacy by the politicians. An additional model using aggregate level data "suggests that as the proportion of neighboring states adopts smoking bans in restaurants, public support for such policies increases in the short run, but not the long term. For instance, a .20 increase in the proportion of neighboring states with antismoking legislation (which is roughly 2 standard deviations above the mean change) increase public support for smoking bans in restaurants in the next year by a third of a percent."

${ }^{186}$ See "Public Opinion" in Jamie Harris and Jacy Reese Anthis, "Is the US Supreme Court a Driver of Social Change or Driven by It? A Literature Review," Literature Reviews, November 27, 2019, https://sentienceinstitute.org/scotus.

${ }^{187}$ James A. Stimson, Tides of Consent: How Public Opinion Shapes American Politics (Cambridge University Press, 2015), chapter 2 provides evidence for this from a number of issues, including on abortion, the environment, taxes, and welfare. These shifts in policy preferences are contrasted to underlying "Support for desegregation (blacks), equal roles (women), and equal job rights (homosexuals)" which have tended to trend upwards. On page 32, Stimson theorizes that "government, which wishes to be popular, will sense the change in majority sentiment and move to a warmer setting to appeal to it. Having done so, it will change the sentiment back toward a neutral level. The majority that wanted 'warmer' got 'warmer,' and now only smaller numbers of heat extremists will insist on 'warmer' still. The consequence, if government is adaptive in this sense, is that no policy preference will ever trend permanently in one direction." Stimson argues in chapters 2 and 3 that these changes are mostly related to the Republican-Democratic Party splits on these issues.

${ }^{188}$ For some discussion of how such factors affect the tractability of change (not focused on public opinion per se), see Jamie Harris and Jacy Reese Anthis, "How Tractable Is Changing the Course of History?," Sentience Institute (blog), April 12, 2019, http://www.sentienceinstitute.org/blog/how-tractable-is-changing-the-course-of-history. 
Referring to the impact of events on public opinion about foreign policy, Oskamp and Schultz (2005) summarize that:

[E]ven spectacular events have no effect on attitudes, or they may cause only a brief fluctuation followed by a return to the preexisting attitude... When rapid attitude shifts occur, they are usually related to major events in international affairs or in the economy, such as the improvement in U.S.-Soviet relations that took place under Gorbachev, and particularly the fall of the Berlin Wall, which signaled the end of the Cold War. As a contrasting example, after the Chinese army's massacre of student protesters in Tiananmen Square in 1989, the percentage of Americans who expressed favorable opinions of China plunged briefly from $72 \%$ to $31 \%$. However, even the most dramatic changes in political alignments usually involve attitude changes by only $20 \%$ to $30 \%$ of the population, and such changes almost always involve a combination of spectacular events and cumulative events. Either type of event alone is apt to produce attitude changes of no more than $10 \% .{ }^{189}$

External events have been found to affect a range of other social and political attitudes, such as hurricanes affecting support for pro-environmental politicians, financial crisis affecting support for conservative economic policies, and nuclear disaster decreasing support for the use of nuclear

\footnotetext{
${ }^{189}$ Stuart Oskamp and P. Wesley Schultz, Attitudes and Opinions (New York, NY: Psychology Press, 2005), 372-3. This seems consistent with examples I have seen.
} 
power. ${ }^{190}$ However, as with the events affecting foreign policy opinions, their effects are often small or temporary. ${ }^{191}$

Public opinion surveys usually find that some demographic variables are statistically significant predictors. For example, Sentience Institute's US surveys find that women, younger people, more liberal people, Democrats, black and Hispanic people, people from the Northeast of the US, and vegetarians and vegans have significantly higher Animal Farming Opposition than other respondents. ${ }^{192}$ We should expect, then, that demographic trends might lead to changes in overall public opinion, ${ }^{193}$ though such changes might be slow and difficult to detect. ${ }^{194}$

${ }^{190}$ Dolores Albarracin and Sharon Shavitt, “Attitudes and Attitude Change," Annual Review of Psychology 69, no. 1 (2018): 315-6, https://doi.org/10.1146/annurev-psych-122216-011911 and J. Mohorčich and Jacy Reese Anthis, "What Can Nuclear Power Teach Us about the Institutional Adoption of Clean Meat?," Technology Adoption Case Studies, November 28, 2017, https://sentienceinstitute.org/nuclear-power-clean-meat. Chapter 4 in Robert S. Erikson and Kent L. Tedin, American Public Opinion: Its Origins, Content and Impact (Abingdon, UK: Routledge, 2015) discusses trends on public opinion on some major issues; some key events are mentioned as potentially influencing the trends, but Erikson and Kent don't attempt to rigorously evaluate what caused changes.

${ }^{191}$ For example, even the Chernobyl disaster did little to dent long-term rises in support for nuclear power usage in France (J. Mohorčich and Jacy Reese Anthis, "What Can Nuclear Power Teach Us about the Institutional Adoption of Clean Meat?," Technology Adoption Case Studies, November 28, 2017,

https://sentienceinstitute.org/nuclear-power-clean-meat). Jun Yin, "Elite Opinion and Media Diffusion: Exploring Environmental Attitudes," Harvard International Journal of Press/Politics 4, no. 3 (June 1, 1999): 62-86, https://doi.org/10.1177/1081180X99004003006 found no significant effects of weather events on public opinion on climate change in time series analysis.

192 Jacy Reese Anthis and Ali Ladak, "Animals, Food, and Technology (AFT) Survey: 2020 Update," Surveys, March 17, 2021, https://sentienceinstitute.org/aft-survey-2020.

${ }^{193}$ See, for example, Matthew E. Kahn, "Demographic Change and the Demand for Environmental Regulation," Journal of Policy Analysis and Management 21, no. 1 (2002): 45-62, https://doi.org/10.1002/pam.1039 for discussion of this hypothesis with reference to a specific policy issue. Chapter 4 in Robert S. Erikson and Kent L. Tedin, American Public Opinion: Its Origins, Content and Impact (Abingdon, UK: Routledge, 2015) discusses trends on public opinion on some major issues; some demographic shifts are mentioned as potentially influencing the trends, but Erikson and Kent don't attempt to rigorously evaluate what caused changes.

${ }^{194}$ For example, overall attitudes to US abortion have changed little in the late 20th and early 21 st century demographic trends might lead us to conclude that this should be counted as a moderate success for the anti-abortion movement, though it is difficult to distinguish the effects of demographic shifts, advocacy efforts, and other factors (see "Changes to public opinion" in Jamie Harris, Jacy Reese Anthis, and Kelly McNamara, "Social Movement Lessons From the US Anti-Abortion Movement," November 26, 2019, https://sentienceinstitute.org/anti-abortion).

Rima Wilkes and Catherine Corrigall-Brown, "Explaining Time Trends in Public Opinion: Attitudes towards Immigration and Immigrants," International Journal of Comparative Sociology 52, no. 1-2 (February 1, 2011): 79-99, https://doi.org/10.1177/0020715210379460 find that "in Canada, changing attitudes over time are the result 
Of course, even if advocates cannot easily influence indirect or long-term factors, they may be able to take advantage of them. For example, it might be possible to implement institutional changes during a temporary spike in public support for certain policies.

\section{Limitations}

- Where I have cited textbooks in this review, I have not tended to look up the individual citations for the claims made. Often, the textbooks will provide a general characterization of certain streams of research and then provide a small number of illustrative examples, rather than rigorously reviewing the strength of evidence for various claims. In this sense, it is possible that some of the characterizations here do not actually have much supporting evidence. $^{195}$

of an ideological shift towards greater acceptance of immigration and immigrants as well as a response to changing macro-conditions." Increasing education and employment rates were both associated with positive attitudes towards immigration and immigrants.

${ }^{195}$ The textbooks seem to usually strive for impartial overviews of topics, though there are some exceptions like Maxwell McCombs and Sebastian Valenzuela, Setting the Agenda: Mass Media and Public Opinion (Cambridge, UK: Polity Press, 2021) which clearly intends to demonstrate the importance and thoroughness of agenda-setting research. Additionally, all of the cited textbooks have very high citation counts, which would presumably not happen if the claims were not mostly credible, although provocative arguments could also generate high citation counts.

I didn't often notice textbooks give conflicting interpretations of the scholarly consensus on key topics. For example, Stuart Oskamp and P. Wesley Schultz, Attitudes and Opinions (New York, NY: Psychology Press, 2005), 204 support the general thrust of McCombs and Valenzuela's (2021) book through the comment that, "[p]robably the most important effect of the mass media is their agenda-setting function." Though they note that, "[t]he causal direction of agenda-setting effects is an important question," they summarize several longitudinal and experimental studies addressing the question and conclude that "it appears clear that the various mass media all fulfill the agenda-setting function.” The following few chapters of Oskamp and Schultz's textbook overlap substantially with the content and summaries in Daniel J. O'Keefe, Persuasion: Theory and Research (Los Angeles, CA: SAGE Publications, 2015) and Richard M. Perloff, The Dynamics of Persuasion: Communication and Attitudes in the Twenty-First Century, 6th ed. (New York, NY: Routledge, 2017), https://doi.org/10.4324/9781315657714. Although focusing on ostensibly different topics, there was some overlap in the conclusions and implications of O'Keefe (2015), Oskamp and Schultz (2005), and Dennis Chong and James N. Druckman, "Framing Theory," Annual Review 
- Reviewed research items often discussed the strengths and weaknesses of different research approaches (e.g. field studies vs. laboratory experiments) and whether the key assumptions of various theories had been tested directly or indirectly, but rarely assessed the risk of bias in included studies.

- I have attempted to avoid selective reporting of findings, but I have not attempted to make the coverage of particular topics in this review systematic or comprehensive. It is possible that some of the findings cited here have been critiqued and challenged by other research that I have not seen.

- Given the many different streams of research relating to the causes of public opinion change, it is likely that some have accidentally been missed. Others have been intentionally excluded in the interests of brevity (e.g. if they had unclear implications for advocacy).

- This review mostly focuses on strategies or factors influencing public opinion that are well-studied in the academic literature. It may therefore miss effective but less well-studied strategies.

\section{Further research}

- This review has focused on the causes of public opinion change under the assumption that public opinion is important for at least some institutional and social movement outcomes. This assumption has been evaluated by sociologists and political scientists -

of Political Science 10, no. 1 (2007): 103-26, https://doi.org/10.1146/annurev.polisci.10.072805.103054, such as noting that it is harder to change the attitudes of individuals with more extreme prior attitudes. 
a review of relevant research on the effects of public opinion change could be informative both for testing the assumption and assessing how to most effectively encourage the intended outcomes. It could also shed further light on the questions examined in this review, since in asking how advocacy and public opinion affect policy, researchers sometimes implicitly evaluate how advocacy affects public opinion. ${ }^{196}$

- This review has covered a wide range of topics fairly briefly; more systematic, in-depth reviews of some of these topics could be valuable. For example, there does not currently seem to be a meta-analysis or detailed review of the effects of protests and activism on public opinion, even though a number of studies exist on this topic. Additionally, a more comprehensive comparison of the effect sizes of various intervention types on public opinion could be valuable, albeit time consuming. ${ }^{197}$

- Experiments could be conducted to more directly assess the relative effectiveness of different influences on public opinion. For example, which matters more: the frames used in media coverage (e.g. animal protection vs. environmental vs. human health focus), or the tone (positive or negative)? Which has a larger effect: a story about a favorable speech by a politician or a story about a well-attended public protest?

- Experiments could be conducted that test out findings from persuasion research specifically in the context of social movements focusing on moral circle expansion. For

\footnotetext{
${ }^{196}$ See, for example, Paul Burstein, American Public Opinion, Advocacy, and Policy in Congress: What the Public Wants and What It Gets (Cambridge University Press, 2014) and Doug McAdam and Yang Su, "The War at Home: Antiwar Protests and Congressional Voting, 1965 to 1973," American Sociological Review 67, no. 5 (2002): 696-721, https://doi.org/10.2307/3088914.

${ }^{197}$ Methods of synthesis and analysis comparable to those in Jamie Harris, Jacy Reese Anthis, and Kelly Anthis, "Health Behavior Interventions Literature Review," July 24, 2020, https://sentienceinstitute.org/health-behavior or Stephen A. Rains, Timothy R. Levine, and Rene Weber, "Sixty Years of Quantitative Communication Research Summarized: Lessons from 149 Meta-Analyses," Annals of the International Communication Association 42, no. 2 (April 3, 2018): 105-24, https://doi.org/10.1080/23808985.2018.1446350 could be employed.
} 
example, are refutational two-sided messages more effective than one-sided messages at building support for institutional reforms that affect animals, like bans on factory farming? Which sources are seen as more or less credible (and hence more or less persuasive in certain contexts) when encouraging moral concern for artificial sentience: AI researchers, philosophers, cognitive scientists, robots, politicians, or members of the public?

- American public opinion has changed substantially on a number of issues, such as the right to gay marriage, legalisation of marijuana, desegregation, and whether the public would vote for qualified women or African Americans for president. ${ }^{198}$ Case studies of these issues could reveal insight into the causes of public opinion change.

- The research on framing and second-level agenda setting suggests that media coverage and persuasive messages will vary substantially in their persuasiveness depending on their content. There are a wide variety of research types that could be conducted to shed light on which frames and attributes specific social movements should prioritize, including content analyses, focus groups, surveys, experiments, and more informal exploration. ${ }^{199}$

\footnotetext{
${ }^{198}$ Robert S. Erikson and Kent L. Tedin, American Public Opinion: Its Origins, Content and Impact (Abingdon, UK: Routledge, 2015), 90-122 discuss each of these examples briefly. They summarize their impression that "[a]brupt changes in public opinion normally can be traced to the public's reaction to current events. Explaining incremental change is more complex. Cohort replacement is certainly one factor... [and] advances of education, urbanization, racial diversity, and media penetration have undoubtedly played a role in the public's changing political attitudes and preferences."

${ }^{199}$ Dennis Chong and James N. Druckman, "Framing Theory," Annual Review of Political Science 10, no. 1 (2007): 103-26, https://doi.org/10.1146/annurev.polisci.10.072805.103054 provide a brief step by step guide on how to conduct such research (see the section "Frames in Communication"). For further discussion, see Jamie Harris, "Frank Baumgartner of UNC-Chapel Hill on Policy Dynamics, Lobbying, and Issue Framing," accessed June 9, 2021, http://www.sentienceinstitute.org/podcast (45:20). For recent examples of research along these lines, see The Humane League UK, "Inspiring Action for Farmed Fishes,” May 2021, https://assets.ctfassets.net/ww1ie0z745y7/2zp5YzRX21IvhblzoOE4cj/afflddbfebe52107be9fabb901fa0659/Inspiring action for farmed fishes.pdf and Belinda Vigors, "Citizens' and Farmers' Framing of 'Positive Animal Welfare'
} 
- It might theoretically be possible to influence attitude formation through repeated positive initial exposure to certain ideas or shaping which attitudes parents pass on to their children (e.g. via educational or supportive services). ${ }^{200}$ In general, such factors shaping initial attitude formation seem likely to be difficult to influence, so this review has mostly ignored them, but a review of relevant research could be useful. ${ }^{201}$

- A review of studies with outcomes different from but related to attitudes — such as knowledge, attention, memory, emotion, identity and so on - could be helpful, e.g. for social marketing purposes.

\title{
Bibliography
}

Aelst, Peter Van, and Stefaan Walgrave. "Political Agenda Setting by the Mass Media: Ten Years of Research, 2005-2015." Handbook of Public Policy Agenda Setting, October 28, 2016. https://www.elgaronline.com/view/edcoll/9781784715915/9781784715915.00018.xml.

\author{
Akl, Elie A., Andrew D. Oxman, Jeph Herrin, Gunn E. Vist, Irene Terrenato, Francesca \\ Sperati, Cecilia Costiniuk, Diana Blank, and Holger Schünemann. "Framing of Health
}

and the Implications for Framing Positive Welfare in Communication," Animals 9, no. 4 (April 2019): 147, https://doi.org/10.3390/ani9040147.

${ }^{200}$ See, for example, Stuart Oskamp and P. Wesley Schultz, Attitudes and Opinions (New York, NY: Psychology Press, 2005), 162-75.

${ }^{201}$ Robert S. Erikson and Kent L. Tedin, American Public Opinion: Its Origins, Content and Impact (Abingdon, UK: Routledge, 2015), 121 summarizes that, "[a]lmost 50 percent of the American electorate is replaced every twenty years (Abramson 1983, 54). When we see dramatic change in support for the ideals of the civil rights movement between 1960 and 1980, it is important to understand that only about half of those comprising the adult population in 1960 were still part of that population in 1980. The new 50 percent enter the electorate often socialized to a different set of political values. Thus, the change that appears in support for the ideas of the civil rights movement does not necessarily mean that people have changed their minds, although that may have happened as well." So understanding the influences on attitude formation could be valuable for understanding longer-term public opinion shifts. 
Information Messages." Cochrane Database of Systematic Reviews, no. 12 (2011). https://doi.org/10.1002/14651858.CD006777.pub2.

Albarracin, Dolores, and Sharon Shavitt. "Attitudes and Attitude Change." Annual Review of Psychology 69, no. 1 (2018): 299-327.

https://doi.org/10.1146/annurev-psych-122216-011911.

Allen, Mike, and Raymond W. Preiss. "Comparing the Persuasiveness of Narrative and Statistical Evidence Using Meta-analysis." Communication Research Reports 14, no. 2 (March 1, 1997): 125-31. https://doi.org/10.1080/08824099709388654.

Amenta, Edwin, and Francesca Polletta. "The Cultural Impacts of Social Movements." Annual Review of Sociology 45, no. 1 (2019): 279-99. https://doi.org/10.1146/annurev-soc-073018-022342.

Andrews, Kenneth T., Kraig Beyerlein, and Tuneka Tucker Farnum. "The Legitimacy of Protest: Explaining White Southerners' Attitudes Toward the Civil Rights Movement." Social Forces 94, no. 3 (March 1, 2016): 1021-44. https://doi.org/10.1093/sf/sov097. Animal Charity Evaluators. “Children’s Rights Report,” February 2018. https://animalcharityevaluators.org/research/social-movement-analysis/childrens-rights/

__. "Leafleting." Animal Charity Evaluators (blog), November 2017. https://animalcharityevaluators.org/advocacy-interventions/interventions/leafleting/. Anthis, Jacy Reese. "3 Big Changes We Need in the Farmed Animal Movement." Sentience Institute (blog), June 25, 2018. http://www.sentienceinstitute.org/blog/three-big-changes. 
Anthis, Jacy Reese, and Ali Ladak. “Animals, Food, and Technology (AFT) Survey: 2020 Update," Surveys, March 17, 2021. https://sentienceinstitute.org/aft-survey-2020.

Atkinson, Matthew D, and Darin DeWitt. "Does Celebrity Issue Advocacy Mobilize Issue Publics?” Political Studies 67, no. 1 (February 1, 2019): 83-99. https://doi.org/10.1177/0032321717751294.

Auger, Béatrice, and Catherine E. Amiot. "The Impact of Imagined Contact in the Realm of Human-Animal Relations: Investigating a Superordinate Generalization Effect Involving Both Valued and Devalued Animals." Journal of Experimental Social Psychology 85 (November 1, 2019): 103872.

https://doi.org/10.1016/i.jesp.2019.103872.

Ayoub, Phillip M., Douglas Page, and Sam Whitt. "Pride amid Prejudice: The Influence of LGBT+ Rights Activism in a Socially Conservative Society.” American Political Science Review 115, no. 2 (May 2021): 467-85.

https://doi.org/10.1017/S0003055420001082.

Baek, Tae Hyun, and Sukki Yoon. "Guilt and Shame: Environmental Message Framing Effects.” Journal of Advertising 46, no. 3 (July 3, 2017): 440-53. https://doi.org/10.1080/00913367.2017.1321069.

Banas, John A., and Stephen A. Rains. "A Meta-Analysis of Research on Inoculation Theory.” Communication Monographs 77, no. 3 (September 1, 2010): 281-311. https://doi.org/10.1080/03637751003758193. 
Banaszak, Lee, and Heather Ondercin. "Public Opinion as a Movement Outcome: The Case of the U.S. Women's Movement.” Mobilization: An International Quarterly 21 (September 1, 2016): 361-78. https://doi.org/10.17813/1086-671X-21-3-361.

Bartels, Larry M. "Remembering to Forget: A Note on the Duration of Campaign Advertising Effects." Political Communication 31, no. 4 (October 2, 2014): 532-44. https://doi.org/10.1080/10584609.2014.956198.

Baumann, Tobias. "Arguments for and against Moral Advocacy." Cause Prioritization Research (blog), July 5, 2017. https://prioritizationresearch.com/arguments-for-and-against-moral-advocacy/.

Baumgartner, Frank R., Suzanna L. De Boef, and Amber E. Boydstun. The Decline of the Death Penalty and the Discovery of Innocence. Cambridge University Press, 2008.

Baumgartner, Frank R., and Bryan D. Jones. Agendas and Instability in American Politics, Second Edition. Chicago, IL: University of Chicago Press, 2010.

Becheur, Imène, and Pierre Valette-Florence. "The Use of Negative Emotions in Health Communication Messages: Study of the Effects of Fear, Guilt, and Shame." Recherche et Applications En Marketing (English Edition) 29, no. 4 (December 1, 2014): 89-109. https://doi.org/10.1177/2051570714552620.

Benoit, William L., Glenn J. Hansen, and Rebecca M. Verser. “A Meta-Analysis of the Effects of Viewing U.S. Presidential Debates.” Communication Monographs 70, no. 4 (December 1, 2003): 335-50. https://doi.org/10.1080/0363775032000179133. Blondé, Jérôme, and Fabien Girandola. "Revealing the Elusive Effects of Vividness: A Meta-Analysis of Empirical Evidences Assessing the Effect of Vividness on 
Persuasion." Social Influence 11, no. 2 (April 2, 2016): 111-29.

https://doi.org/10.1080/15534510.2016.1157096.

Bongiorno, Renata, Paul G. Bain, and Nick Haslam. “When Sex Doesn't Sell: Using Sexualized Images of Women Reduces Support for Ethical Campaigns." PLOS ONE 8, no. 12 (December 18, 2013): e83311. https://doi.org/10.1371/journal.pone.0083311.

Boudewyns, Vanessa, Monique M. Turner, and Ryan S. Paquin. "Shame-Free Guilt Appeals: Testing the Emotional and Cognitive Effects of Shame and Guilt Appeals." Psychology \& Marketing 30, no. 9 (2013): 811-25. https://doi.org/10.1002/mar.20647.

Braunsberger, Karin. "The Impact of Animal Welfare Advertising on Opposition to the Canadian Seal Hunt and Willingness to Boycott the Canadian Seafood Industry." Anthrozoös 27, no. 1 (March 1, 2014): 111-25.

https://oi.org/10.2752/175303714X13837396326530.

Bullock, John G. "Elite Influence on Public Opinion in an Informed Electorate." American Political Science Review 105, no. 3 (August 2011): 496-515. https://doi.org/10.1017/S0003055411000165.

Burnett, Craig M., and Vladimir Kogan. "When Does Ballot Language Influence Voter Choices? Evidence from a Survey Experiment.” Political Communication 32, no. 1 (January 2, 2015): 109-26. https://doi.org/10.1080/10584609.2014.894160.

Burstein, Paul. American Public Opinion, Advocacy, and Policy in Congress: What the Public Wants and What It Gets. Cambridge University Press, 2014. 
Carey, Tony E., Regina P. Branton, and Valerie Martinez-Ebers. "The Influence of Social Protests on Issue Salience among Latinos.” Political Research Quarterly 67, no. 3 (September 1, 2014): 615-27. https://doi.org/10.1177/1065912914534074.

Carnahan, Dustin, Daniel E. Bergan, and Sangwon Lee. "Do Corrective Effects Last? Results from a Longitudinal Experiment on Beliefs Toward Immigration in the U.S." Political Behavior, January 9, 2020. https://doi.org/10.1007/s11109-020-09591-9.

Carpenter, Christopher J. "A Meta-Analysis of the Effectiveness of the 'But You Are Free' Compliance-Gaining Technique.” Communication Studies 64, no. 1 (January 1, 2013): 6-17. https://doi.org/10.1080/10510974.2012.727941.

Chan, Man-pui Sally, Christopher R. Jones, Kathleen Hall Jamieson, and Dolores Albarracín. "Debunking: A Meta-Analysis of the Psychological Efficacy of Messages Countering Misinformation." Psychological Science 28, no. 11 (November 1, 2017): 1531-46. https://doi.org/10.1177/0956797617714579.

Chilton, Adam. "Experimentally Testing the Effectiveness of Human Rights Treaties." SSRN Scholarly Paper. Rochester, NY: Social Science Research Network, April 14, 2017. https://doi.org/10.2139/ssrn.2615143.

Chong, Dennis, and James N. Druckman. "Framing Theory." Annual Review of Political Science 10, no. 1 (2007): 103-26. https://doi.org/10.1146/annurev.polisci.10.072805.103054. Cohen, Jacob. Statistical Power Analysis for the Behavioral Sciences. New York, NY: Academic Press, 2013. 
Cohen, Jeffrey E. "Presidential Leadership of Public Opinion: An Embedded Survey Experiment." Political Communication 32, no. 3 (July 3, 2015): 345-55. https://doi.org/10.1080/10584609.2014.944321.

Coppock, Alexander, Seth J. Hill, and Lynn Vavreck. "The Small Effects of Political Advertising Are Small Regardless of Context, Message, Sender, or Receiver: Evidence from 59 Real-Time Randomized Experiments." Science Advances 6, no. 36 (September 1, 2020): eabc4046. https://doi.org/10.1126/sciadv.abc4046.

Costain, Anne N., and Steven Majstorovic. "Congress, Social Movements and Public Opinion: Multiple Origins of Women's Rights Legislation.” Political Research Quarterly 47, no. 1 (March 1, 1994): 111-35. https://doi.org/10.1177/106591299404700106.

David, Yossi. "Public Opinion, Media and Activism: The Differentiating Role of Media Use and Perceptions of Public Opinion on Political Behaviour." Social Movement Studies 0, no. 0 (January 12, 2021): 1-21. https://doi.org/10.1080/14742837.2021.1875321.

Derzon, James H., and Mark W. Lipsey. “A Meta-Analysis of the Effectiveness of Mass-Communication for Changing Substance-Use Knowledge, Attitudes, and Behavior." In Mass Media and Drug Prevention, edited by William D. Crano, Michael Burgoon, and Stuart Oskamp. Mahwah, NJ: Lawrence ErIbaum, 2002.

Druckman, James N., Erik Peterson, and Rune Slothuus. "How Elite Partisan Polarization Affects Public Opinion Formation.” American Political Science Review 107, no. 1 (February 2013): 57-79. https://doi.org/10.1017/S0003055412000500. 
Duhachek, Adam, Nidhi Agrawal, and Dahee Han. "Guilt versus Shame: Coping, Fluency, and Framing in the Effectiveness of Responsible Drinking Messages." Journal of Marketing Research 49, no. 6 (December 1, 2012): 928-41. https://doi.org/10.1509/jmr.10.0244.

Dür, Andreas. "How Interest Groups Influence Public Opinion: Arguments Matter More than the Sources." European Journal of Political Research 58, no. 2 (2019): 514-35. https://doi.org/10.1111/1475-6765.12298.

Eisend, Martin. "The Third-Person Effect in Advertising: A Meta-Analysis." Journal of Advertising 46, no. 3 (July 3, 2017): 377-94. https://doi.org/10.1080/00913367.2017.1292481.

Epton, Tracy, Peter R. Harris, Rachel Kane, Guido M. van Koningsbruggen, and Paschal Sheeran. "The Impact of Self-Affirmation on Health-Behavior Change: A Meta-Analysis." Health Psychology: Official Journal of the Division of Health Psychology, American Psychological Association 34, no. 3 (March 2015): 187-96. https://doi.org/10.1037/hea0000116.

Erikson, Robert S., and Kent L. Tedin. American Public Opinion: Its Origins, Content and Impact. Abingdon, UK: Routledge, 2015.

Feng, Guangchao Charles, and Steve Zhongshi Guo. "Support for Censorship: A Multilevel Meta-Analysis of the Third-Person Effect." Communication Reports 25, no. 1 (January 1, 2012): 40-50. https://doi.org/10.1080/08934215.2012.661019.

Fristoe, Chelsea. "The Persuasive Impact of Disgust-Provoking Images in Animal-Rights Campaigns.” Michigan State University, 2010. 
https://www.proquest.com/openview/ba84b8acea $8 \mathrm{~b} 2 \mathrm{cf} 2 \mathrm{a} 95 \mathrm{cc} 85 \mathrm{~d} 8 \mathrm{fdd} 9 \mathrm{fdb} / 1$ ?pq-origsit

$\underline{\mathrm{e}=\mathrm{gscholar} \& \mathrm{cbl}=18750 \& \text { diss }=\mathrm{y}}$.

Gallagher, Kristel M., and John A. Updegraff. "Health Message Framing Effects on Attitudes, Intentions, and Behavior: A Meta-Analytic Review.” Annals of Behavioral Medicine 43, no. 1 (February 1, 2012): 101-16.

https://doi.org/10.1007/s12160-011-9308-7.

Garthwaite, Craig, and Timothy J. Moore. "Can Celebrity Endorsements Affect Political Outcomes? Evidence from the 2008 US Democratic Presidential Primary.” The Journal of Law, Economics, and Organization 29, no. 2 (April 1, 2013): 355-84.

https://doi.org/10.1093/jleo/ewr031.

Gass, Robert H., and John S. Seiter. Persuasion: Social Influence and Compliance Gaining. 6th ed. New York: Routledge, 2018. https://doi.org/10.4324/9781315209302.

Gayle, Barbara Mae, and Raymond W. Preiss. "Exploring the Relationship Between Listening Comprehension and Rate of Speech.” In Classroom Communication and Instructional Processes: Advances Through Meta-Analysis, edited by Barbara Mae Gayle, Raymond W. Preiss, Nancy Burrell, and Mike Allen, 315-28. Mahwah, NJ: Routledge, 2009.

Goggin, Stephen N. "How Quickly We Selectively Forget: Experimental Tests of Information Order on Memory and Candidate Evaluation." Political Psychology 40, no. 1 (2019): 125-45. https://doi.org/10.1111/pops.12499. 
Guisinger, Alexandra, and Elizabeth N. Saunders. "Mapping the Boundaries of Elite Cues: How Elites Shape Mass Opinion across International Issues.” International Studies Quarterly 61, no. 2 (June 1, 2017): 425-41. https://doi.org/10.1093/isq/sqx022. Halkjelsvik, Torleif, and Jostein Rise. "Disgust in Fear Appeal Anti-Smoking Advertisements: The Effects on Attitudes and Abstinence Motivation.” Drugs: Education, Prevention and Policy 22, no. 4 (July 4, 2015): 362-69. https://doi.org/10.3109/09687637.2015.1015491.

Harris, Jamie. "Frank Baumgartner of UNC-Chapel Hill on Policy Dynamics, Lobbying, and Issue Framing.” Accessed June 9, 2021. http://www.sentienceinstitute.org/podcast.

—. "Kristof Dhont of University of Kent on Intergroup Contact Research and Research Careers.” Accessed May 27, 2021. http://www.sentienceinstitute.org/podcast.

Harris, Jamie, and Jacy Reese Anthis. "How Tractable Is Changing the Course of History?" Sentience Institute (blog), April 12, 2019.

http://www.sentienceinstitute.org/blog/how-tractable-is-changing-the-course-of-history. —. "Is the US Supreme Court a Driver of Social Change or Driven by It? A Literature Review," Literature Reviews, November 27, 2019. https://sentienceinstitute.org/scotus. Harris, Jamie, Jacy Reese Anthis, and Kelly Anthis. "Health Behavior Interventions Literature Review,” July 24, 2020. https://sentienceinstitute.org/health-behavior. Harris, Jamie, Jacy Reese Anthis, and Ali Ladak. "Key Lessons From Social Movement History.” Sentience Institute (blog), June 30, 2021. http://www.sentienceinstitute.org/blog/key-lessons-from-social-movement-history. 
Harris, Jamie, Jacy Reese Anthis, and Kelly McNamara. "Social Movement Lessons From the US Anti-Abortion Movement," November 26, 2019.

https://sentienceinstitute.org/anti-abortion.

—. "Social Movement Lessons from the US Anti-Death Penalty Movement," May 22, 2020. https://sentienceinstitute.org/death-penalty.

Hill, Joshua B., Willard M. Oliver, and Nancy E. Marion. "Presidential Politics and the Problem of Drugs in America: Assessing the Relationship Between the President, Media, and Public Opinion.” Criminal Justice Policy Review 23, no. 1 (March 1, 2012): 90-107. https://doi.org/10.1177/0887403410396211.

Hill, Seth J., James Lo, Lynn Vavreck, and John Zaller. "How Quickly We Forget: The Duration of Persuasion Effects From Mass Communication.” Political Communication 30, no. 4 (October 2013): 521-47. https://doi.org/10.1080/10584609.2013.828143.

Hornik, Jacob, Chezy Ofir, and Matti Rachamim. "Quantitative Evaluation of Persuasive Appeals Using Comparative Meta-Analysis." The Communication Review 19, no. 3 (July 2, 2016): 192-222. https://doi.org/10.1080/10714421.2016.1195204.

Huff, Connor, and Dominika Kruszewska. "Banners, Barricades, and Bombs: The Tactical Choices of Social Movements and Public Opinion." Comparative Political Studies 49, no. 13 (November 2016): 1774-1808. https://doi.org/10.1177/0010414015621072.

Jäger, Kai. "When Do Campaign Effects Persist for Years? Evidence from a Natural Experiment.” American Journal of Political Science 64, no. 4 (2020): 836-51. https://doi.org/10.1111/ajps.12488. 
Johnston, Hank, and John A. Noakes. Frames of Protest: Social Movements and the Framing Perspective. Rowman \& Littlefield Publishers, 2005.

Jungherr, Andreas, Alexander Wuttke, Matthias Mader, and Harald Schoen. "A Source Like Any Other? Field and Survey Experiment Evidence on How Interest Groups Shape Public Opinion.” Journal of Communication 71, no. 2 (April 1, 2021): 276-304. https://doi.org/10.1093/joc/jqab005.

Kahn, Matthew E. "Demographic Change and the Demand for Environmental Regulation." Journal of Policy Analysis and Management 21, no. 1 (2002): 45-62. https://doi.org/10.1002/pam.1039.

Kalla, Joshua L., and David E. Broockman. “The Minimal Persuasive Effects of Campaign Contact in General Elections: Evidence from 49 Field Experiments.” American Political Science Review 112, no. 1 (February 2018): 148-66. https://doi.org/10.1017/S0003055417000363.

Karsh, Noam, and Tal Eyal. "How the Consideration of Positive Emotions Influences Persuasion: The Differential Effect of Pride Versus Joy.” Journal of Behavioral Decision Making 28, no. 1 (2015): 27-35. https://doi.org/10.1002/bdm.1826.

Kepplinger, Hans Mathias. "Effects of the News Media on Public Opinion." In The SAGE Handbook of Public Opinion Research, edited by Wolfgang Donsbach and Michael W. Traugott, 192-204. London, UK: SAGE, 2007.

Kim, Min-Sun, and John E. Hunter. "Relationships Among Attitudes, Behavioral Intentions, and Behavior: A Meta-Analysis of Past Research, Part 2." Communication Research 20, no. 3 (June 1, 1993): 331-64. https://doi.org/10.1177/009365093020003001. 
Knoll, Johannes, and Jörg Matthes. "The Effectiveness of Celebrity Endorsements: A Meta-Analysis." Journal of the Academy of Marketing Science 45, no. 1 (January 2017): 55-75. https://doi.org/10.1007/s11747-016-0503-8.

Knoll, Johannes, Jörg Matthes, Andrea Münch, and Migena Ostermann. "How Long Does Celebrity Meaning Transfer Last? Delayed Effects and the Moderating Roles of Brand Experience, Celebrity Liking, and Age.” International Journal of Advertising 36, no. 4 (July 4, 2017): 588-612. https://doi.org/10.1080/02650487.2016.1213062.

Krämer, Benjamin, and Christina Peter. "Exemplification Effects: A Meta-Analysis." Human Communication Research 46, no. 2-3 (July 1, 2020): 192-221. https://doi.org/10.1093/hcr/hqz024.

Kraus, Stephen J. "Attitudes and the Prediction of Behavior: A Meta-Analysis of the Empirical Literature." Personality and Social Psychology Bulletin 21, no. 1 (January 1, 1995): 58-75. https://doi.org/10.1177/0146167295211007.

Kühberger, Anton. "The Influence of Framing on Risky Decisions: A Meta-Analysis." Organizational Behavior and Human Decision Processes 75, no. 1 (July 1, 1998):

23-55. https://doi.org/10.1006/obhd.1998.2781.

Lai, Calvin K., Allison L. Skinner, Erin Cooley, Sohad Murrar, Markus Brauer, Thierry Devos, Jimmy Calanchini, et al. "Reducing Implicit Racial Preferences: II. Intervention Effectiveness across Time.” Journal of Experimental Psychology. General 145, no. 8 (August 1, 2016): 1001-16. https://doi.org/10.1037/xge0000179. Lakoff, George. The All New Don't Think of an Elephant!: Know Your Values and Frame the Debate. White River Junction, VT: Chelsea Green Publishing, 2014. 
Lau, Richard R., Lee Sigelman, and Ivy Brown Rovner. "The Effects of Negative Political Campaigns: A Meta-Analytic Reassessment.” The Journal of Politics 69, no. 4 (November 1, 2007): 1176-1209. https://doi.org/10.1111/j.1468-2508.2007.00618.x. Lecheler, Sophie, and Claes H. de Vreese. "Getting Real: The Duration of Framing Effects." Journal of Communication 61, no. 5 (October 1, 2011): 959-83. https://doi.org/10.1111/j.1460-2466.2011.01580.x.

Lecheler, Sophie, and Claes H. de Vreese. "How Long Do News Framing Effects Last? A Systematic Review of Longitudinal Studies." Annals of the International

Communication Association 40, no. 1 (January 1, 2016): 3-30.

https://doi.org/10.1080/23808985.2015.11735254.

Lenz, Gabriel S. "Learning and Opinion Change, Not Priming: Reconsidering the Priming Hypothesis." American Journal of Political Science 53, no. 4 (2009): 821-37. https://doi.org/10.1111/j.1540-5907.2009.00403.x.

Leshner, Glenn, Paul Bolls, and Erika Thomas. "Scare' Em or Disgust 'Em: The Effects of Graphic Health Promotion Messages.” Health Communication 24, no. 5 (July 31, 2009): 447-58. https://doi.org/10.1080/10410230903023493.

Li, Xinyi, Yangmu Huang, Ruoyu Yin, Chenyu Pan, Yan Cai, and Zhaokun Wang. "Visualized Nutrition Education and Dietary Behavioral Change: A Systematic Review and Meta-Analysis." Critical Reviews in Food Science and Nutrition 59, no. 12 (July 4, 2019): 1976-85. https://doi.org/10.1080/10408398.2018.1469466.

Luo, Yunjuan, Hansel Burley, Alexander Moe, and Mingxiao Sui. "A Meta-Analysis of News Media’s Public Agenda-Setting Effects, 1972-2015.” Journalism \& Mass 
Communication Quarterly 96, no. 1 (March 1, 2019): 150-72.

https://doi.org/10.1177/1077699018804500.

Mathur, Maya B., Jacob Peacock, David B. Reichling, Janice Nadler, Paul A. Bain, Christopher D. Gardner, and Thomas N. Robinson. "Interventions to Reduce Meat Consumption by Appealing to Animal Welfare: Meta-Analysis and Evidence-Based Recommendations.” Appetite 164 (September 1, 2021): 105277. https://doi.org/10.1016/j.appet.2021.105277.

Mathur, Maya, Jacob Peacock, Thomas Robinson, and Christopher D. Gardner. "Effectiveness of a Theory-Informed Documentary to Reduce Meat and Animal-Product Consumption: Three Randomized Controlled Experiments." OSF Preprints, September 21, 2021. https://doi.org/10.31219/osf.io/vgu6z.

Matthes, Jörg, Johannes Knoll, and Christian von Sikorski. "The 'Spiral of Silence' Revisited: A Meta-Analysis on the Relationship Between Perceptions of Opinion Support and Political Opinion Expression.” Communication Research 45, no. 1 (February 1, 2018): 3-33. https://doi.org/10.1177/0093650217745429.

Mazumder, Soumyajit. "Black Lives Matter for Whites' Racial Prejudice: Assessing the Role of Social Movements in Shaping Racial Attitudes in the United States." SocArXiv, May 6, 2019. https://doi.org/10.31235/osf.io/ap46d.

McAdam, Doug, and Yang Su. "The War at Home: Antiwar Protests and Congressional Voting, 1965 to 1973." American Sociological Review 67, no. 5 (2002): 696-721. https://doi.org/10.2307/3088914. 
McCombs, Maxwell E., and Donald L. Shaw. "The Agenda-Setting Function of Mass

Media." Public Opinion Quarterly 36, no. 2 (January 1, 1972): 176-87. https://doi.org/10.1086/267990.

McCombs, Maxwell, and Sebastian Valenzuela. Setting the Agenda: Mass Media and Public Opinion. Polity Press, 2021.

McDonald, Kelsey, Rose Graves, Siyuan Yin, Tara Weese, and Walter Sinnott-Armstrong. "Valence Framing Effects on Moral Judgments: A Meta-Analysis." Cognition 212 (July 1, 2021): 104703. https://doi.org/10.1016/j.cognition.2021.104703.

Mohorčich, J., and Jacy Reese Anthis. "What Can Nuclear Power Teach Us about the Institutional Adoption of Clean Meat?," Technology Adoption Case Studies, November 28, 2017. https://sentienceinstitute.org/nuclear-power-clean-meat.

Mondak, Jeffery J., Christopher J. Lewis, Jason C. Sides, Joohyun Kang, and J. Olyn Long. “Presidential Source Cues and Policy Appraisals, 1981-2000:” American Politics Research, July 26, 2016. https://doi.org/10.1177/1532673X03259940.

Monroe, Alan D. "Public Opinion and Public Policy, 1980-1993.” The Public Opinion Quarterly 62, no. 1 (1998): 6-28.

Morales, Andrea C., Eugenia C. Wu, and Gavan J. Fitzsimons. "How Disgust Enhances the Effectiveness of Fear Appeals." Journal of Marketing Research 49, no. 3 (June 1, 2012): 383-93. https://doi.org/10.1509/jmr.07.0364.

Morgan, Michael, and James Shanahan. "Two Decades of Cultivation Research: An Appraisal and Meta-Analysis." Annals of the International Communication Association 20, no. 1 (January 1, 1997): 1-45. https://doi.org/10.1080/23808985.1997.11678937. 
Muñoz, Jordi, and Eva Anduiza. "'If a Fight Starts, Watch the Crowd': The Effect of Violence on Popular Support for Social Movements." Journal of Peace Research 56, no. 4 (July 1, 2019): 485-98. https://doi.org/10.1177/0022343318820575.

Nabi, Robin L. "The Effect of Disgust-eliciting Visuals on Attitudes toward Animal Experimentation.” Communication Quarterly 46, no. 4 (September 1, 1998): 472-84. https://doi.org/10.1080/01463379809370116.

Nelson, Thomas E., and Donald R. Kinder. "Issue Frames and Group-Centrism in American Public Opinion.” The Journal of Politics 58, no. 4 (November 1996): 1055-78. https://doi.org/10.2307/2960149.

Nelson, Thomas E., Zoe M. Oxley, and Rosalee A. Clawson. "Toward a Psychology of Framing Effects.” Political Behavior 19, no. 3 (September 1, 1997): 221-46. https://doi.org/10.1023/A:1024834831093.

Nisbet, Matthew C., and John E. Kotcher. “A Two-Step Flow of Influence?: Opinion-Leader Campaigns on Climate Change.” Science Communication 30, no. 3 (March 1, 2009): 328-54. https://doi.org/10.1177/1075547008328797.

Niven, David. "Bolstering an Illusory Majority: The Effects of the Media's Portrayal of Death Penalty Support.” Social Science Quarterly 83, no. 3 (2002): 671-89. https://doi.org/10.1111/1540-6237.00108.

O’Keefe, Daniel J. Persuasion: Theory and Research. Los Angeles, CA: SAGE Publications, 2015.

O’Keefe, Daniel J., and Jakob D. Jensen. “The Relative Persuasiveness of Gain-Framed Loss-Framed Messages for Encouraging Disease Prevention Behaviors: A 
Meta-Analytic Review." Journal of Health Communication 12, no. 7 (October 11, 2007): 623-44. https://doi.org/10.1080/10810730701615198.

Ort, Alexander, Perina Siegenthaler, and Andreas Fahr. "How Positively Valenced Health Messages Can Foster Information Selection: Evidence from Two Experiments."

Frontiers in Communication 6 (2021): 16. https://doi.org/10.3389/fcomm.2021.534496.

Oschatz, Corinna, and Caroline Marker. "Long-Term Persuasive Effects in Narrative Communication Research: A Meta-Analysis." Journal of Communication 70, no. 4 (August 1, 2020): 473-96. https://doi.org/10.1093/joc/jqaa017.

Oskamp, Stuart, and P. Wesley Schultz. Attitudes and Opinions. New York, NY: Psychology Press, 2005.

Pacheco, Julianna. "The Social Contagion Model: Exploring the Role of Public Opinion on the Diffusion of Antismoking Legislation across the American States." The Journal of Politics 74, no. 1 (January 1, 2012): 187-202.

https://doi.org/10.1017/S0022381611001241.

Page, Benjamin I., and Robert Y. Shapiro. "Effects of Public Opinion on Policy." The American Political Science Review 77, no. 1 (1983): 175-90. https://doi.org/10.2307/1956018.

Page, Benjamin I., Robert Y. Shapiro, and Glenn R. Dempsey. "What Moves Public Opinion?" American Political Science Review 81, no. 1 (March 1987): 23-43. https://doi.org/10.2307/1960777. 
Paluck, Elizabeth Levy, Roni Porat, Chelsey S. Clark, and Donald P. Green. "Prejudice Reduction: Progress and Challenges." Annual Review of Psychology 72, no. 1 (January 4, 2021): 533-60. https://doi.org/10.1146/annurev-psych-071620-030619.

Paul, Bryant, Michael B. Salwen, and Michel Dupagne. "The Third-Person Effect: A Meta-Analysis of the Perceptual Hypothesis." Mass Communication and Society 3, no. 1 (February 1, 2000): 57-85. https://doi.org/10.1207/S15327825MCS0301 04. Perloff, Richard M. The Dynamics of Persuasion: Communication and Attitudes in the Twenty-First Century. 6th ed. New York, NY: Routledge, 2017. https://doi.org/10.4324/9781315657714.

Pettigrew, Thomas F., and Linda R. Tropp. “A Meta-Analytic Test of Intergroup Contact Theory." Journal of Personality and Social Psychology 90, no. 5 (2006): 751-83. https://doi.org/10.1037/0022-3514.90.5.751.

Porzig-Drummond, Renata, Richard Stevenson, Trevor Case, and Megan Oaten. "Can the Emotion of Disgust Be Harnessed to Promote Hand Hygiene? Experimental and Field-Based Tests.” Social Science \& Medicine (1982) 68 (February 1, 2009): 1006-12. https://doi.org/10.1016/j.socscimed.2009.01.013.

Rains, Stephen A., Timothy R. Levine, and Rene Weber. "Sixty Years of Quantitative Communication Research Summarized: Lessons from 149 Meta-Analyses." Annals of the International Communication Association 42, no. 2 (April 3, 2018): 105-24. https://doi.org/10.1080/23808985.2018.1446350.

Reynolds, J. P., K. Stautz, M. Pilling, S. van der Linden, and T. M. Marteau. "Communicating the Effectiveness and Ineffectiveness of Government Policies and 
Their Impact on Public Support: A Systematic Review with Meta-Analysis." Royal Society Open Science 7, no. 1 (January 2020): 190522.

https://doi.org/10.1098/rsos.190522.

Rhodes, Nancy, Hillary C. Shulman, and Nikki McClaran. "Changing Norms: A Meta-Analytic Integration of Research on Social Norms Appeals." Human Communication Research 46, no. 2-3 (July 1, 2020): 161-91. https://doi.org/10.1093/hcr/hqz023.

Rothgerber, Hank. "Efforts to Overcome Vegetarian-Induced Dissonance among Meat Eaters." Appetite 79 (August 1, 2014): 32-41.

https://doi.org/10.1016/j.appet.2014.04.003.

Rottinghaus, Brandon. "Presidential (Non) Leadership of Public Opinion, 1953-2001."

White House Studies 6, no. 3 (June 22, 2006): 309-27.

__. "Strategic Leaders: Determining Successful Presidential Opinion Leadership

Tactics Through Public Appeals.” Political Communication 26, no. 3 (July 31, 2009):

296-316. https://doi.org/10.1080/10584600903053510.

Sentience Institute. "A Summary of Evidence for Foundational Questions in Effective Animal Advocacy.” Accessed April 12, 2021.

http://www.sentienceinstitute.org/foundational-questions-summaries.

Seo, Kiwon. "Meta-Analysis on Visual Persuasion- Does Adding Images to Texts Influence Persuasion?" Athens Journal of Mass Media and Communications 6, no. 3 (June 30, 2020): 177-90. https://doi.org/10.30958/ajmmc.6-3-3. 
Shen, Fuyuan, Vivian Sheer, and Ruobing Li. "Impact of Narratives on Persuasion in Health Communication: A Meta-Analysis.” Journal of Advertising 44 (April 3, 2015): 105-13. https://doi.org/10.1080/00913367.2015.1018467.

Slothuus, Rune, and Martin Bisgaard. "How Political Parties Shape Public Opinion in the Real World." American Journal of Political Science, November 4, 2020. https://doi.org/10.1111/ajps.12550.

Smith, Ronald D. Strategic Planning for Public Relations. New York, NY: Routledge, 2017. https://doi.org/10.4324/9781315270876.

Sopory, Pradeep, and James Dillard. "The Persuasive Effects of Metaphor: A Meta-Analysis." Human Communication Research 28 (January 10, 2006): 382-419. https://doi.org/10.1111/j.1468-2958.2002.tb00813.x.

Steiger, Alexander, and Anton Kühberger. “A Meta-Analytic Re-Appraisal of the Framing Effect.” Zeitschrift Für Psychologie 226, no. 1 (2018): 45-55. https://doi.org/10.1027/2151-2604/a000321.

Stimson, James A. Tides of Consent: How Public Opinion Shapes American Politics. Cambridge University Press, 2015.

Sun, Ye, Zhongdang Pan, and Lijiang Shen. "Understanding the Third-Person Perception: Evidence From a Meta-Analysis." Journal of Communication 58, no. 2 (June 2008): 280-300. https://doi.org/10.1111/j.1460-2466.2008.00385.x.

The Humane League UK. “Inspiring Action for Farmed Fishes,” May 2021. https://assets.ctfassets.net/ww1ie0z745y7/2zp5YzRX21IvhblzoOE4cj/affl ddbfebe5210 7be9fabb901fa0659/Inspiring_action_for_farmed_fishes.pdf. 
Vigors, Belinda. 'Citizens' and Farmers' Framing of 'Positive Animal Welfare' and the Implications for Framing Positive Welfare in Communication.” Animals 9, no. 4 (April 2019): 147. https://doi.org/10.3390/ani9040147.

Walgrave, Stefaan, and Rens Vliegenthart. "The Complex Agenda-Setting Power of Protest: Demonstrations, Media, Parliament, Government, and Legislation in Belgium, 1993-2000.” Mobilization: An International Quarterly 17, no. 2 (July 10, 2012):

129-56. https://doi.org/10.17813/maiq.17.2.pw053m281356572h.

Walter, Nathan, Michael J Cody, Larry Zhiming Xu, and Sheila T Murphy. "A Priest, a Rabbi, and a Minister Walk into a Bar: A Meta-Analysis of Humor Effects on Persuasion." Human Communication Research 44, no. 4 (October 1, 2018): 343-73. https://doi.org/10.1093/hcr/hqy005.

Walter, Nathan, Jonathan Cohen, R. Lance Holbert, and Yasmin Morag. "Fact-Checking: A Meta-Analysis of What Works and for Whom.” Political Communication 37, no. 3 (May 3, 2020): 350-75. https://doi.org/10.1080/10584609.2019.1668894.

Walter, Nathan, Riva Tukachinsky, Ayellet Pelled, and Robin Nabi. "Meta-Analysis of Anger and Persuasion: An Empirical Integration of Four Models.” Journal of Communication 69, no. 1 (February 1, 2019): 73-93. https://doi.org/10.1093/joc/jqy054.

Wanta, Wayne, and Salma Ghanem. "Effects of Agenda Setting." In Mass Media Effects Research: Advances Through Meta-Analysis, edited by Raymond W. Preiss, Barbara Mae Gayle, Nancy Burrell, and Barbara Mae Gayle, 37-51. Routledge, 2006. 
Wasow, Omar. “Agenda Seeding: How 1960s Black Protests Moved Elites, Public Opinion and Voting.” American Political Science Review 114, no. 3 (August 2020): 638-59. https://doi.org/10.1017/S000305542000009X.

Watts, Duncan J., and Peter Sheridan Dodds. "Influentials, Networks, and Public Opinion Formation." Journal of Consumer Research 34, no. 4 (December 1, 2007): 441-58. https://doi.org/10.1086/518527.

Wilkes, Rima, and Catherine Corrigall-Brown. "Explaining Time Trends in Public Opinion: Attitudes towards Immigration and Immigrants." International Journal of Comparative Sociology 52, no. 1-2 (February 1, 2011): 79-99.

https://doi.org/10.1177/0020715210379460.

Wirtz, John G., Johnny V. Sparks, and Thais M. Zimbres. "The Effect of Exposure to Sexual Appeals in Advertisements on Memory, Attitude, and Purchase Intention: A Meta-Analytic Review." International Journal of Advertising 37, no. 2 (March 4, 2018): 168-98. https://doi.org/10.1080/02650487.2017.1334996.

Wouters, Ruud. "The Persuasive Power of Protest. How Protest Wins Public Support." Social Forces 98, no. 1 (September 1, 2019): 403-26. https://doi.org/10.1093/sf/soy110. Xu, Jie, and William J. Gonzenbach. "Does a Perceptual Discrepancy Lead to Action? A Meta-Analysis of the Behavioral Component of the Third-Person Effect." International Journal of Public Opinion Research 20, no. 3 (October 1, 2008): 375-85. https://doi.org/10.1093/ijpor/edn031.

$\mathrm{Xu}$, Jie, and Guanxiong Huang. "The Relative Effectiveness of Gain-Framed and Loss-Framed Messages in Charity Advertising: Meta-Analytic Evidence and 
Implications." International Journal of Nonprofit and Voluntary Sector Marketing 25, no. 4 (2020): e1675. https://doi.org/10.1002/nvsm.1675.

Xu, Zhan, and Hao Guo. "A Meta-Analysis of the Effectiveness of Guilt on Health-Related Attitudes and Intentions." Health Communication 33, no. 5 (May 4, 2018): 519-25. https://doi.org/10.1080/10410236.2017.1278633.

Yang, Chun. "The Impact of Disgust on Threat Appeals: Enhancement or Attenuation of Persuasion?," August 17, 2017. https://etda.libraries.psu.edu/catalog/14716cuy129. Yin, Jun. "Elite Opinion and Media Diffusion: Exploring Environmental Attitudes." Harvard International Journal of Press/Politics 4, no. 3 (June 1, 1999): 62-86. https://doi.org/10.1177/1081180X99004003006.

Young, Ben, Sarah Lewis, Srinivasa Vittal Katikireddi, Linda Bauld, Martine Stead, Kathryn Angus, Mhairi Campbell, et al. "Effectiveness of Mass Media Campaigns to Reduce Alcohol Consumption and Harm: A Systematic Review." Alcohol and Alcoholism 53, no. 3 (May 1, 2018): 302-16. https://doi.org/10.1093/alcalc/agx094.

Zebregs, Simon, Bas van den Putte, Peter Neijens, and Anneke de Graaf. "The Differential Impact of Statistical and Narrative Evidence on Beliefs, Attitude, and Intention: A Meta-Analysis." Health Communication 30, no. 3 (March 4, 2015): 282-89. https://doi.org/10.1080/10410236.2013.842528.

\section{Acknowledgements}

Many thanks to Janet Pauketat, Courtney Dillard, Jacy Reese Anthis, and Ilana Rudaizky for reviewing and providing feedback. 